\title{
Dynamic capabilities for managing logistics challenges of retailers
}

\section{Linnea Haag}

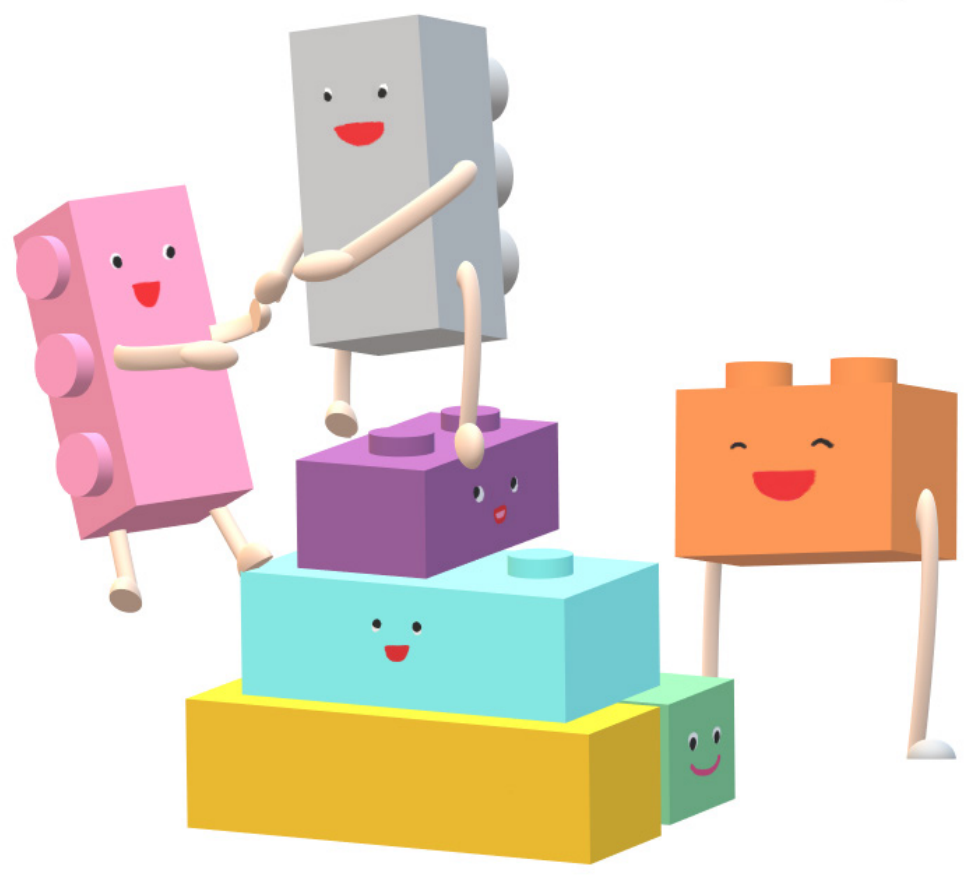



Linköping studies in Science and Technology

Dissertation No. 2158

\title{
Dynamic capabilities for managing logistics challenges of retailers
}

\author{
Linnea Haag
}

2021

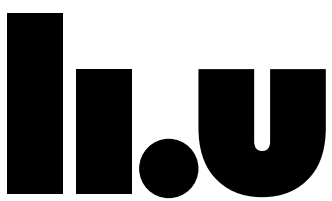

LINKÖPING UNIVERSITY

Logistics and Quality Management

Department of Management and Engineering

Linköping University, SE-581 83 Linköping, Sweden 
$(\mathrm{cc})$ EY-NO NonCommercial 4.0 International License.

https://creativecommons.org/licenses/by-nc/4.0/

(C) Linnea Haag

Dynamic capabilities for managing logistics challenges of retailers

Linköping studies in Science and Technology, Dissertation No. 2158

ISBN: 978-91-7929-001-6

ISSN: 0345-7524

Printed by LiU-Tryck, Linköping 2021

Distributed by:

Linköping University

Department of Management and Engineering

SE-581 83 Linköping, Sweden

Tel: +4613281000 




\begin{abstract}
The increase in globalisation of trade, digitalisation and new technical advances in marketing, IT, and logistics have created new opportunities for retailers to expand and reshape their businesses. These changes have resulted in more complex logistics, and retailers are now facing several critical logistics challenges. To manage these challenges, retailers need to have dynamic capabilities (DCs) that enable them to continuously modify their logistics in order to create and maintain wellfunctioning logistics systems that are both cost-effective and service oriented. In addition, retailers need to have specific antecedents in place that enable them to develop and use such DCs. Despite the importance of DCs in retail, there is a limited understanding of these DCs and their antecedents, and how they enable retailers to adapt their logistics to manage logistics challenges. Hence, the purpose of this dissertation is to: Using a DC lens, explain how retailers can manage logistics challenges.
\end{abstract}

This dissertation is based on two studies and includes six appended papers, which together cover the two logistics challenges of geographical expansion of retailers and transition to omni-channel retailing. The methodologies applied include a combination of literature studies and multiple case studies of large-sized Swedish retailers, in order to identify, describe, and explain DCs and their antecedents in a retail setting. A DC lens was used to study DCs and their antecedents from an intraorganisational and an interorganisational perspective, in which intraorganisational DCs were first studied in the geographical expansion of retailers, followed by interorganisational DCs (IDCs) in the transition to omni-channel retailing. The findings present accessing, integration, and utilisation as three important DCs to manage the geographical expansion of retailers. In addition, the findings present three receive-oriented IDCs: accessing, integration, and utilisation, as well as two transferoriented IDCs: identify knowledge-transfer opportunities and transfer of knowledge, which together are important for the transition to omni-channel retailing. In terms of antecedents, four antecedents of intraorganisational DCs: centralised logistics control, centralised logistics structure, standardisation of logistics operations, and learning orientation, were found to support the geographical expansion of retailers. In the transition to omni-channel retailing, two antecedents of IDCs: supply chain orientation and learning orientation, were found.

This research provides in-depth insight into how retailers can manage two important logistics challenges in retail: the geographical expansion of retailers and the transition to omni-channel retailing. In addition, this research provides a refinement of DCs and their antecedents to increase our understanding of how such DCs and their antecedents enable retailers to manage different logistics challenges. Previous research has not identified, described, or explained how DCs enable retailers to systematically adapt their logistics to new conditions and issues related to different challenges. By studying DCs from both an intraorganisational and an interorganisational perspective, this research identifies a distinction between receive-oriented and transfer-oriented DCs, which are essential for accessing, integration, and utilisation of external resources, as well as for identifying and transferring internal resources, in order to facilitate new logistics solutions to manage different logistics challenges. For logistics practitioners, this research demonstrates the importance of retailers working systematically to manage different logistics challenges and provides several concrete examples of how retailers can take on such challenges, as well as summarising valuable learning and experiences from retail practitioners. In addition, the research reveals the importance of a shared logistics vision, a proactive role taken by the logistics function of retailers, and collaboration between retailers and LSPs, in order to better manage logistics challenges in retail. 



\section{Sammanfattning}

Ökad globalisering av handeln, digitalisering och nya tekniska framsteg inom marknadsföring, IT och logistik har skapat nya möjligheter för detaljhandelsföretag att expandera och utveckla sin verksamhet. Dessa förändringar har resulterat i alltmer komplex logistik och detaljhandeln står idag inför många kritiska logistikutmaningar. För att hantera logistikutmaningar behöver handelsföretag ha dynamiska förmågor som möjliggör för dem att kontinuerligt förändra sin logistik och på så sätt skapa och behålla välfungerande logistik som är både serviceinriktad och kostnadseffektiv. Handelsföretag behöver dessutom ha specifika förutsättningar på plats för att kunna utveckla och använda dynamiska förmågor. Trots betydelsen av dynamiska förmågor saknas djupare förståelse för hur sådana förmågor och deras förutsättningar möjliggör för handelsföretag att hantera olika logistikutmaningar. Baserat på detta är syftet med denna avhandling: Att frän en lins av dynamiska förmågor förklara hur detaljhandelsföretag kan hantera logistikutmaningar.

Avhandlingen är baserad på två studier och sex artiklar som tillsammans studerar två olika logistikutmaningar inom detaljhandeln, inklusive geografisk expansion och övergången till omnikanal. Metoderna som använts i avhandlingen innefattar en kombination av litteraturstudier och ett flertal multipla fallstudier av flera storskaliga, svenska detaljhandelsföretag för att studera dynamiska förmågor och deras förutsättningar som behövs för att hantera logistikutmaningar. Vidare användes teorin om dynamiska förmågor som lins för att studera dessa från både ett intra- och interorganisatoriskt perspektiv. Resultatet visade att àtkomst, integration och utnyttjande som tre viktiga dynamiska förmågor för att hantera geografisk expansion. Vidare visade resultaten tre mottagarorienterade interorganisatoriska dynamiska förmågor inklusive àtkomst, integration och utnyttjande, samt två överföringsorienterade dynamiska förmågor inklusive identifiera kunskapsutbyten och överföra kunskap som var viktiga för övergången till omnikanal. Vidare identifierades fyra förutsättningar för dynamiska förmågor, inklusive centraliserad logistikekontroll, centraliserad logistikstruktur, standardisering av logistikoperationer och inlärningsorientering som stödjer geografisk expansion. Vid övergången till omnikanal identifierades två förutsättningar för interorganisatoriska dynamiska förmågor, inklusive flödesorientering och inlärningsorientering.

Denna forskning ger en djupare inblick i hur detaljhandelsföretag kan hantera två viktiga logistikutmaningar inom detaljhandeln, inklusive geografisk expansion och övergången till omnikanal. Dessutom tillhandahåller denna forskning en förfining av dynamiska förmågor och deras förutsättningar för att öka vår förståelse för hur sådana dynamiska förmågor och förutsättningar gör det möjligt för handelsföretag att hantera olika logistikutmaningar. Tidigare forskning har inte förklarat hur dynamiska förmågor gör det möjligt för företag att systematiskt anpassa sin logistik till nya förhållanden och olika utmaningar. Genom att studera dynamiska förmågor från både ett intraorganisatoriskt och interorganisatoriskt perspektiv visar denna forskning en distinktion mellan olika mottagarorienterade och transferorienterade dynamiska förmågor som är viktiga för att få åtkomst och överföra både interna och externa resurser, samt integrera, utnyttja och underlätta implementering av nya logistiklösningar. För logistikutövare visar denna forskning vikten av ett systematiskt arbetssätt för att hantera olika logistikutmaningar och visar konkreta exempel på hur handelsföretag tar sig an olika logistikutmaningar samt sammanfattar värdefulla lärdomar och erfarenheter från praktiker. Forskningen visar även vikten av att ha en gemensam logistikvision, en proaktiv roll av logistikfunktionen, samt nära samarbete mellan handelsföretag och logistikföretag för att bättre hantera olika logistikutmaningar inom handeln. 



\section{Acknowledgements}

In your hands, you are holding a copy of my dissertation. This is the end of my research journey to become a PhD in logistics. My interest in logistics goes back to my master's studies at Linköping University. In fact, one of my most memorable "Aha" moments was in fact during a course on basic logistics, when I suddenly realised the importance of well-functioning logistics in the world that we live in. I became truly fascinated by the complexity of logistics and I wanted to learn more. Throughout my master's degree, I studied several logistics courses and wrote my master's thesis on logistics in the Swedish steel industry. At the end of my master's studies, I wanted to continue to develop my knowledge of logistics and I was in luck because a very interesting $\mathrm{PhD}$ application was announced in the spring of 2016, which I eagerly applied for and later got. Since then, it has been a true privilege to work in-depth with one of my favourite subjects. My research journey has been a very rewarding experience and I have achieved many important learnings along the way. Looking back, I am very satisfied with how my research journey turned out and there are many people whom I wish to thank for supporting me along the way.

First of all, I want to express my deepest gratitude to the Hakon Swenson Foundation, who funded the research project of which this dissertation is a part. I am very glad for the interest shown in this research.

Furthermore, I would like to thank the respondents to this research. Your participation has been truly essential, and it has been an absolute pleasure to meet all of you!

I would also like to express a very special thanks to my supervisors, Erik and Uni. I am so grateful for all your support along my research journey. I think you complement each other so well and I have learned a lot from both of you.

I also wish to pay special regards to my amazing colleagues at the Division of Logistics and Quality Management. It has been a privilege to work alongside such knowledgeable and caring people. Thank you all so much for your support! Also, an extra thanks to my fellow (and previous fellow) doctoral students, with whom I have shared so many fun memories through the years. I am looking forward for new ones soon.

To my family and friends, I really appreciate your heart-warming support and your curiosity about my work during these past five years. I cherish all the moments that we share together and I am looking forward to many more to come. To end, I want to pay a special thanks to my dear family. Mum and Dad, Maria and Anna with families, and Adam, I love you all so much!

Linköping, August 2021

Linnea Haag 



\section{Contents}

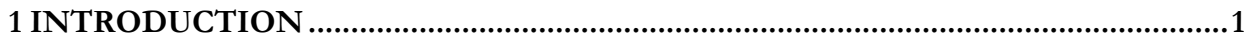

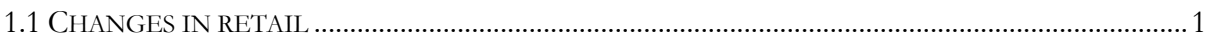

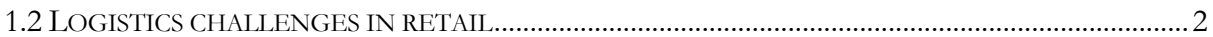

1.3 THE NEED FOR DYNAMIC CAPABILITIES IN RETAIL …………......................................................

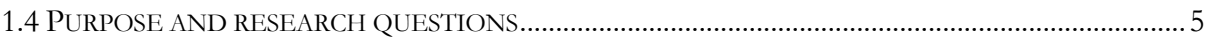

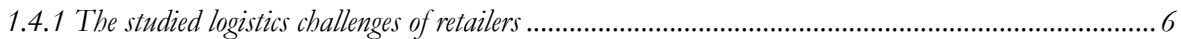

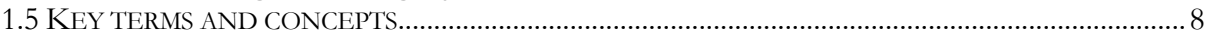

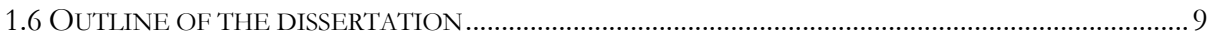

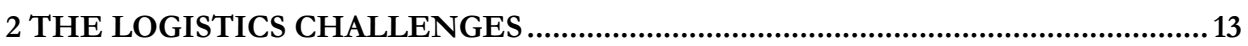

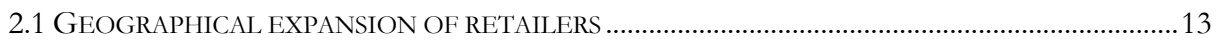

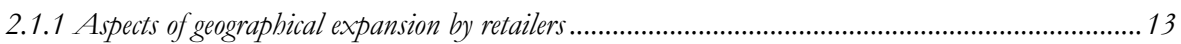

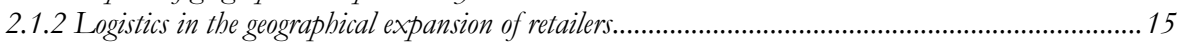

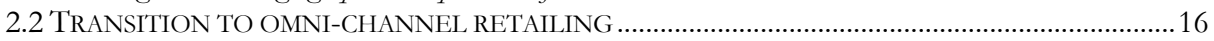

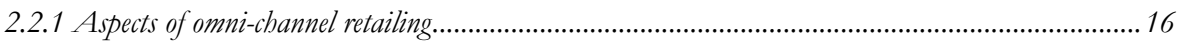

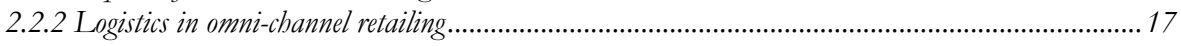

3 THEORETICAL FRAME OF REFERENCE ........................................................... 21

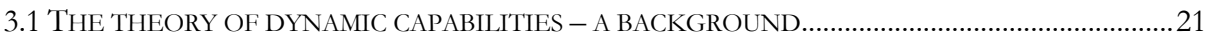

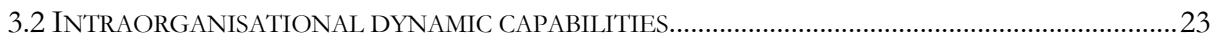

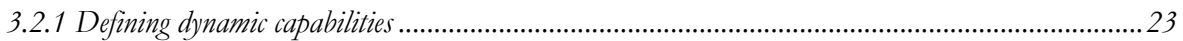

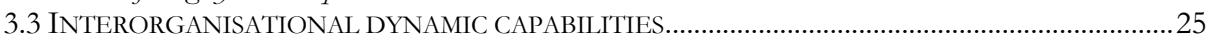

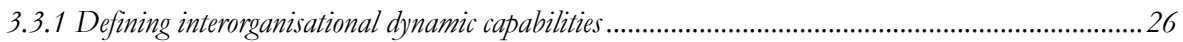

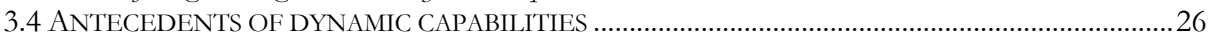

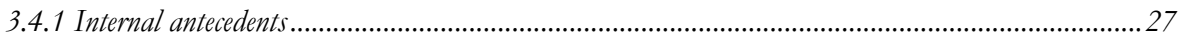

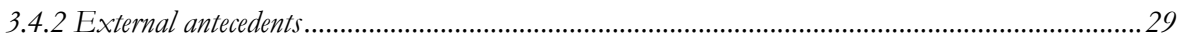

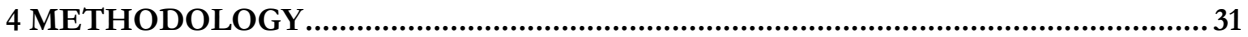

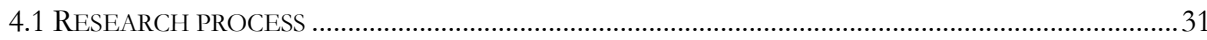

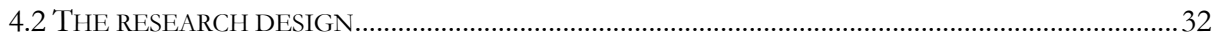

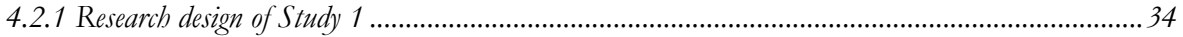

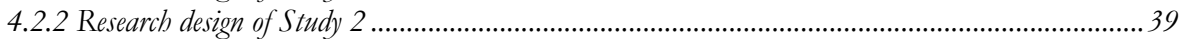

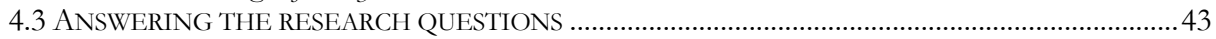

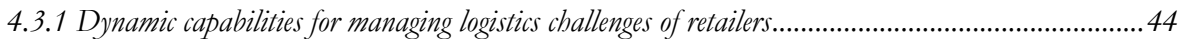

4.3.2 Antecedents of dynamic capabilities for managing logistics challenges of retailers ..............................46

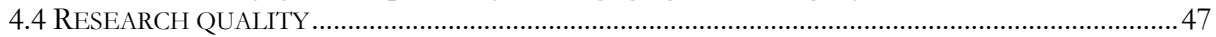

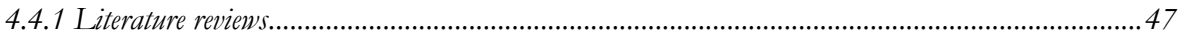

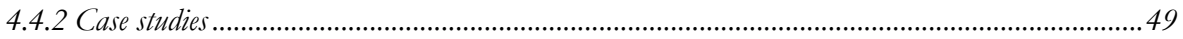

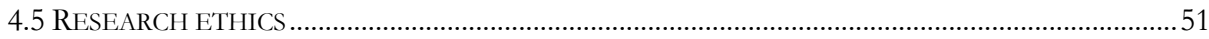

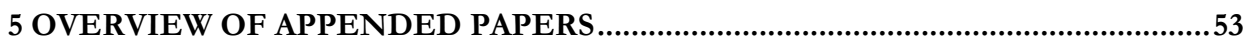

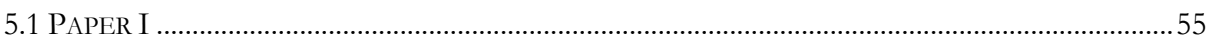

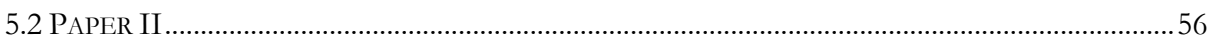

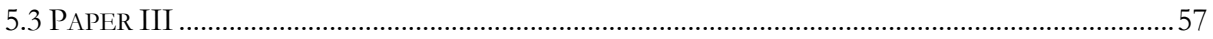

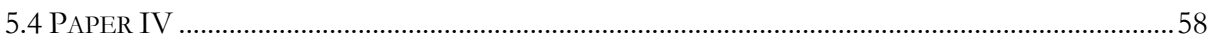

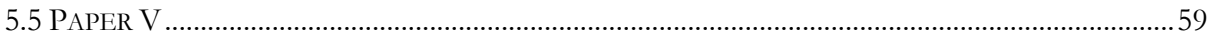

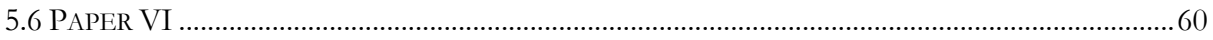

6 DYNAMIC CAPABILITIES FOR MANAGING LOGISTICS CHALLENGES OF

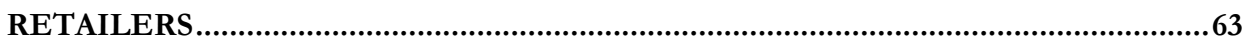


6.1 INTRAORGANISATIONAL DYNAMIC CAPABILITIES FOR MANAGING THE GEOGRAPHICAL

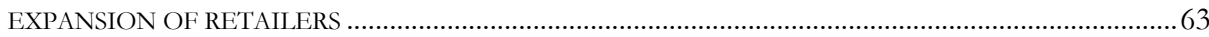

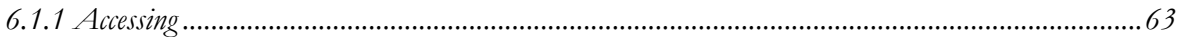

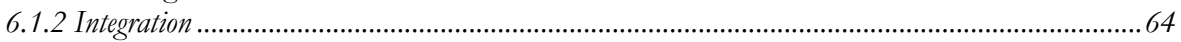

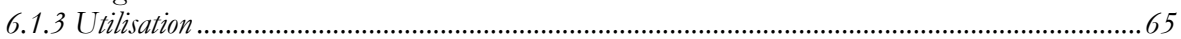

6.1.4 Summary of the intraorganisational dynamic capabilities...............................................................6 66

6.2 INTERORGANISATIONAL DYNAMIC CAPABILITIES FOR MANAGING THE TRANSITION TO

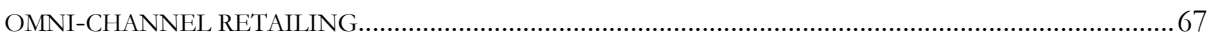

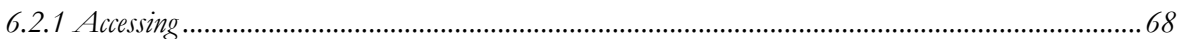

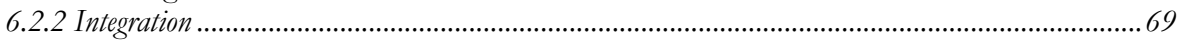

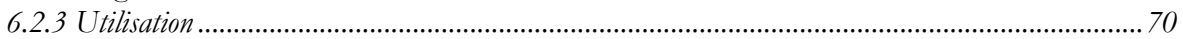

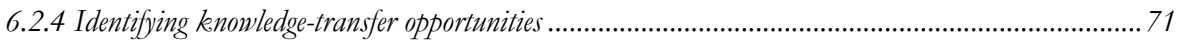

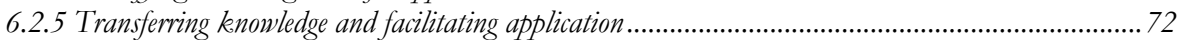

6.2.6 Summary of interorganisational dynamic capabilities..................................................................... 72

\section{ANTECEDENTS OF DYNAMIC CAPABILITIES FOR MANAGING LOGISTICS}

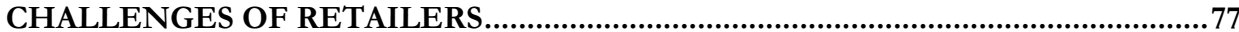

7.1 ANTECEDENTS OF INTRAORGANISATIONAL DYNAMIC CAPABILITIES FOR MANAGING

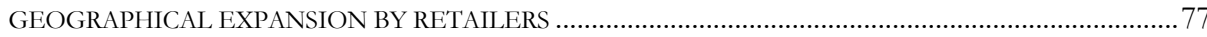

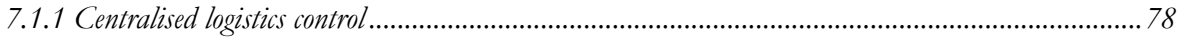

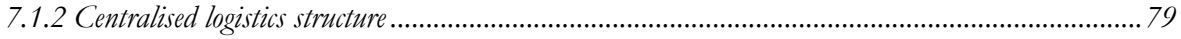

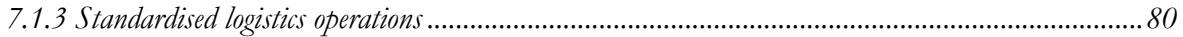

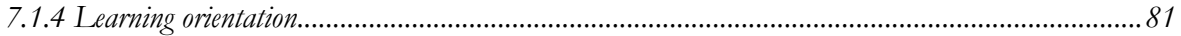

7.1.5 Summary of the antecedents of intraorganisational dynamic capabilities ...........................................8 82

7.2 ANTECEDENTS OF INTERORGANISATIONAL DYNAMIC CAPABILITIES FOR MANAGING THE

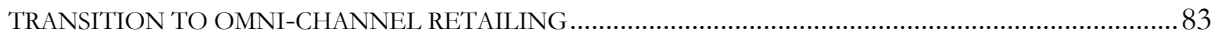

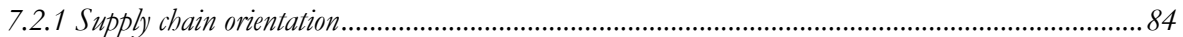

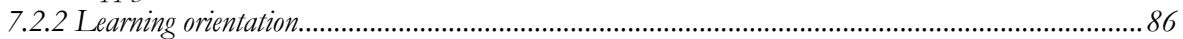

7.2.3 Summary of the antecedents of interorganisational dynamic capabilities ........................................... 87

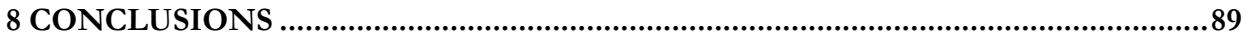

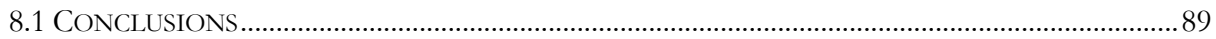

8.2 DISCUSSION - A COMPARISON BETWEEN THE STUDIES.................................................................. 90

8.2.1 Dynamic capabilities for managing the logistics challenges of retailers ............................................ 90

8.2.2 Antecedents of dynamic capabilities for managing the logistics challenges of retailers.........................92

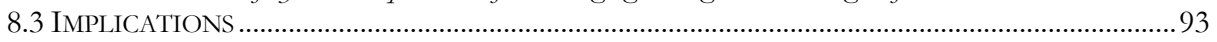

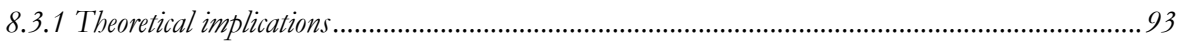

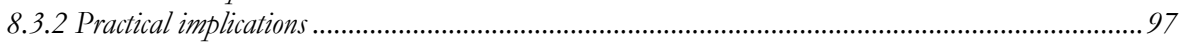

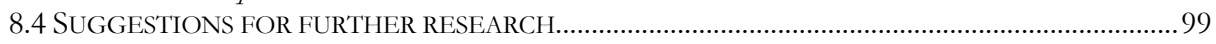

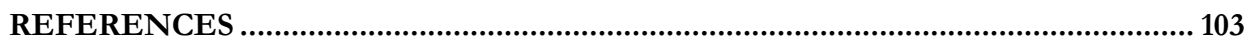

\section{APPENDICES}

Appendix 1 - Appended papers

Appendix 2 - Interview guide in Study 1

Appendix 3 - Interview guide in Study 2 


\section{List of Tables}

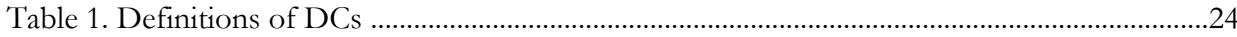

Table 2. Summary of the research design used in the appended papers in Study 2.........................34

Table 3. Overall information about the case companies in Study 1....................................................37

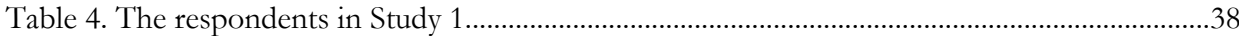

Table 5. Summary of the research design used in the appended papers in Study 2 .........................39

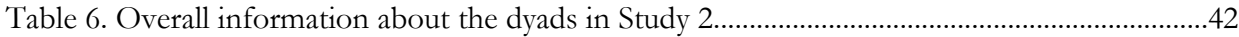

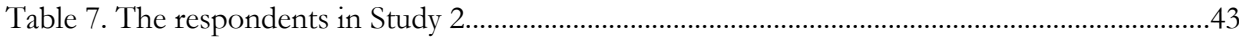

Table 8. Linking the research questions to the studies and appended papers....................................44

Table 9. Content analysis milestones used in the dissertation (based on Seuring and Gold, 2012).

Table 10. Means to ensure research quality in case studies..................................................................50

\section{List of Figures}

Figure1. An overview of the dissertation

Figure 2. An evolution of resource-based theories including the traditional RBV, the relational view, DCs and IDCs

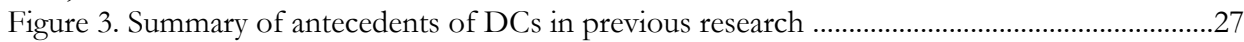

Figure 4. An overview of the research process for the dissertation....................................................31

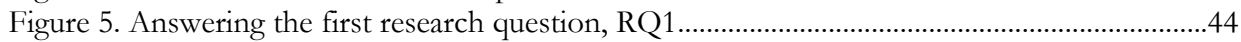

Figure 6. Answering the second research question, RQ2 ….............................................................46

Figure 7 . The phases in the establishment process of retailers into foreign sales markets (from

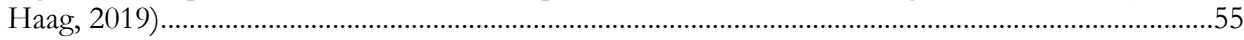

Figure 8. Logistics characteristics supporting the geographical expansion of retailers (inspired by

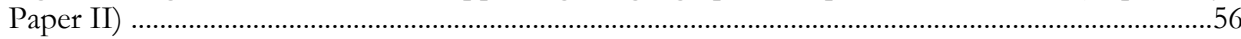

Figure 9. Supply-chain capability categories supporting the geographical expansion of retailers

(inspired by Paper III) ........................................................................................................................57

Figure 10. The conceptual framework of IDCs (from Paper IV). ..................................................58

Figure 11. The interplay of the absorptive and desorptive capacities in the five learning situations

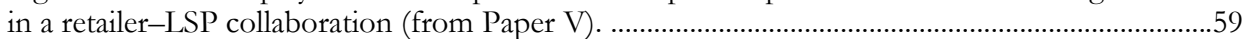

Figure 12. The findings of Paper VI (from Paper VI). ...................................................................60

Figure 13. The structure to identify, describe and explain intraorganisational DCs for retailers to

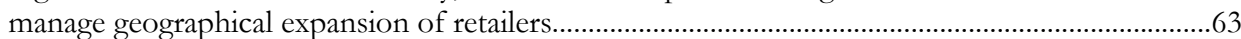

Figure 14. A summary of the intraorganisational DCs that support the geographical expansion of

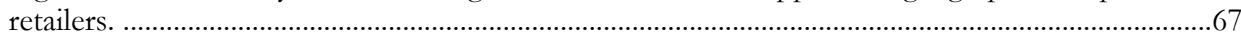

Figure 15. The structure used to identify, describe and explain the IDCs used by retailers to

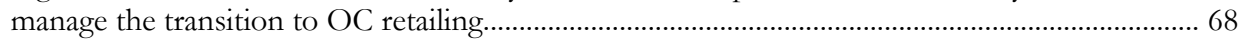

Figure 16. A summary of the IDCs that support the transition to OC retailing. ............................ 74

Figure 17. The structure used to identify, describe and explain the antecedents of intraorganisational DCs needed for retailers to manage their geographical expansion.....................77 Figure 18. The antecedents of intraorganisational DCs for managing geographical expansion by

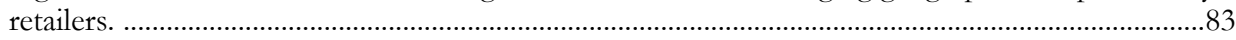

Figure 19. The structure used to identify, describe and explain the antecedents of IDCs for

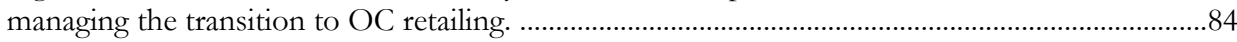

Figure 20. The antecedents of IDCs for managing the transition to OC retailing...........................87

Figure 21. Framework for how retailers can manage logistics challenges using DCs......................90 



\section{List of appended papers}

\section{Paper I}

Haag, L. (2018), "The identification of phases of the retail establishment into foreign markets - a multiple case study of two Swedish retailers". Books of proceedings presented at the Recent Advances in Retail and Consumer Service conference 17-18 July 2018, Portugal.

\section{Paper II}

Haag, L. and Sandberg, E. (2020), "Exploring key logistics characteristics supporting embeddedness in retailers' geographical expansion". The International Review of Retail, Distribution and Consumer Research, Vol. 30 No. 1, pp. 1-26.

\section{Paper III}

Haag, L., Sallnäs, U. and Sandberg, E. (2019), "Supply chain capabilities for facilitating the internationalisation of retailers - a multiple case study of three Swedish retail companies". The International Review of Retail, Distribution and Consumer Research, Vol. 29 No. 3, pp. 321339.

\section{Paper IV}

Sandberg, E., Kindström, D. and Haag, L. (2021), "Delineating interorganizational dynamic capabilities: A literature review and a conceptual framework". The Journal of InterOrganizational Relationships, pp. 1-16.

\section{Paper V}

Haag, L., Sandberg, E. and Sallnäs, U. (202X), "Towards an increased understanding of learning: A case study of a collaborative dyad between a retailer and a logistics service provider". This paper has been submitted and is under review at a journal.

\section{Paper VI}

Haag, L. (202X), "Dynamic supply chain capabilities supporting collaboration between retailers and logistics service providers". Books of proceedings presented at the NOFOMA digital conference 17-18 September 2020. Awarded with the Best Doctoral Student Paper at the Nordic Logistics Conference NOFOMA 2020. A new version of the paper is in progress. 



\section{My contributions to the papers}

\section{Paper I}

I am the sole author of Paper I.

\section{Paper II}

I took part in the work for several sections of this paper, but with a larger contribution to the methodology, the case company descriptions and the analysis chapter.

\section{Paper III}

I took part in the work for all sections of this paper, but my main contributions were in the introduction, the methodology, the case descriptions and the analysis chapter. I was also closely involved in the writing of an extended abstract (including introduction, preliminary methodology and preliminary findings), which was used for the conference application.

\section{Paper IV}

I took part in the work for all sections of this paper, but my main contributions were in the methodology, including the structured literature review, and the analysis.

\section{Paper V}

I took part in the work for all sections of this paper, but with a larger contribution to the methodology, findings, discussion and concluding remarks.

\section{Paper VI}

I am the sole author of Paper VI. 



\section{Introduction}

This chapter presents an introduction to the dissertation. The chapter begins with an introduction to major changes in retail, followed by a description of logistics challenges related to these changes. Thereafter, the need for dynamic capabilities is presented. Later, the purpose and research questions of the dissertation are presented. The chapter ends with a description of key terms and concepts, and an outline of the rest of the dissertation.

\subsection{Changes in retail}

We live in a dynamic world that is constantly changing.

The arena of retail has changed rapidly in the last decade. The increasing globalisation of trade, digitalisation and new technical advances in marketing, IT and logistics have changed how customers shop for retail goods and perceive retailing. These changes create new opportunities for retailers to shape their businesses to meet customer demands. For instance, globalisation allows retailers to reach new customers all over the world, due to free trade agreements, alongside advanced marketing and supply-chain operations. Globalisation has also been driven by digitalisation, which has allowed international retailers to create and use digital marketing platforms to reach new customers worldwide. The Internet has also enabled the development of e-commerce, which allows customers to shop for retail goods from anywhere and at any time, using technical devices (e.g. mobile phones and tablets). E-commerce has expanded explosively over the last five years with an annual double-digit growth, and now online business accounts for 14 percent of total retail sales and is expected to continue to grow in the coming decade (Clement, 2019). Similar patterns are also seen in the Swedish retail sector.

In the same way as opportunities arise from these major retail changes, they also present a number of new challenges for retailers. For instance, increased globalisation has resulted in tougher competition, as local retailers are no longer competing only with retailers in their home market but also with international retailers. Furthermore, increased digitalisation and e-commerce has changed customer behaviour (Sievers, 2020). Now customers are able to choose among numerous retailers and can access a vast amount of information about retail goods via technical devices, which enables them to easily compare retail offers based on their own preferences (e.g. low price or customisation). This has made it more difficult for retailers to stand out in a sea of competitors as well as to attract new customers and keep existing ones (Sievers, 2020). For instance, well-known fashion retailers such as H\&M and Zara, with similar retail offers, are struggling to remain relevant among the new online players such as Zalando, ASOS and Boozt. In addition, the increase in e-commerce has led to the closing of many brick-and-mortar ${ }^{1}$ retailers and the so-called retail apocalypse (Mende and Noble, 2019). This in turn has forced brick-and-mortar retailers to move online and apply multi-channel approaches (Loeb, 2020). For instance, an increasing number of brick-and-mortar retailers and e-retailers have begun to apply an omni-channel ${ }^{2}$ strategy.

\footnotetext{
1 The term "brick-and-mortar" refers to "a traditional street-side business that offers products and services to its customers face-to-face in an office or store that the business owns or rents" (Murphy, 2020).

2 An omni-channel includes multiple sales channels that are integrated in order to create a seamless shopping experience, whether customers shop online or in a brick-and-mortar store (Ishfaq et al., 2016).
} 
Other major changes in retail include increased urbanisation, more expensive raw materials and demographic changes, such as an increasing world population (Sievers, 2020), which all have an impact upon how retailers develop their businesses. Another major change for retailers is the increased awareness of sustainability issues. These issues are becoming an important area in retail, in which both social and ecological standards need to be established and maintained along retailers' supply chains (Sievers, 2020).

To take on these major changes, retailers must navigate a new course in order to remain successful in the global and digital "world of retail". Retailers need to continuously adapt their retail and supply-chain operations to manage the new challenges. This dissertation focuses on the logistics challenges faced by retailers.

\subsection{Logistics challenges in retail}

The major changes in retail have resulted in several logistics challenges. The logistics function of retailers, with the logistics manager at the forefront, plays a key role in managing different logistics challenges of retailers. The traditional role of logistics was typically to cut costs and lead times (Abrahamson and Rehme, 2010); however, retailers are becoming more aware of the importance of logistics to support marketing strategies and to create customer value to achieve competitive advantage ${ }^{3}$ (Kembro and Norrman, 2019a).

The increase in globalisation increases the complexity of logistics systems, which now include numerous supply-chain members scattered around the globe. For instance, material is sourced in one country, retail goods are produced in another, transported, and later sold in another part of the world. The coordination of such complex supply chains constitutes one of the major challenges for logistics managers worldwide (Straube et al., 2008; Swoboda et al., 2014; Tenorio et al., 2021). In line with globalisation, the geographical expansion of retailers into new foreign sales markets is another logistics challenge, in which retailers need to ensure that they can provide logistical support for foreign retail operations (Marchet et al., 2016). In the same way as marketing operations (e.g. sales operations in brick-and mortar stores or/and online stores) need to be in place, well-functioning supply-chain operations need to be established in order to supply foreign sales markets (Swoboda and Elsner, 2013; Swoboda et al., 2008). The establishment into new foreign markets requires extensive logistics preparations and requires retailers to be able to adjust their logistics to efficiently support foreign retail operations (Straube et al., 2008; Swoboda and Elsner, 2013).

Furthermore, the increasing volume of e-commerce has also transformed logistics from a part of retail that happens "behind the scenes" to a highly visible aspect of the retail offer (Kembro and Norrman, 2019a). For instance, customers can now choose delivery options (e.g. home deliveries and click-and-collect) based on their own preferences. Hence, logistics as a "spin-off service" has become an important part of the shopping experience and retailers need to carefully design their logistics systems in a way that can handle the increased customer demands (Kembro and Norrman, 2019a). For instance, customers now expect shorter delivery times of just a few days, a broader range of flexible delivery options,

\footnotetext{
${ }^{3}$ Competitive advantage is typically defined in terms of economic net value gained, where either greater benefits are achieved at the same cost (in comparison to rivals) or the same benefits as rivals are produced at a lower cost (Barney and Clark, 2007).
} 
and easy ways to handle returns. There are also increased demands for broader product ranges and product availability in warehouses near to customers, which in turn requires more storage space (Sievers, 2020). At the same time, there is a strong focus on low prices that require cost-efficient logistics (Kembro and Norrman, 2019a). This is seen among both international and Swedish retailers. For instance, the Swedish e-retailer Apotea offers a broad product range of pharmacy products along with fast deliveries (within two hours in some Swedish regions) free of charge.

In addition, the transition from a separate brick-and-mortar strategy respectively online strategy, to an omni-channel strategy also constitutes a major logistics challenge for retailers (Hübner et al., 2016; Kembro and Norrman, 2019a; Kembro et al., 2018). An omni-channel integrates different flows of retail goods and the associated information into a seamless shopping experience, in which customers can choose how they shop, pick up and return retail goods (Kembro and Norrman, 2019a). For example, a customer can order online, pick up the goods at a local delivery point and return them to a physical store. This in turn result in even more complex logistics systems, in which the logistics function must handle large fluctuations in demand, demand for faster deliveries and an increase in smaller shipments to a larger number of delivery points, while at the same time achieving cost efficiency (Hübner et al., 2016). Omni-channel retailing depends on well-functioning logistics, including warehousing and distribution, that needs to be carefully planned and executed (Ishfaq et al., 2016). Hence, the transition to omni-channel logistics presents a number of logistics challenges in itself. In particular, the increase in mixed flows (e.g. flows of store orders and e-orders) requires a higher level of logistics expertise, more advanced information systems and new operations and processes in order to combine and coordinate frontend and backend flows (e.g. returns) (Hübner et al., 2016; Kembro and Norrman, 2019b). This typically involves joint efforts (e.g. developing standardised packaging, shortening lead-times to end customers) with other supply-chain members, both upwards (e.g. producers, suppliers) and downwards (e.g. logistics service providers, end customers) in order to improve the overall performance experienced by end customers (Kembro and Norrman, 2019b).

\subsection{The need for dynamic capabilities in retail}

To manage upcoming changes in the retail sector, retailers need to be able to perform daily operations and support strategic objectives, as well as adapting to changing conditions in the retail environment (e.g. increased globalisation, digitalisation, regulations and changed customer behaviour), in order to remain competitive. Retailers have their own unique resource base (Wernerfelt, 1984), including both tangible (e.g. capital, equipment, buildings and inventory) and intangible (e.g. skills of individual employees, brand and copyrights) assets, as well as organisational processes and expertise, which can be combined to achieve a competitive advantage (Barney, 1991; Grant, 1991). This resource base also includes logistics resources (e.g. logistics staff, logistics equipment and warehouse facilities) and the capabilities needed both to perform daily logistics operations (e.g. picking operations and last-mile deliveries) and to support strategic objectives (e.g. omni-channel retailing). However, in order to manage changing conditions, retailers need more "dynamic" capabilities that enable them to systematically adapt their logistics in order to manage the 
various issues related to different logistics challenges in retail. In particular, specific dynamic capabilities (DCs) are needed.

The theory of DC is a well-recognised paradigm. DCs are crucial in a dynamic business environment (including the retail sector), enabling firms to modify their existing resource base (Barreto, 2010; Helfat et al., 2007; Teece et al., 1997; Teece, 2007) in order to meet changing conditions and achieve long-term competitive advantage (Barreto, 2010). DCs can be defined in numerous ways, but a typical definition is: "the capacity of an organisation to purposefully create, extend, or modify its resource base" (Helfat et al., 2007, p. 4). DCs have been studied extensively in multiple research disciplines, including retail logistics. However, the studies on DCs related to retail logistics are limited apart from a few interesting contributions (e.g. Esper et al., 2007; Frasquet et al., 2018; Hüseyinoglu et al., 2018; Rajaguru and Matanda, 2019). For instance, Esper et al. (2007) explored how a logistics learning capability enables organisations to maintain a long-term competitive advantage. Nevertheless, in spite of a few interesting contributions, studies on DCs are still rare in retail research, and more research is needed to understand how DCs enable retailers to manage the logistics challenges that arise in their dynamic environment.

Furthermore, due to the interorganisational nature of organisations, scholars have also highlighted the need for interorganisational DCs to enable organisations to identify and use resources from external actors. In particular, previous research has highlighted the need for logistics-related interorganisational DCs that enable supply-chain members to benefit from other members' resources and capabilities, as well as enabling them to renew their joint resource base (e.g. Beske et al., 2014; Defee and Fugate, 2010). For instance, interorganisational relationships between supply-chain members can serve as a key source of knowledge, in which a member often relies on the expertise of external actors (Defee and Fugate, 2010). For instance, retailers typically outsource all or parts of their logistics processes (e.g. warehousing and distribution) to logistics service providers, which makes retailers dependent on the knowledge and logistics performance of their logistics service providers (Perdana et al., 2019). Despite some interesting contributions (e.g. Beske et al., 2014; Defee and Fugate, 2010), IDCs are still highly conceptual and there is a lack of empirically grounded research seeking to understand how interorganisational DCs are portrayed between different supply-chain members, including retailers (Chen et al., 2019). In a similar vein, there are only a few contributions on interorganisational DCs from a dyadic or multiple perspective involving various supply chain members (e.g. Halldórsson and Skjøtt-Larsen, 2004; Yang, 2016). In general, previous research on DCs has applied the perspective of individual firms, with a focus on manufacturers, while other supply chain members have been only sparsely studied.

In close relation to DCs, previous scholars (e.g. Ambrosini and Bowman, 2009; Teece, 2007) have also acknowledged the importance of antecedents in order for firms to actually develop and use DCs. Antecedents refer to specific factors or conditions that influence the development and use of DCs (Ambrosini and Bowman, 2009). DCs typically depend on a number of different antecedents that enable firms to modify their resource base (Eriksson, 2014). Previous scholars (e.g. Eriksson, 2014; Teece, 2007) have studied different types of internal and external antecedents, which can influence the outcome of DCs. For instance, Teece (2007) has presented a set of so-called micro-foundations, including various 
organisational processes, business models and other organisational factors, which can influence DCs. Scholars have also studied specific antecedents of IDCs at a conceptual level (e.g. Defee and Fugate, 2010; Forkmann et al., 2018). In spite of these interesting contributions, there is a lack of empirical understanding of antecedents in a retail setting. To improve our understanding of how retailers manage different logistics challenges, there is a need for more empirical research on how antecedents support the DCs of retailers.

\subsection{Purpose and research questions}

Based on previous sections, it is clear that retailers are facing several major logistics challenges. To manage such challenges, retailers need to possess specific DCs that enable them to adapt their existing resource base. Despite the importance of DCs, there is a limited understanding of such capabilities in a retail setting and how such capabilities can enable retailers to manage logistics challenges. Based on this, the purpose of this dissertation is to:

\section{Using a DC lens, explain how retailers can manage logistics challenges.}

Based on the purpose, this dissertation includes two research questions (RQs). As mentioned in previous sections, retailers needs both intra- and interorganisational DCs in order to manage their logistics challenges. Without such DCs in place, retailers' logistics strategies and operations risk becoming outdated and unable to meet current and future customer demands, which in turn can result in poor logistics performance and lost sales. Therefore, it is vital to explore how DCs enable retailers to manage different logistics challenges. Despite this recognition, DCs are rarely studied in a retail setting (Chen et al., 2019; Rajaguru and Matanda, 2019) and it is unclear how such DCs enable retailers to manage different logistics challenges. Therefore, an improved understanding of how DCs support retailers in managing logistics challenges is needed. Therefore, the first research question, RQ1, is:

RQ1: How do DCs enable retailers to manage logistics challenges?

To develop and use DCs, specific antecedents are needed (Ambrosini and Bowman, 2009; Teece, 2007). DCs typically depend on a number of antecedents, which enable firms to modify their resource base in a dynamic business environment (Eriksson, 2014). Previous literature has studied some antecedents of DCs (e.g. Defee and Fugate, 2010; Forkmann et al., 2018; Zollo and Winter, 2002). However, antecedents are still often conceptual, and seldom studied in a retail setting. Therefore, a further understanding of how antecedents support DCs that enable retailers to manage different logistics challenges is needed. Based on this section, the second and last research question, RQ2, is:

RQ2: How do antecedents support the DCs that enable retailers to manage logistics challenges?

To fulfil the purpose of this dissertation and answer the two RQs, two logistics challenges have been studied in two separate studies. In the next section, the chosen logistics challenges are presented, which are (1) the geographical expansion of retailers, and (2) the transition to omni-channel (OC) retailing, which have been studied individually in two 
different studies, Study 1 and Study 2, respectively. These challenges have been used to study DCs and their antecedents from both an intra- and interorganisational perspective. Figure 1 presents an overview of the research purpose, the two research questions and the two studies of the dissertation, including the logistics challenges studied in this dissertation.

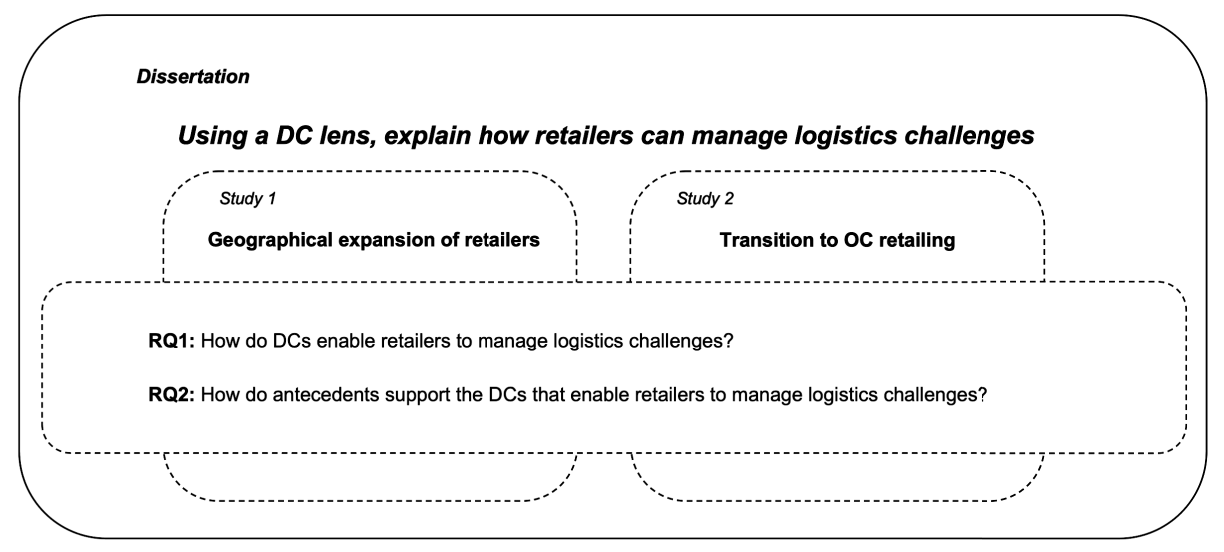

Figure 1. An overview of the dissertation

\subsubsection{The studied logistics challenges of retailers}

As previously mentioned, retailers are facing several major logistics challenges. However, it is only possible to cover a few here in this dissertation. Therefore, two representative and valid logistics challenges have been chosen to explain the DCs of retailers and the antecedents of such capabilities. In particular, this dissertation focuses on two major logistics challenges: (1) the geographical expansion of retailers, and (2) the transition to OC retailing. These were covered individually in two different studies, Study 1 and Study 2, respectively. The selected logistics challenges address multifaceted issues, including the need to develop new or enhanced competencies, and the importance of coordination and collaboration between cross-functional teams within both the retail organisation and external actors, which are key issues for most of the logistics challenges of retailers.

Firstly, intraorganisational DCs are addressed in Study 1, based on the logistics challenge posed by the geographical expansion of retailers. Logistics is crucial for this geographical expansion and has been considered "the backbone of the internationalisation process" (Marchet et al., 2016, p. 74). In the same way as marketing operations (e.g. sales operations in brickand-mortar stores and/or online stores) need to be in place, logistics operations must be established in order to supply new foreign sales markets (Swoboda et al., 2008). The establishment into new foreign sales markets requires extensive logistics preparations and requires logistics managers to be able to adjust their logistics function in order to efficiently support these foreign sales operations (Straube et al., 2008; Swoboda et al., 2008). During the expansion, retailers need to possess DCs that enable them to adapt their logistics strategy and operations to supply the new foreign sales markets. In particular, the logistics function of retailers needs to modify the existing logistics in order to adapt to the changing conditions in multiple sales markets. Without DCs in place, the logistics strategies and 
operations of retailers can become outdated and fail to answer to foreign customer demands, which in turn can result in poor performance and lost sales. Despite the extensive research on geographical expansion and the recognition of DCs, such capabilities have only been studied to a limited extent in previous retail research (Golgeci and Arslan, 2014). In a retail setting, DCs have received some research attention (e.g. Cao, 2011; Frasquet, 2013; Frasquet et al., 2018; Lowe et al., 2012). For instance, Frasquet et al. (2013) identified three generic DCs (knowledge acquisition and learning, adaptation capability and entrepreneurial vision), as well as four retail-specific DCs (location and store-design management, channel management, brand building and customer relationship management), which support geographical expansion. Despite these contributions, DCs are rarely studied in a retail setting, and it is unclear how such DCs enable retailers to manage the expansion into foreign sales markets (Golgeci and Arslan, 2014). Therefore, a lens of DCs for understanding geographical expansion of retailers has been requested (Dimitrova et al., 2018). Based on this, an improved understanding of how DCs enable retailers to manage geographical expansion is needed.

Secondly, interorganisational DCs (IDCs) are studied in Study 2 based on the challenge of the transition to $\mathrm{OC}$ retailing. OC retailing refers to the integration of physical and online channels to create a seamless shopping experience (Ishfaq et al., 2016). In this development, retailers are faced with the challenge of establishing well-functioning logistics that can effectively and efficiently fulfil the needs of both physical and online channels (Hübner et al., 2016). This conflates both frontend and backend flows (e.g. returns), including warehousing and distribution, which need to be carefully planned and executed to meet the needs of different sales channels (Ishfaq et al., 2016). In particular, OC retailing requires a higher level of logistics expertise, advanced information systems, and new processes in order to combine and coordinate the mixed flows from different sales channels (Kembro and Norrman, 2019a). As retailers often outsource all or parts of their logistics to one or more logistics service providers (LSPs) (Perdana et al., 2019), the interaction between retailers and LSPs becomes crucial for a successful transition to OC retailing. In particular, the transition to $\mathrm{OC}$ retailing requires both parties to share their competencies and to jointly develop the logistics system in order to create a seamless shopping experience. Retailers and LSPs have their own set of resources and capabilities related to their own field of work, which, when combined, can become a powerful source of competitive advantage (Hartmann and Grahl, 2011). In particular, a retailer and an LSP can combine their specific competencies in order to jointly improve their service offerings to end customers (e.g. the creation of new delivery solutions). To do this, both retailers and LSPs need specific IDCs that enable their logistics function to both access and use external resources and jointly combine them in a way that improves their logistics. In particular, such capabilities enable them to identify, analyse and use external resources and capabilities, as well as enabling them to together renew and refine their joint resource base in order to achieve superior performance (Beske et al., 2014; Defee and Fugate, 2010).

Despite the importance of OC retailing, there is a lack of understanding about how IDCs support the transition to $\mathrm{OC}$ retailing. Previous research has looked at multichannel and OC logistics, primarily from the overall network perspective (e.g. Agatz et al., 2008; Hübner et al., 2016; Melacini et al., 2018). Meanwhile, there have been several literature reviews conducted on the topic of warehouse operations and design (e.g. Faber et al., 2013; Gu et 
al., 2007; Davarzani and Norrman, 2015). However, very few focus on OC retailing using a DC lens (Hüseyinoglu et al., 2018). In general, IDCs have been studied to some extent in previous SCM literature (e.g. Beske, 2012; Beske et al., 2014; Defee and Fugate, 2010). However, these capabilities are still highly conceptual, and it is empirically unclear how they enable retailers and LSPs to combine their joint resource base in order to jointly manage their logistics system (Chen et al., 2019; Defee and Fugate, 2010) and the transition to OC retailing. Based on this, an improved understanding of how IDCs support the transition to OC retailing is needed.

\subsection{Key terms and concepts}

In this section, the key terms and concepts used in the dissertation are briefly described.

\section{Dynamic capabilities}

In this dissertation, DCs are a key term that encompasses both intra- and interorganisational DCs related to retail logistics. In this dissertation, DCs are defined as "the capacity of an organisation to purposefully create, extend, or modify its resource base" (Helfat et al., 2007, p. 4). Based on this definition, DCs can be seen as specific routines for modifying the resource base. Furthermore, DCs in this dissertation cover more than just the "pure" DCs found within the logistics function of retailers, but also encompass DCs closely related to the logistics function, including the top management team, and other functions within the company, as well as external actors, which all influence the logistics.

\section{Antecedents of dynamic capabilities}

The antecedents of DCs is another key term used in this dissertation, and encompasses the antecedents of both intra- and interorganisational DCs. In this dissertation, the antecedents of DCs refer to specific factors or conditions that influence the development and use of DCs (Ambrosini and Bowman, 2009; Teece, 2007). In a similar vein as for DCs, the antecedents of DCs in this dissertation cover more than just antecedents found within the logistics function of retailers. The antecedents of DCs cover both internal and external factors related to a firm, with the latter able to act as either enablers or hindrances for DCs.

\section{Logistics management and supply chain management}

It is also important to clarify the distinction between logistics management and supply chain management, as these terms are often used interchangeably. Logistics management typically refers to the management of logistics operations and has an impact on the logistics performance of a firm, while supply chain management typically has a wider scope that often focuses on the performance of the overall supply chain. In this dissertation, the focus is on logistics performance from retailers to the end customer, including logistics service providers. Therefore, the logistics management of retailers is studied in this dissertation.

\section{Geographical expansion}

In this dissertation, geographical expansion is a key term that refers to the expansion of the sales operations of retailers into foreign sales markets. This term has several synonyms, such as retail internationalisation and internationalisation of retailers, which have frequently been used in the previous literature. In this dissertation, these synonyms for the geographical expansion of retailers are used for the theoretical frame of references as well 
as in the appended papers, Paper II and Paper III, but all refer to the retail expansion of foreign sales operations into new markets.

\section{Omni-channel retailing}

$O C$ retailing refers to a strategy that includes multiple sales channels that are integrated in order to create a seamless shopping experience, whether customers shop online or in a brick-and-mortar store (Ishfaq et al., 2016). This dissertation focus on the logistics aspects in the transition to OC retailing.

\subsection{Outline of the dissertation}

In this last section, the outline of the dissertation is presented. This dissertation is a compilation thesis and includes seven chapters as well as six appended papers. The dissertation can be read without the appended papers, but the papers contribute more or less to all parts of the dissertation.

\section{Chapter 1 - Introduction}

In the first chapter, a background to the research topic of the dissertation is presented. In particular, both a theoretical and a practical background are provided in order to describe the topic and motivate the research purpose and the research questions of the dissertation. In addition, key concepts and the outline of the dissertation are presented.

\section{Chapter 2 - The logistics challenges}

The second chapter presents the logistics challenges studied in this dissertation. It studies two specific challenges, geographical expansion of retailers and the transition to OC retailing. The chapter presents the key aspects of the logistics challenges, in order to provide a basic understanding of the challenges studied in the dissertation.

\section{Chapter 3 - Theoretical frame of reference}

The theoretical frame of reference presents the theoretical lens that is applied in order to study the chosen logistics challenges in this dissertation. In particular, the chapter presents a brief background to DCs, as well as more in-depth literature on DCs, and the antecedents of DCs.

\section{Chapter 4 - Methodology}

This chapter presents the methodology of the dissertation. The chapter includes a presentation of the research approach and design, including the research design of the studies and appended papers. In addition, an analysis of the research questions is presented. The final section presents a discussion on the research quality and research ethics.

\section{Chapter 5 - Overview of appended papers}

In this chapter, the appended papers of the dissertation are presented. The papers are summarised and their contribution to the dissertation's analysis are specified. The final section presents how the appended papers are used to answer the dissertation's research questions. 
Chapter 6 - Dynamic capabilities for managing logistics challenges of retailers

This chapter presents the answers to the first research question, RQ1. In particular, the answer is presented and discussed, followed by a summary in order to answer the research question.

\section{Chapter 7 - Antecedents of dynamic capabilities for managing logistics challenges} of retailers

This chapter presents the answers to the second research question, RQ2. In particular, the answer is presented and discussed, followed by a summary in order to answer the research question.

\section{Chapter 8 - Conclusions}

In the final chapter, the conclusions of the dissertation are presented. This chapter includes a reflective discussion about the answers of the research questions, as well as discuss the theoretical and practical implications of the research. In addition, suggestions for future research were presented. 




\section{The logistics challenges}

This chapter presents the logistics challenges studied in this dissertation. The aim of this chapter is to provide a basic understanding of the logistics challenges that are used to study DCs and their antecedents. The chapter is divided into two sections: Geographical expansion of retailers and Transition to $O C$ retailing. The first section presents the literature on the geographical expansion of retailers, including key aspects of geographical expansion, followed by logistics related to it. The second and final section presents the literature on OC retailing, including key aspects of such retailing, followed by logistics related to it.

\subsection{Geographical expansion of retailers}

Geographical expansion, also known as retail internationalisation, can be described as the expansion of a retailer's store and non-store (e.g. online) operations into foreign countries (Dawson, 2007). The expansion of retailers into foreign sales markets is an important success factor for many retailers; however, it is also a major retail challenge (Dimitrova et al., 2018).

The expansion of retailers into foreign sales markets is mostly driven by growth incentives, saturated home markets (Alexander, 1995; Dimitrova et al., 2018) and the easing of legal trading barriers across countries (Assaf et al., 2012). Due to slow growth and saturated domestic markets, many retailers seek to expand into international sales markets as a strategy to achieve further growth. However, such expansion faces several impediments. Numerous retailers have underestimated this challenge and have suffered serious financial losses as well as damaging their reputation due to this expansion (Bianchi, 2011 Christopherson, 2007). For instance, retail giants such as US retailers Walmart and Target, and French retail chain Carrefour, have all suffered from failed expansion efforts. Furthermore, lack of management and resource commitment and limited international experience among managers, as well as insufficient market infrastructure, are major internal impediments to geographical expansion (Dimitrova et al., 2018). In addition, a retailer's lack of knowledge and experience of foreign cultures, regulations, competitive structures and consumer behaviour can be a major barrier for becoming established in foreign markets (Burt et al., 2016; Douglas and Craig, 2011). In addition, retailers expanding through an online store face similar impediments as retailers expanding internationally through brickand-mortar stores (Dimitrova et al., 2018).

The topic of geographical expansion has attracted a lot of research attention. In particular, previous research has focused on marketing-oriented aspects, including drivers for and impediments to the geographical expansion of retailers (e.g. Corstjens and Lal, 2012; Dimitrova et al., 2018), strategies including foreign market selection (Dimitrova et al., 2018; Swoboda et al., 2007), market channels (e.g. Agatz et al., 2008; Akehurst and Alexander, 2013), foreign entry modes (e.g. Dimitrova et al., 2018; Picot-Coupey et al., 2014) and retail formats (e.g. Swoboda and Elsner, 2013).

\subsubsection{Aspects of geographical expansion by retailers}

Geographical expansion by retailers involves several strategic decisions, establishment activities and resources, which are necessary to plan, enter and operate in the new foreign sales market. Such key aspects are further presented in this section. 
In terms of strategic decisions, geographical expansion typically encompasses three key market-oriented decisions: (1) foreign market selection, (2) retail market entry mode and (3) retail format transfer. All three need to be considered for each foreign establishment (Elsner, 2012). These strategic decisions strongly influence the geographical expansion of retailers (Dimitrova et al., 2018; Picot-Coupey, 2009). Firstly, foreign market selection refers to the selection of which market(s) to enter, which is crucial for the success of international retailers (Dimitrova et al., 2018). This selection is typically based on a combination of market-specific (e.g. market potential and market risks) and company-specific (e.g. resources and capabilities) aspects (Brouthers et al., 2009). Typically, retailers choose to expand first into "psychically" close markets in terms of culture, language and business practices, before entering more distant markets (Elsner, 2012; Johanson and WidersheimPaul, 1975). This market selection approach based on psychic distance is common among retailers in Europe (Swoboda et al., 2009) and the USA (Vida, 2000). When establishing online stores, the psychological distance has some impact on foreign market selection but not to the same extent as for brick-and-mortar retailers (Sakarya et al., 2007).

Secondly, retail market entry mode refers to the entry approach used for expanding into new foreign sales markets (Elsner, 2012; Root, 1994) and includes a range of full or sharedcontrol entry modes. These modes involve a varied level of risk, control and investment. For instance, wholly owned subsidiaries and acquisitions involve a high level of control, investment and risk, whereas franchises and joint ventures involve a low level of control, investment and risk. Elsner (2012) argued that retailers need to choose an entry mode that matches their resource base. For instance, the establishment of brick-and-mortar stores requires large investments that in turn require large financial resources, which are often found in large-sized retailers rather than small and medium-sized retailers. In contrast, expansion through e-commerce can be quite effective for small, specialised retailers because it enables them to quickly gain access to many foreign markets without a significant capital investment (Foscht et al., 2006).

Thirdly, the decision about retail format transfer refers to the transfer of the business concept and internal retail systems and processes (i.e. marketing and supply-chain operations) into a new foreign market (Goldman, 2001; Swoboda and Elsner, 2013). A retailer can typically choose to transfer a standardised, adapted or mixed retail format. Previous research has studied different approaches. For instance, Johansson and Thelander (2009) and Wigley and Chiang (2009) argued for the importance of adapting a company's business concept in order to successfully operate in foreign sales markets. In contrast, other scholars (e.g. Gamble, 2010) highlighted the importance of the standardisation of a business concept and processes in order to achieve economies of scale and scope. In addition to these two extremes, there are scholars (e.g. Bengtsson, 2008; Burt et al., 2005; Jonsson and Foss, 2011; Winter and Szulanski, 2001) who have favoured a combination of standardisation and adaptation of the retail format. For instance, the Swedish global retail chain IKEA uses a flexible replication of its retail business concept, which includes a standardised retail concept in terms of fundamental values and vision, but adapts its merchandise, store formats and location, in-store layout and marketing communications to each market (Burt et al., 2016; Jonsson and Foss, 2011). In addition, international retailers tend to employ an 
adapted retail strategy when the psychological distance is greater because the risk perception tends to be higher and retailers are therefore more careful (Evans et al., 2008).

In terms of establishment activities, a retailer needs to perform a number of different activities in order to become established in a new sales market. These activities are highly influenced by the chosen strategy. The establishment of brick-and-mortar stores typically includes activities such as identification of the site location, building the store and the education of store staff (Sandberg, 2014). The establishment of online stores includes activities such as content preparation in terms of organising and presenting information and establishing a payment system related to the online store (Liao et al., 2008). According to Liao et al. (2008), local information preferences need to be integrated in order to better serve local customers. In a similar vein, Hwang et al. (2006) argued that adaptation to local market conditions, such as the economy, infrastructure and culture, is key in order to create well-functioning retail operations in foreign sales markets. In a similar vein, Coe and Hess (2005) recognised the importance of transferring internal retail systems and processes. For instance, retail infrastructure in terms of IT, logistics and finance need to be transferred, which can be achieved by either standardisation or adaptation of retail systems and processes.

In terms of resources, expansion into a new foreign sales market requires a considerable number of resources, including both internal resources, such as physical and financial assets, capabilities, information and knowledge, and external resources, such as knowledge and experience possessed by other actors. Retailers typically lack resources and experience at the beginning of their expansion (Burt et al., 2016; Douglas and Craig, 2011), which requires them to acquire new external resources from networks and interorganisational relationships (Dimitrova et al., 2018). For instance, retailers can use export promotions organisations to acquire local knowledge of foreign sales markets (Brewer, 2009). The inability of retailers to establish a network can be a major barrier to expanding into foreign markets (Dimitrova et al., 2018). Furthermore, retailers' coordination of internal and external resources constitutes a key success factor in terms of coordinating their international activities efficiently and effectively, including both marketing and supply-chain activities (Swoboda and Anderer, 2008).

\subsubsection{Logistics in the geographical expansion of retailers}

Logistics is crucial for retailers to manage their geographical expansion and has been considered "the backbone of the internationalisation process" (Marchet et al., 2016, p. 74). In the same way as marketing operations (e.g. sales operations in brick-and-mortar stores and/or online stores) need to be in place, logistics operations need to be established to supply new foreign sales markets (Swoboda et al., 2008). Establishment into new foreign markets requires extensive logistics preparations (Swoboda et al., 2008) and requires logistics managers to be able to adjust their logistics function to efficiently support foreign retail operations (Marchet et al., 2016). For successful geographical expansion, logistics managers expand their logistics function and logistics operations in a way that supports the overall expansion strategy, including foreign market selection, entry mode and retail format (Marchet et al., 2016). Previous research on geographical expansion has recognised the importance of a match between marketing-oriented decisions and operations on the one hand, and how logistics is organised and operated on the other. For instance, Chen et al. 
(2009) studied capabilities related to marketing and logistics and stressed the need for an "effective relationship" between these two functions to create value for end customers. Similar to this, Schramm-Klein and Morschett (2006) argued that the establishment of "effective coordination" between these functions is crucial in order to avoid poor company performance. Furthermore, a sufficient interplay between operational performance, such as logistics, and strategic market positioning is important for increasing company profits (Abrahamsson and Brege, 2004; Abrahamsson and Rehme, 2010). In relation to the geographical expansion of retailers, a similar observation was made by Swoboda et al. (2008), who claimed that marketing-oriented processes (e.g. sales promotion and customer relationships) and supply-chain processes (e.g. logistics operations and order management) are reciprocal and need to be carefully combined in order to achieve both external effectiveness (represented by a marketing-oriented logic) and internal efficiencies (ensured by well-functioning logistics).

\subsection{Transition to omni-channel retailing}

Another major challenge faced by retailers is the transition to OC retailing. OC retailing refers to the integration of physical and online channels into a seamless shopping experience for end customers (Ishfaq et al., 2016). An OC integrates different flows of retail goods and associated information into a complete solution, within which customers can choose how they purchase, pick up and return retail goods (Kembro and Norrman, 2019b). The strategy of OC retailing is becoming increasingly common among retailers and constitutes a major success factor for many retailers.

OC transition is mostly driven by technical advances, increased e-commerce (Cai and Lo, 2020) and increased customer demand (Simone and Sabbadin, 2018). Due to technical advances, more retailers are applying an OC strategy in order to better connect with shoppers across different channels, meet different customer demands and personalise retail offers based on data analytics (Simone and Sabbadin, 2018). The integration of physical and online channels enables retailers to offer different products and services through multiple channels. However, the OC transition involves several issues, including channel integration, changes in channel management and optimization of the physical channel, as well as integrating payment systems (Simone and Sabbadin, 2018). In addition, numerous retailers have struggled to keep up with technical advances as well as upholding a well-functioning OC strategy (Simone and Sabbadin, 2018).

This topic has attracted a lot of research attention over the last decade. Previous research has focused on various aspects of OC retailing, including OC strategies (e.g. Brynjolfsson et al., 2013; Zhang et al., 2019), OC customer service (e.g. Brynjolfsson et al., 2009), OC marketing (e.g. Cai and La, 2020; Verhoef et al., 2017), OC logistics and fulfilment (Galipoglu et al., 2018; Hübner et al., 2016; Ishfaq et al., 2016) and OC customer behaviour and preferences (e.g. Chen et al., 2018; Lazaris, 2014).

\subsubsection{Aspects of omni-channel retailing}

OC retailing involves several important aspects that are necessary in order to plan, implement and operate an OC. Firstly, an OC strategy involves several strategic decisions in different areas of retail, including marketing and logistics (Galipoglu et al., 2018; Mishra 
et al., 2021), which shape the business activities and strategy of retailers (Mishra et al., 2021). Therefore, retail managers need to understand how OC impacts upon the value proposition and future demand, as well as potential changes in network structures and the roles of different material-handling nodes. For instance, the transition to OC retailing involves issues such as channel integration, optimisation of the physical channel (Simone and Sabbadin, 2018) and management of reverse flow (Galipoglu et al., 2018). In terms of channel integration, retailers need to find a balance between different sales channels without creating conflict between them (Agatz et al., 2008). Such conflicts typically arise when resources such as staff, capital and technology are scarce, or when goals conflict (Kembro et al., 2018). Channel integration is also closely related to optimisation of the physical channel, which is another important OC issue. To optimise physical stores, store renovations and the implementation of innovative in-store technologies are important in order to make stores more attractive and up to date (Simone and Sabbadin, 2018). The management of reverse flow is another key aspect of OC retailing, which typically requires retailers to manage returns to a much greater extent, as online return rates are much higher than through physical channels (Simone and Sabbadin, 2018). Therefore, when transitioning to an OC strategy it is important for retailers to determine a suitable returns policy that balances cost and customer service. In addition to reverse flow management, retailers also need to manage several other business activities, including different shipping services (e.g. click-and-collect and in-store returns of online orders), logistics (e.g. inventory integration, in-store packing of click-and-collect orders, and using online returns as inventory), sales tools (e.g. seeing the contents of packages), and performance measurements (e.g. tracking additional sales from click-and-collect, online statistics) (Zhang et al., 2019).

\subsubsection{Logistics in omni-channel retailing}

OC retailing leads to multiple logistics issues, including how online orders should be fulfilled, how delivery and returns processes should be organised and how context-specific OC distribution systems should be designed (Hübner et al., 2016). An OC integrates mixed flows of retail goods and associated information, which enables customers to choose how they purchase, pick up and return retail goods (Kembro et al., 2018). For example, a customer might order online, pick up the delivery at a local delivery point and return it to a physical store. This type of flexibility results in a need for more complex logistics systems, in which the logistics function of retailers must handle high fluctuations in demand, a demand for faster deliveries and an increase in smaller shipments to a larger number of delivery points, while simultaneously achieving cost-efficient logistics (Hübner et al., 2016). OC retailing requires a higher level of logistics expertise, and new logistics processes in order to combine and coordinate frontend and backend flows (e.g. returns) of retail goods (Hübner et al., 2016; Kembro and Norrman, 2019). OC retailing depends on wellfunctioning logistics operations, including warehousing and distribution (Kembro and Norrman, 2019b), which needs to be carefully planned and executed (Ishfaq et al., 2016). The increase in mixed flows of retail orders (e.g. flows of store orders and e-orders) typically increases the degree of sorting between different retail flows (Kembro and Norrman, 2019). For example, click-and-collect orders are often sorted together with replenishment orders for joint delivery to stores, while e-orders with home delivery are sorted in a separate flow. In addition, if a retailer offers the option to buy online and pick-up in-store, it needs to consider where inventory will come from and if products will be picked in-store, in an e- 
commerce distribution centre, or in a brick-and-mortar distribution centre. Thus, retailers need to create new distribution systems to serve customers through multiple channels (Hübner et al., 2016). For instance, physical stores can function as small fulfilment centres, which are additional distribution and storage facilities (Simone and Sabbadin, 2018). Hence, a physical store can be used by costumers to pick up online orders or as a local distribution node for the shipment of online orders.

Furthermore, OC retailing typically requires more integrated information systems to handle different retail flows (Oh et al., 2012), as well as the implementation of automated solutions to manage the material handling of retail orders (Kembro and Norrman, 2019b). According to Larke et al. (2018), IT becomes a crucial ingredient for successfully managing the entire logistics system. An integrated system can increase the visibility of inventory across all material-handling nodes and improve the coordination of inventories (Hübner et al., 2016). It also simplifies the decision-making related to order fulfilment, including how and where orders should be fulfilled, in order to improve service levels and decrease logistics costs (Mahar and Wright, 2009).

In addition, collaborative efforts with other supply-chain members both upwards (e.g. producers, suppliers) and downwards (e.g. logistics service providers, customers) are important for managing an OC strategy and can improve the overall supply chain performance (Kembro and Norrman, 2019a). For instance, standardising packaging, controlling deliveries according to stricter time windows, postponing the sorting of customer orders to optimise transport, and reducing lead times to end customers are common objectives in collaborative efforts (Kembro and Norrman, 2019). In addition, previous research (e.g. Gadde and Hultén, 2009) has shown the need for increased interaction between shippers and providers for successful logistics outsourcing, including the logistics involved in OC retailing. The next section focuses on aspects of shipperprovider relationships related to $\mathrm{OC}$ retailing.

\section{Shipper-provider relationships in omni-channel retailing}

Retailers often outsource all or parts of their logistics to one or more logistics service providers (LSPs) (Perdana et al., 2019), which makes the interaction between retailers and LSPs crucial for the OC transition. The OC transition typically involves one or more LSPs that manage and perform logistics activities on behalf of retailers. Such logistics activities include warehousing, transportation, demand forecasting and planning, order processing, inventory management, material handling and packaging, customer service and reverse logistics (Hotrawaisaya et al., 2014). Retailers and LSPs need to work together to develop logistics systems that can handle multiple flows and returns. A good shipper-provider relationship can improve service, flexibility and information sharing, as well as visibility, inventory management and resource use (Aharonovitz et al., 2018). From the shipper's point of view, the shipper-provider relationship can in general result in improved logistics solutions, and better service for end customers, which improves the overall logistics performance (Aharonovitz et al., 2018). For LSPs, such relationships can reduce costs and improve the logistics performance through joint activities and information sharing (Aharonovitz et al., 2018). In particular, the OC transition requires both parties to actively share their existing competencies, and create new competencies to jointly improve the logistics system related to OC retailing (e.g. the creation of new delivery solutions) (Kembro 
et al., 2018). Retailers and LSPs have their own set of resources and capabilities related to their own field of work, which, when combined, can become a powerful source of competitive advantage (Hartmann and Grahl, 2011).

In terms of shipper-provider relationships, Cox (1996) mentioned that there are different types of relationships, which extend from short-lived arms-length relationships that focus primarily on low prices, to more collaborative relationships that focus on jointly developing unique logistics solutions to solve different challenges (e.g. OC transition), as well as achieving mutual benefits (Halldórsson and Skjøtte-Larsen, 2004). A shipper-provider relationship is typically composed of strategic, tactical and interpersonal factors, including relationship history, meetings, supplier selection and logistics performance in logistics triads, which influence the outcomes of the relationship (Aharonovitz et al., 2018). Such strategic, tactical and interpersonal factors play a central role in improving logistics performance. Firstly, it is critical for shippers to select the optimal provider by aligning their interorganisational needs and capabilities (Aharonovitz et al., 2018). The selection of LSPs involves relational and organisational factors that enable collaboration, such as information sharing, trust, commitment, the involvement of top management and cultural aspects (Coltman et al., 2011; Fawcett et al., 2012). Secondly, the relationship history is essential for strengthening the logistics relationship as it indicates that partners fulfil each other's needs and expectations (Aharonovitz et al., 2018). In addition, long-term partnerships are likely to experience performance improvements (e.g. Krause et al., 2007). Relationship history practices lead to performance improvements by fostering joint actions and information sharing, which can improve the logistics performance (Aharonovitz et al., 2018). In particular, a long relationship often supports the "learning curve" of collaborative efforts, in which knowledge and competencies are further developed with time (Halldórsson and Skjøtte-Larsen, 2004). Thirdly, a high frequency of joint meetings (Fawcett et al., 2012), training sessions and visits can improve communication among logistics partners and provide opportunities to better understand one another's operational features, limitations and problems, and to identify areas for improvement (Min et al., 2005; Krause et al., 2007). Moreover, these meetings are essential for establishing and maintaining a collaborative relationship that involves the top management of both firms and that is focused on strategically defined objectives (Aharonovitz et al., 2018). In addition, Vieira et al. (2009) emphasised the importance of frequent joint meetings to encourage collaborative efforts, such as the alignment of objectives, information sharing and joint problem-solving of logistics issues. For instance, the $\mathrm{OC}$ transition requires the continuous realignment of distribution channels (Ishfaq et al., 2016). For instance, end customers desire visible stock availability for different channels, product information and order tracking (Hübner et al., 2016), which in turn requires centralised inventory management (Hübner et al., 2016b) as well as integrated information systems (Kembro and Norrman, 2019b). Firstly, centralised inventory management enables different delivery and return options (Wollenburg et al., 2018), whereas integrated information systems enable the synchronisation of channels to better customise the logistics service for OC customers (Beck and Rygl, 2015). 



\section{Theoretical frame of reference}

This chapter presents the theoretical frame of reference for this dissertation. The aim of this chapter is to provide an in-depth understanding of DCs, including a background to the theory of DCs, as well as definitions and characteristics of DCs and their antecedents. This frame of reference provides the theoretical lens for explaining how DCs enable retailers to manage logistics challenges.

\subsection{The theory of dynamic capabilities - a background}

The theory of dynamic capabilities (DCs) was first introduced by Teece and Pisano (1994) in the strategic management literature. Strategic management research studies company performance and focuses on the question: why do some companies outperform others? (Barney and Clark, 2007). Before the theory of DCs was introduced, the dominant paradigm in the field during the 1980s was the competitive forces approach (or competitive positioning) developed by Porter (1980). According to Porter (1980; 1985), competitive advantage comes from firms' market positioning, and Porter (1985) presented three generic positioning strategies: cost leadership, differentiation and focus. According to Porter (1980), a firm needs to find a favourable position within an industry in order to defend itself against competitive forces, or influence such forces in its own favour by strategic actions such as deterring entry or raising barriers to entrance (Porter, 1980). This paradigm has, however, been found insufficient in supporting competitive advantage as it neglects firms' resources (Barney, 1991; Grant, 1991).

As a reaction to this, scholars (e.g. Teece et al., 1997) argued for the importance of firms' resources in order to achieve competitive advantage. Hence, a new paradigm called "the resource-based theory of the firm" (RBV) was introduced by Wernerfelt (1984) and later popularised by Barney (1991). This became the dominant paradigm of the strategic management field in the 1990s (e.g. Ketchen and Giunipero, 2004; Lavie, 2006). In contrast to competitive positioning, RBV postulates an inside-out approach and focuses on a firm's own resources for generating competitive advantage. For instance, Wernerfelt (1984, p. 172) described companies as "bundles of resources", where a firm's resources are typically defined as "all assets, capabilities, organisational processes, firm attributes, information, knowledge etc. controlled by a firm that enable the firm to conceive of and implement strategies that improve its efficiency and effectiveness" (Barney, 1991, p. 101). In a further development of RBV, Grant (1991) made a distinction between resources and capabilities. According to Grant (1991), resources consist of tangible (e.g. capital, equipment, buildings and inventory) and intangible (e.g. skills of individual employees, brand, goodwill and intellectual property such as trademarks and copyrights) inputs, whereas capabilities are the "cooperation and coordination of resources" (Grant, 1991, p. 119). Furthermore, Grant (1991) stated that "while resources are the source of a firm's capabilities, capabilities are the main source of its competitive advantage" (Grant, 1991, p. 119). However, it is important to note that not all resources and capabilities result in competitive advantage. In particular, scholars argued that resources need to be valuable, rare and difficult to imitate (Barney, 2002; Barney and Clark, 2007), non-substitutable (Wang et al., 2007) and supported by the organisation to be effectively and efficiently exploited (Kihlén, 2007). In other words, resources and capabilities can be a source of competitive advantage if they demonstrate valuable, rare, inimitable and non-substitutable (VRIN) traits (Wang et al., 2007; Wernerfelt, 1989). 
Since the introduction of RBV, there have arisen many parallel views and research directions, and it become more relevant to describe resource-based theories (RBT), rather than RBV as a single theory alone (Barney, 2001). For instance, the relational view is an extension of the traditional RBV (Dyer and Singh, 1998; Lavie, 2006) that emphasises socalled network resources, which are defined as "external resources embedded in the firm's alliance network that provide strategic opportunities and affect firm behaviour and value" (Lavie, 2006, p. 638). In addition to internal resources that are owned and controlled by a firm, external resources are embedded between firms, and are an important source of competitive advantage (Dyer and Singh, 1998). Based on the relational view, companies should not be solely valued on the basis of their internal resources but also in terms of the accessibility of external resources from their alliances (Lavie, 2006). In a similar vein, Dyer and Singh (1998) mentioned that relational rents are created by joint contributions between alliance partners, in which the investment of resources, knowledge exchange or a combination of complementary resources between partners contribute to relational rent.

A shared characteristic between the previously described paradigms is the static view of how competitive advantage is achieved (Wang et al., 2007). For instance, the essence of RBT lies in its emphasis on resources and capabilities as the source of competitive advantage, in which resources are heterogeneously distributed among firms (Barney, 1991; Penrose, 1959; Wernerfelt, 1984). However, RBT typically fails to explain how sustainable competitiveness is achieved over time in more dynamic business environments (Eisenhardt and Martin, 2000). Several scholars (e.g. Eisenhardt and Martin, 2000; Teece et al., 2007) have argued that the existing resource base of a firm is not enough to achieve long-term competitiveness. Instead, firms need the ability to change their resource base to make better use of their resources and adapt them to manage their dynamic environment. In particular, firms need to have the capacity to create, extend and modify their resource base over time in order to manage new conditions in their business environment and sustain their competitive advantage (Helfat et al., 2007). In turn, this notion resulted in the introduction of the theory of DCs (Eisenhardt and Martin, 2000; Helfat, 1997; Teece et al., 1992, 1997; Zahra and George, 2002). Since their introduction, dynamic capabilities have been applied in various research areas and have become well-recognised among scholars. DCs are typically viewed from an intraorganisational perspective, in which a firm needs DCs to manage its own internal resource base. However, due to the cross-organisational nature of firms, several scholars (e.g. Teece et al., 1997) also argue for the need for so-called interorganisational DCs that enable firms to manage and use external resources. Figure 2 provides an overview of the evolution of RBT. For this study, both intraorganisational and interorganisational DCs are relevant and are described in the upcoming sections. 


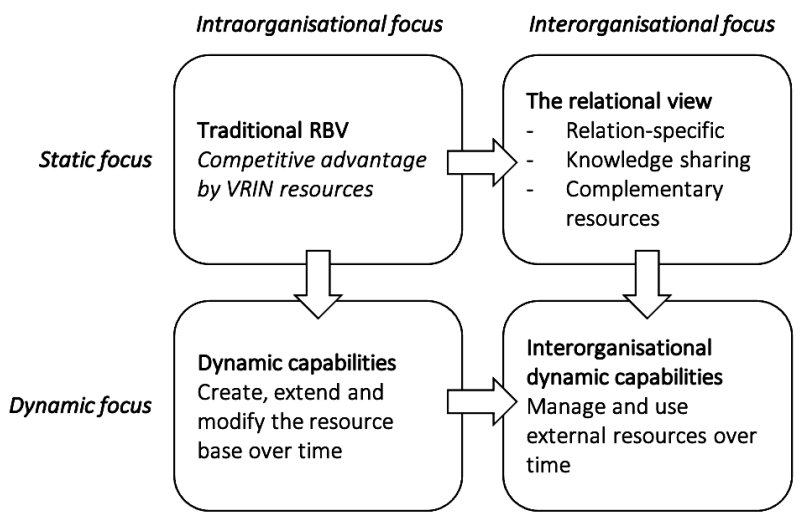

Figure 2. An evolution of resource-based theories including the traditional RBV, the relational view, DCs and IDCs

\subsection{Intraorganisational dynamic capabilities}

The theory of DCs was first introduced by Teece and Pisano (1994). The first explicit definition of DCs was made by Teece et al. (1997, p. 516), who defined DCs as "the firm" ability to integrate, build, and reconfigure internal and external competences to address rapidly changing environments". Although DCs can be of both an intra- and interorganisational nature, previous research has mostly focused on intraorganisational DCs. They can be seen as routines that are present in the managerial and organisational processes of firms and enable them to constantly revise their resource base in order to adapt to changing conditions and in turn sustain the firm's competitive advantage (Teece et al., 1997; Teece, 2007; Zollo and Winter, 2002). According to Sune and Gibb (2015), DCs can be seen as "responses to the need for change". In a similar vein, Helfat et al. (2007, p. 2) argue that "the concept of dynamic capabilities includes the capacity with which to identify the need or opportunity for change, formulate a response to such need or opportunity and implement a course of action". In this dissertation, DCs are seen as a necessary capacity to manage changing conditions within the dynamic business environments of firms, including the retail sector.

\subsubsection{Defining dynamic capabilities}

Since their introduction, DCs have been defined in numerous ways (e.g. Eisenhardt and Martin, 2000; Helfat et al., 2007; Pavlou and El Sawy, 2011; Wang and Ahmed, 2007; Zahra et al., 2006; Zollo and Winter, 2002). A selection of common definitions is presented in Table 1. According to Barreto (2010) and Eriksson (2014), there are two common views of DCs in previous research. Firstly, DCs can be viewed as learning abilities, which typically refers to the abilities to integrate, build and reconfigure internal and external resources and capabilities (e.g. sense, seize and reconfigure) (Teece et al., 1997; Wang and Ahmed, 2007; Zahra et al., 2006). For instance, Teece et al. (1997, p. 516) defined DCs as "the firm's ability to integrate, build, and reconfigure internal and external competences to address rapidly changing environments". In a similar vein, Zollo and Winter (2002, p. 340) defined DCs as "a learned 
and stable pattern of collective activity through which the organisation systematically generates and modifies its operating routines in pursuit of improved effectiveness".

Secondly, DCs can be seen as specific processes or routines used by firms to adapt their resource base to changing business conditions (e.g. Eisenhardt and Martin, 2000; Lopez, 2005). For instance, Eisenhardt and Martin (2000, p. 1107) presented DCs as specific and identifiable processes and defined DCs as "the firm's processes that use resources - specifically the processes to integrate, reconfigure, gain, and release resources - to match and even create market change... the organisational and strategic routines by which firms achieve new resources and configurations as markets emerge, collide, split, evolve, and die". Helfat et al. (2007, p. 1) sharpen the focus and refer to DCs as "the capacity of an organisation to purposefully create, extend or modify its resource base". In other words, these definitions identify DCs as patterned and intentionally applied activities that bring change to a firm's existing resource base. Helfat et al. (2007) use the term capacity to refer to DCs, not just in terms of the ability to perform a task in an at least minimally acceptable manner, but also to emphasise its repeatability (Barreto, 2010).

Table 1. Definitions of DCs

\begin{tabular}{|c|c|}
\hline Author & Definition \\
\hline Teece et al., 1997, p. 516 & $\begin{array}{l}\text { "the firm's ability to integrate, build, and reconfigure internal and external } \\
\text { competences to address rapidly changing environments." }\end{array}$ \\
\hline $\begin{array}{l}\text { Eisenhardt and Martin, } \\
\text { 2000, p. } 1107\end{array}$ & $\begin{array}{l}\text { "The firm's processes that use resources - specifically the processes to } \\
\text { integrate, reconfigure, gain and release resources - to match and even create } \\
\text { market change. Dynamic capabilities thus are the organisational and strategic } \\
\text { routines by which firms achieve new resource configurations as markets } \\
\text { emerge, collide, split, evolve, and die." }\end{array}$ \\
\hline $\begin{array}{l}\text { Zollo and Winter, 2002, } \\
\text { p. } 340\end{array}$ & $\begin{array}{l}\text { "A learned and stable pattern of collective activity through which the } \\
\text { organisation systematically generates and modifies its operating routines in } \\
\text { pursuit of improved effectiveness" }\end{array}$ \\
\hline Winter, 2003, p. 991 & $\begin{array}{l}\text { "one can define dynamic capabilities as those that operate to extend, modify } \\
\text { or create ordinary capabilities." }\end{array}$ \\
\hline Zahra et al., 2006, p. 918 & $\begin{array}{l}\text { "the abilities to reconfigure a firm's resources and routines in the manner } \\
\text { envisioned and deemed appropriate by its principal decision-maker" }\end{array}$ \\
\hline Helfat et al., 2007, p. 4 & $\begin{array}{l}\text { "the capacity of an organisation to purposefully create, extend, or modify its } \\
\text { resource base" }\end{array}$ \\
\hline $\begin{array}{l}\text { Wang and Ahmed, 2007, } \\
\text { p. } 35\end{array}$ & $\begin{array}{l}\text { "a firm's behavioural orientation constantly to integrate, reconfigure, renew } \\
\text { and recreate its resources and capabilities and, most importantly, upgrade } \\
\text { and reconstruct its core capabilities in response to the changing environment } \\
\text { to attain and sustain competitive advantage" }\end{array}$ \\
\hline $\begin{array}{l}\text { Pavlou and El Sawy, } \\
2011 \text {, p. } 242\end{array}$ & $\begin{array}{l}\text { "those capabilities that help units extend, modify, and reconfigure their } \\
\text { existing operational capabilities into new ones that better match the changing } \\
\text { environment" }\end{array}$ \\
\hline
\end{tabular}

Despite these numerous definitions and views, DCs are still difficult to identify and explain (Sune and Gibb, 2015). In addition, it is common for scholars to fail to explicitly state which definition or view of DCs they are using, and it is also common for scholars to mix both views when studying DCs. To simplify the identification of DCs, Sune and Gibb (2015) summarised three key characteristics that need to be fulfilled to qualify as a DC: (a) a 
patterned element, (b) degree of intent, and (c) change of resource base. Firstly, a DC must contain some pattern-like element otherwise it is just ad hoc problem solving (Winter 2003); hence, DCs must be distinguished from one-time idiosyncratic changes to the firm's resource base (Sune and Gibb, 2015). Secondly, in contrast to organisational routines, which consist of repetitive organisational activities that lack intent, DCs need some degree of intent (Dosi et al., 2000; Sune and Gibb, 2015). This characteristic is key for distinguishing DCs from pure luck or an accident, which is emphasised in both the definitions by Zahra et al. (2006) and Helfat et al. (2007). Third and lastly, it is characteristic that all DCs are about one type of change, which is changes in the resource base (Ambrosini et al., 2009). According to Sune and Gibb (2015), these three characteristics can be applied to various definitions and views of DCs. In addition, Eisenhardt and Martin (2000, p. 1117) argued that DCs are only a source of competitive advantage if they are applied "sooner, more astutely and more fortuitously" than by competitors. This is also in line with the arguments of other scholars (e.g. Barney et al., 2001; Wang et al., 2007). In addition, Barney et al. (2001) argued that the ability to change quickly, as well as alertness to market changes, are costly for others to imitate and can therefore be a source of sustained competitive advantage. Furthermore, DCs are conditioned by a firm's unique history (Kirci et al., 2015). In a highly dynamic environment, competitive advantage is typically short term and requires the managers of a firm to compete by "creating a series of temporary advantages" (Eisenhardt and Martin, 2000, p. 1117), while less dynamic environments require DCs in the form of wellmade, complex routines that can be valid for a longer period of time (Teece et al., 1997).

For this dissertation, the definition provided by Helfat et al. (2007) was chosen because it captures the key characteristics of DCs described by Sune and Gibb (2015). Although this definition is often associated with the second view, Helfat et al.'s (2007) definition does not necessarily exclude DCs from being portrayed as learning abilities either. Instead, their definition can encompass DCs as both learning abilities and processes or routines, which was important for this research because it did not restrict it, and enables us to be mindful that DCs can be viewed as both learning abilities and processes. In this research, the key is to be aware of both views and use them to explain DCs and their antecedents.

\subsection{Interorganisational dynamic capabilities}

DCs are typically viewed from an intraorganisational perspective, in which firms need capabilities to manage and modify their own resource base in order to sustain their competitive advantage. However, the relational view provides a wider scope for DCs that extends beyond the individual firm. In particular, Dyer and Singh (1998) and Lavie (2006) argued that sustainable competitive advantage is typically not based solely on internal resources and capabilities controlled by a particular firm, but rather on that firm's ability to access external resources (Lavie, 2006). In a similar vein, Teece et al. (1997, p. 516) state that the DCs of a firm aim to integrate, build and reconfigure both internal and external competencies, by which competencies "may extend outside the firm to embrace alliance partners". Valuable, rare and difficult to imitate external resources can be found between firms and are typically embedded in interorganisational relationships (Lavie, 2006), such as strategic alliances and networks of firms (Schepis et al., 2018). Such interorganisational relationships enable firms to identify and use external resources (e.g. identifying business opportunities) beyond their own internal resource base (Mitrega et al., 2018; Möller and Svahn, 2003). The 
ability to identify and manage external resources is therefore vital for achieving a sustainable competitive advantage (Forkmann et al., 2016; Mitrega et al., 2018; Schepis et al., 2018; Zaefarian et al., 2017). Based on the cross-organisational nature of firms, externally oriented DCs are needed, which enable firms to manage and use external resources (Eisenhardt and Martin, 2000; Teece et al., 1997). This, in turn, has led to the introduction of interorganisational DCs (IDCs).

\subsubsection{Defining interorganisational dynamic capabilities}

IDCs are an extension of intraorganisational DCs, which arose when previous DC research indicated the need for interorganisational DCs. For instance, Teece et al. (1997, p. 516) claimed that a firm's DCs aim to integrate, build and reconfigure both internal and external competencies, where external competencies are based on external sources outside the firm. In a similar vein, Eisenhardt and Martin (2000) also discussed the existence of externally oriented DCs. Despite the recognition of IDCs in various research disciplines (e.g. supply chain), they are seldom explicitly defined. However, some authors do give more externally oriented definitions, such as Teece et al. (1997, p. 516), who defined DCs as "the firm's ability to integrate, build, and reconfigure internal and external competences to address rapidly changing environments".

Previous research has presented various types of IDCs in multiple research disciplines. For instance, Eisenhardt and Martin (2000) mentioned acquisition and alliancing as externally oriented DCs. In addition, the concept of absorptive capacity in knowledge-management research is found to be a type of externally oriented DC that is typically defined as "a set of organisational routines and processes by which firms acquire, assimilate, transform, and exploit knowledge to produce a dynamic organisational capability" (Zahra and George, 2002, p. 186). Absorptive capacity enables firms to identify, understand and use external knowledge (Cohen and Levinthal, 1990; Zahra and George, 2002). This DC has been frequently studied in previous research, including logistics and SCM research (e.g. Knoppen et al., 2015; Saenz et al., 2014; Yang et al., 2019). In addition to absorptive capacity, previous research has also recognised the need for a desorptive capacity in order to identify knowledge-transfer opportunities as well as transferring and facilitating the application of knowledge (Bravo et al., 2016; Lichtenthaler and Lichtenthaler, 2009). In a supply-chain setting, desorptive capability is particularly important in order to understand learning between supply-chain members (Meinlschmidt et al., 2016) and can also be seen as an IDC.

\subsection{Antecedents of dynamic capabilities}

The development of DCs and IDCs depends on several antecedents. Previous research has focused on the antecedents of DCs, while the antecedents of IDCs have rarely been investigated. However, due to the similar characteristics and natures of DCs and IDCs, the antecedents of DCs can often also apply to IDCs. The antecedents of DCs refer to factors or conditions that influence the development and use of DCs (Ambrosini and Bowman, 2009; Teece, 2007). Such factors can either enhance or inhibit the development and use of DCs and IDCs. According to previous scholars (e.g. Eriksson, 2014; Zahra et al., 2006), antecedents can be considered as inputs to DCs, while outcomes (e.g. improved logistics performance) are outputs from them. Previous research (e.g. Eriksson, 2014; Teece, 2007) has identified a vast number of antecedents. In particular, Eriksson (2014) stated that 
antecedents can be of both an internal and external nature and categorised antecedents into two types, internal and external antecedents, which are further presented in the following sections. Figure 3 summarises the different antecedents of DCs.

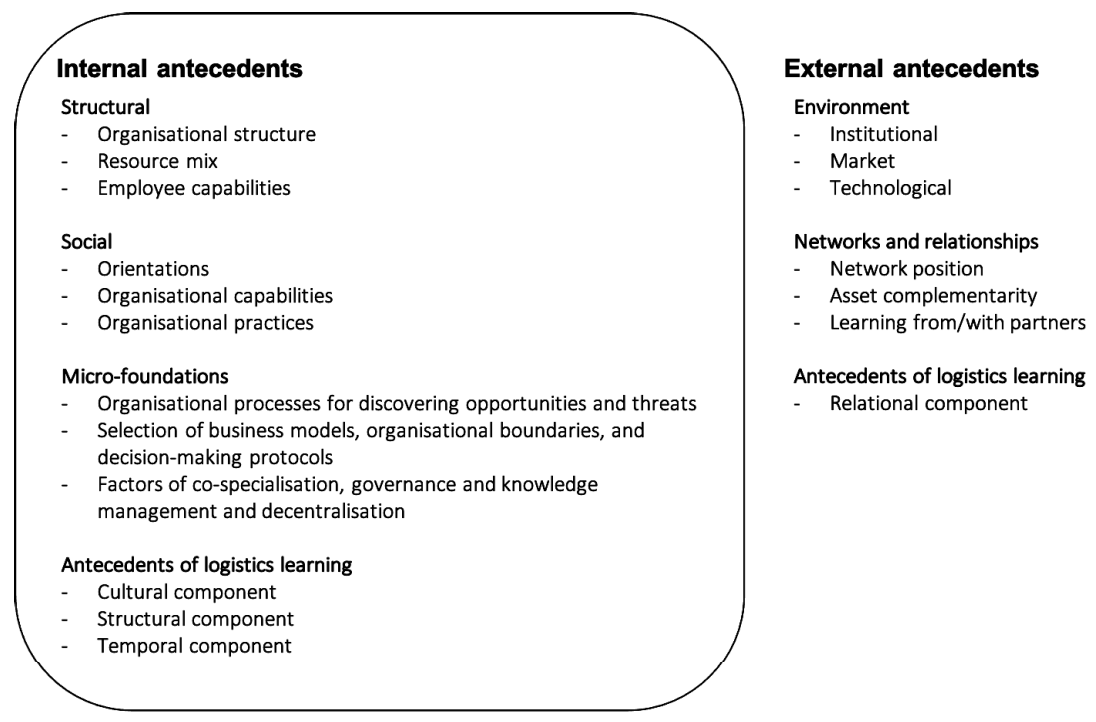

Figure 3. Summary of antecedents of DCs in previous research.

\subsubsection{Internal antecedents}

Internal antecedents refer to the structural and social factors of an organisation that influence the development and use of DCs (Eriksson, 2014). Eriksson (2014) summarised the antecedents of previous DC research and concluded that internal antecedents can be divided into social and structural antecedents. According to Eriksson (2014), social antecedents refer to three key factors: orientations, organisational capabilities and organisational practices, which can all serve as antecedents of DCs.

Various orientations have been highlighted by previous research as key for developing DCs. Orientations can be organisational, such as an organisational learning (Zollo and Winter, 2002) or market orientation, or individual, such as an entrepreneurial orientation (Eriksson, 2014). Organisational learning has been identified as a major antecedent of DCs (Zollo and Winter, 2002), in which organisational learning depends on different learning mechanisms at an organisational and individual level, which enable firms to accumulate experience and to articulate and codify knowledge (Zollo and Winter, 2002). In addition, they can be interorganisational. For instance, Defee and Fugate (2010) identified supply chain orientation and learning orientation as key orientations that support the development of IDCs. Two key organisational capabilities are flexibility and collaboration, which support the development of DCs (Eriksson, 2014). For instance, flexibility refers to a capability for organisational change, which determines effectiveness in implementing continuous change, and is suggested to be an important antecedent of all DCs (Eriksson, 2014). Furthermore, the importance of a collaboration capability is being increasingly acknowledged, and this 
can be an antecedent of DCs (Blomqvist et al., 2004). This is also strongly related to externally oriented DCs, such as IDCs. Finally, organisational practices are practices that increase employee motivation and these can work as another social antecedent of DCs (Wooten and Crane, 2004).

Structural antecedents include factors such as organisational structure, resource mix and employee capabilities, which can all serve as antecedents of DCs (Eriksson, 2014). Firstly, the organisational structure of a firm can have a decisive influence on DCs. This is especially true in larger firms, which typically need a more structured organisation to coordinate and modify their resources (Karim, 2009). In smaller firms, the development of human capital is more decisive (Døving and Gooderham, 2008). Secondly, a firm's resource mix, including both internal and external resources, can influence the development of DCs (Eriksson, 2014). DCs depend on the specific resource mix of the firm, and the resources need to be aligned with emerging opportunities and threats (Eriksson, 2014). On the other hand, resource scarcity seems to have a significant influence on DCs, and can act as a hindrance. Thirdly, in relation to resources, employee capabilities have also been emphasised for developing DCs. Managerial capabilities can influence DCs because they can influence decisions regarding resource allocation and organisational strategies (Eriksson, 2014). In a similar vein, Teece et al. (1997, p. 515) stressed that "the key role of strategic management in appropriately adapting, integrating, and reconfiguring internal and external organisational skills, resources, and functional competences to match the requirements of a changing environment". DCs underline the processes of transforming a firm's resources and capabilities into outputs in the form of products or services that deliver superior value to customers. Managers can have both a positive and negative impact on DCs. For instance, Eriksson (2014) argued the crucial role of managers in accumulating relevant knowledge that can support change. In contrast, Penrose (1959) recognised managers as the biggest constraint regarding a firm's growth. In addition to managers, the capabilities of other individuals within a firm can also influence its DCs.

Teece (2007) also identified micro-foundations as antecedents of three generic DCs: sense, seize and reconfigure. Micro-foundations are defined as "the distinct skills, processes, procedures, organisational structures, decision rules, and disciplines - which undergird enterprise-level sensing, seizing, and reconfiguring capacities [and] are difficult to develop and deploy” (Teece, 2007, p. 1319). Firstly, the micro-foundations of the sensing capability include organisational processes for discovering opportunities and threats, as well as the capacities of individuals (Teece, 2007). Secondly, seizing builds on a selection of business models, organisational boundaries, decision-making protocols and the building of employee loyalty. Thirdly, the microfoundations of the reconfiguring capability include the factors of co-specialisation, governance and knowledge management and decentralisation (Teece, 2007). In addition, Esper et al. (2007) proposed a DC called a logistics learning capability, which consists of a combination of cultural, structural, relational and temporal components. These components can be viewed as antecedents that can influence or hinder the development and use of that supply-chain oriented DC. 


\subsubsection{External antecedents}

In addition to internal antecedents, external antecedents are also important for developing DCs and IDCs, as they are strongly influenced by the environment in which firms operate (Di Stefano et al., 2010). External antecedents typically refer to environmental factors and factors related to interorganisational relationships (Eriksson, 2014). Environmental antecedents draw attention to the context in which DCs are developed, such as the retail sector. In particular, such antecedents refer to turbulence in the markets (e.g. the retail market) (Chung and Beamish, 2005), the institutional environment (Delmas, 2002; Yiu and Lau, 2008), and/or the technological environment (Benner, 2009; Song et al., 2005). Turbulence in any one of these dimensions increases the need for DCs (Macher and Mowery, 2009).

In addition to environmental antecedents, network and interorganisational relationship antecedents refer to factors such as network position, asset complementarity and learning with/from partners. Although DCs were originally studied at an organisational level, the role of networks has proven essential for the development of DCs (Eriksson, 2014; Macpherson et al., 2004). In a similar vein, other scholars (e.g. Eriksson, 2014; Liao et al., 2009) argued for the importance of external resources and capabilities, as well as the ability to access additional assets through networks and partnerships in order to develop DCs. Asset complementarity is especially important for smaller firms because their internal assets are very limited (Døving and Gooderham, 2008). Large firms, on the other hand, can trigger the development of DCs both internally and within their networks (Athreye et al., 2009). In addition, partners can help with sensing opportunities for a firm because they can identify unmet needs in the market (Ayuso et al., 2006). Lastly, learning in interorganisational relationships seems to have a significant impact on DCs (Defee and Fugate, 2010; Kale and Singh, 2007). Interorganisational relationships, such as retailer-LSP collaborations, typically start with a cost focus that can develop into a learning partnership, which in turn can result in new capabilities and resource configurations (Vivek et al., 2009) through the exploration and exploitation of knowledge (Cegarra Navarro, 2005). 



\section{Methodology}

This chapter presents the methodology that was applied in this dissertation. The first sections present the research process, followed by the research design, including the design of the two studies associated with the dissertation. Thereafter, the analysis for answering the research questions is presented. The last section presents a discussion on the research quality and research ethics.

\subsection{Research process}

The research process aims to describe the overall process of the conducted research, including the associated studies and appended papers. An overview of the process is illustrated in Figure 4.

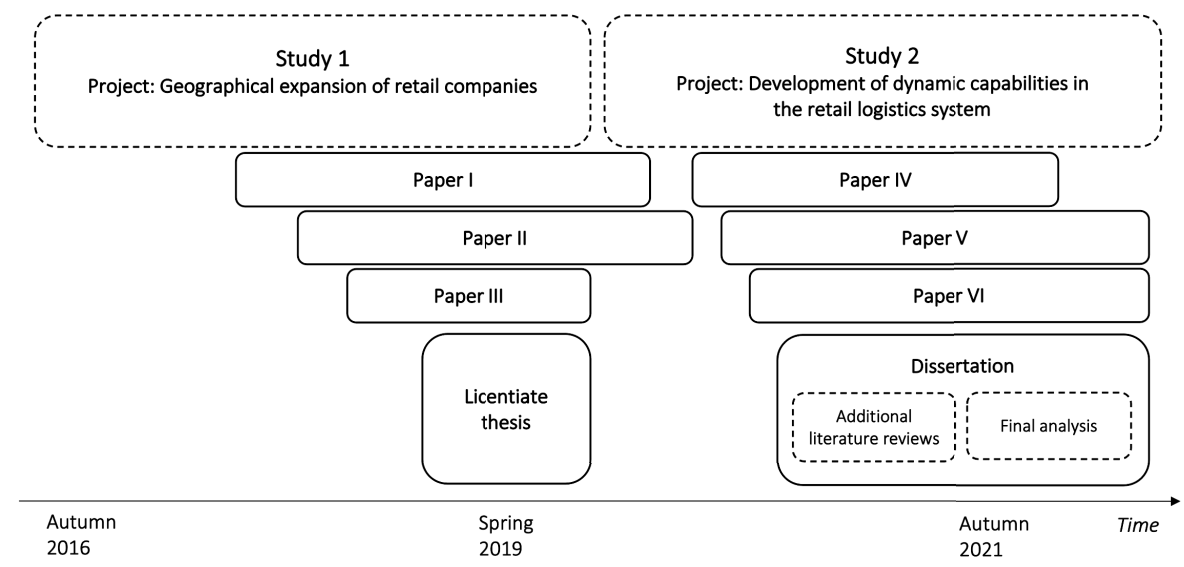

Figure 4. An overview of the research process for the dissertation.

The dissertation consists of two studies, Study 1 and Study 2, which were performed sequentially, starting with Study 1. This study was a part of a research project called Geographical expansion of retail companies (Swedish: Geografisk expansion av detaljhandelsföretag). It included three papers: Paper I, Paper II and Paper III, and a licentiate thesis. Study 1 contributed with new knowledge about DCs and their antecedents in the geographical expansion of retailers. Firstly, Paper I explored the establishment process of retailers, including the different establishment phases and key resources (e.g. key staff and functions) involved. Previous research has focused on strategic aspects (e.g. entry modes, retail formats) but neglected the actual process of entering a new foreign sales market, including the key activities, decisions and resources involved. Furthermore, the establishment process presented in Paper I provides a base for understanding how logistics can support expansion. Based on the establishment process, different logistics aspects and logistics preparations were found, which were further explored in Paper II. This paper explored the key logistics characteristics of retailers that support expansion using the theory of embeddedness. It provided valuable insights into how different logistics characteristics can support embeddedness in foreign sales markets. To further understand how logistics supports geographical expansion, an RBT lens was found useful for studying logistics resources and capabilities. An RBT lens has been applied to some extent previously to study 
geographical expansion, but not for understanding logistics capabilities. This resulted in Paper III. As a final step, Study 1 resulted in a licentiate thesis (Haag, 2019), which was defended in March 2019. The purpose of the licentiate thesis was to "explore the supporting role of logistics during the early stage of geographical expansion". The findings of the thesis provided an extensive overview of how the logistics function of retailers can play a reactive and/or proactive role when supporting geographical expansion. Based on the RBT lens applied in both Paper III and the licentiate thesis, a more dynamic lens was found to be important for further understanding how logistics supports expansion over time. In addition, the findings of Study 1 highlighted the importance of collaboration within company functions, as well as with external actors, in order to successfully expand abroad.

Based on the findings of Study 1, the importance of DCs and collaboration with external actors (e.g. LSPs) was recognised, and this resulted in the initiation of the second study, Study 2. This study was a part of a research project called Development of dynamic capabilities in the retail logistics system (Swedish: Utveckling av dynamiska förmågor i detaljhandelns logistiksystem). Study 2 includes three papers: Paper IV, Paper V and Paper VI. The study contributed with new knowledge on interorganisational DCs (IDCs) and the antecedents of such IDCs in the transition to OC retailing. Firstly, based on a structured literature review, Paper IV provided an overview of IDCs in different contexts (e.g. strategic management, marketing and SCM) and different categories of IDCs, which resulted in a conceptual framework for categorising IDCs. This was followed by Paper V, which studied learning between retailers and LSPs. Absorptive and desorptive capacities (presented by Zahra and George, 2002) were used to study learning between retailers and LSPs. In addition, Paper VI studied retailer-LSP collaboration based on a conceptual model developed by Defee and Fugate (2010). This includes two IDCs called dynamic supply chain capabilities, and resulted in an improved understanding of how IDCs support collaborative efforts between retailers and LSPs related to OC retailing.

As the final step in the research process, the findings of Study 1 and Study 2 were analysed in this dissertation to answer the research questions and fulfil the research purpose to: Using a DC lens, explain how retailers can manage logistics challenges. Additional literature on DCs and IDCs, as well as literature on the two logistics challenges, were collected. Thereafter, a final analysis was conducted to explain how DCs and IDCs and their antecedents enable retailers to manage logistics challenges.

\subsection{The research design}

The research design of this dissertation refers to the plan detailing how the research was conducted (Patton, 2015). For this dissertation, the research design provided a structure for how the research purpose and research questions were answered (Bryman and Bell, 2011; Saunders et al., 2007), whereby the purpose and questions influence the choice of appropriate research methods (Yin, 2009). The approach of this dissertation is of an "explanatory" nature and the research questions are "how" questions, which aim to explain why a phenomenon acts the way it does (Yin, 2014). The phenomenon was to explain how DCs enable retailers to manage logistics challenges. For such an explanatory research approach, case studies are suitable because they enable a detailed study of the phenomenon in question (Bryman and Bell, 2011; Yin, 2014). This approach enables DCs to be studied 
in their "natural" setting and to capture the unique paths of retailers. A path-dependent approach is important for explaining DCs because they are conditioned by the unique history and path of the firm (Sune and Gibb, 2015).

Furthermore, the lens of DC has been chosen to identify, describe and explain DCs and their antecedents. A DC lens was appropriate for understanding how different logistics resources and capabilities enable retailers to manage different logistics challenges. In contrast to previous RBT, a DC lens considers the dynamics of business environments and that the resource base of firms needs to be constantly modified. This is also true for the logistics challenges faced by retailers, which include various unforeseen issues that need to be solved quickly by modifying the retailers' resource base. In other words, the lens of DC is suitable for understanding how retailers adapt their resource base to manage different logistics challenges.

In this dissertation, the lens of DC encompasses the chosen definition of DCs along with other characteristics of DCs that were useful for identifying, describing and explaining DCs. DCs can be defined as "the capacity of an organisation to purposefully create, extend, or modify its resource base" (Helfat et al., 2007, p. 4). This capacity can see DCs as either learning abilities or strategic processes, which enable modification of the resource base. To qualify as a DC, three characteristics need to be fulfilled: (a) a patterned element, (b) degree of intent and (c) change of resource base (Sune and Gibb, 2015). In addition, the antecedents of DCs have also been studied based on a DC lens. Antecedents are typically defined as factors or conditions that influence DCs (Ambrosini and Bowman, 2009; Teece, 2007). In this research, antecedents were found based on the definition above as well as characteristics mentioned in previous research. For instance, Eriksson (2014) argued that there are different types of antecedents, including structural (e.g. organisational structure, resource mix) and social antecedents (e.g. orientations, organisational practices), which support the development and use of DCs.

In the dissertation, DCs and their antecedents have been studied from both an intraorganisational and an interorganisational perspective based on the two studied logistics challenges, the geographical expansion of retailers and the transition to OC retailing. Firstly, Study 1 examined intraorganisational DCs and their antecedents based on the logistics challenge of geographical expansion, and focused primary on the resources of the retail organisation itself. Secondly, Study 2 studied IDCs and their antecedents, based on the logistics challenge of $\mathrm{OC}$ transition, and focused on the joint resource base of both internal and external resources between retailers and LSPs. Note, both logistics challenges studied in this dissertation are interorganisational challenges, as both require an extensive amount of resources from both internal (e.g. the retail organisation) and external (e.g. LSPs) sources in order to be successfully managed. Furthermore, the unit of analysis differs between the studies (including the appended papers), but the overall unit of analysis in this dissertation is the retailer.

Based on this, the two studies have individual research designs (including purpose, research approach, unit of analysis, perspective and methods) that complement each other in order to increase our understanding of DCs and their antecedents in retail. The research designs are presented in the following sections. 


\subsubsection{Research design of Study 1}

Due to the limited research on DCs in the geographical expansion of retailers, Study 1 is based on an explorative approach. This approach is appropriate for providing new knowledge about a specific phenomenon that lacks previous research (Patel and Davidson, 2011). Hence, a multiple case-study approach was chosen since it is an appropriate method for explorative research (Miles et al., 2014). A case study combines both empirical data and literature to provide an improved understanding of the studied phenomenon (Alvesson and Sköldberg, 1994), which in this case was to improve the understanding of how DCs and their antecedents help to manage geographical expansion of retailers. Case studies are often used for theory generation (Gammelgaard, 2017), which was the focus of Study 1. In addition to the case studies, several literature reviews were conducted to develop a basic understanding of the challenges of geographical expansion, including marketing and logistics aspects. Study 1 included three papers (i.e. Papers I, II and III), which each had their own research design. These papers provided an improved contextual understanding of the expansion of retailers, including the different resources, logistics characteristics and logistics capabilities involved. The research design of the appended papers is summarised in Table 2, and the appended papers are presented in full in the Appendix 1. The next sections present the case studies and literature reviews that make up Study 1.

Table 2. Summary of the research design used in the appended papers in Study 1.

\begin{tabular}{|c|c|c|c|}
\hline & Paper I & Paper II & Paper III \\
\hline Purpose & $\begin{array}{l}\text { Explore the phases of } \\
\text { the retail establishment } \\
\text { process into new } \\
\text { foreign markets, } \\
\text { including the internal } \\
\text { and external } \\
\text { individuals/functions } \\
\text { involved }\end{array}$ & $\begin{array}{l}\text { Explore how the } \\
\text { logistics function and } \\
\text { operations support } \\
\text { embeddedness in } \\
\text { retailers' geographical } \\
\text { expansion }\end{array}$ & $\begin{array}{l}\text { Explore supply-chain- } \\
\text { oriented capabilities } \\
\text { that facilitate the } \\
\text { process of retail } \\
\text { internationalisation }\end{array}$ \\
\hline Research approach & Explorative & Explorative & Explorative \\
\hline Unit of analysis & The retailer & The retailer & The retailer \\
\hline Perspective & $\begin{array}{l}\text { A process perspective } \\
\text { is applied to identify } \\
\text { activities and resources } \\
\text { (including staff) } \\
\text { involved in the } \\
\text { establishment process } \\
\text { to geographically } \\
\text { nearby markets }\end{array}$ & $\begin{array}{l}\text { A focus on supply- } \\
\text { chain processes in the } \\
\text { geographical expansion } \\
\text { of retailers }\end{array}$ & $\begin{array}{l}\text { Resource-based } \\
\text { theories (RBT) }\end{array}$ \\
\hline Theory & $\begin{array}{l}\text { The frame of reference } \\
\text { includes literature that } \\
\text { together describes the } \\
\text { establishment process } \\
\text { of retailers into foreign } \\
\text { markets by both } \\
\text { physical and online } \\
\text { stores }\end{array}$ & $\begin{array}{l}\text { The concept of } \\
\text { embeddedness }\end{array}$ & $\begin{array}{l}\text { RBT (including the } \\
\text { relational view and the } \\
\text { theory of DCs) }\end{array}$ \\
\hline Method & $\begin{array}{l}\text { Inductive, multiple } \\
\text { case-study approach }\end{array}$ & $\begin{array}{l}\text { Inductive, multiple } \\
\text { case-study approach }\end{array}$ & $\begin{array}{l}\text { Inductive, multiple } \\
\text { case-study approach }\end{array}$ \\
\hline
\end{tabular}




\begin{tabular}{llll} 
Key findings & $\begin{array}{l}\text { The establishment } \\
\text { process includes three }\end{array}$ & $\begin{array}{l}\text { Centralised logistics } \\
\text { chases (i.e. a market- } \\
\text { analysis phase, an }\end{array}$ & $\begin{array}{l}\text { Three logistics } \\
\text { capability }{ }^{4} \text { categories: }\end{array}$ \\
$\begin{array}{l}\text { implementation phase } \\
\text { and a follow-up phase) }\end{array}$ & $\begin{array}{l}\text { Standardised logistics } \\
\text { operations, and }\end{array}$ & $\begin{array}{l}\text { leadership capability } \\
\text { category, integration } \\
\text { capability category, and }\end{array}$ \\
& & $\begin{array}{l}\text { learning capability } \\
\text { category }\end{array}$ \\
\hline
\end{tabular}

\section{Literature reviews}

In Study 1, several literature reviews were conducted with the main objective of developing an in-depth understanding of the geographical expansion of retailers, including the logistics resources and capabilities involved.

\section{Selection}

In Study 1, three strategies were used to collect literature. As an initial strategy, basic literature on geographical expansion was identified based on recommendations from supervisors and colleagues. This initial literature provided a basic understanding of the previous literature on geographical expansion and enabled the identification of keywords that were useful for future literature reviews. As a second strategy, literature was sourced based on keywords from the initial literature review to provide an in-depth contextual understanding of the logistics resources and capabilities related to expansion. Separate literature reviews were conducted for each paper, which each had their own specific focus. Search terms were combined manually based on the particular goal of the specific literature review. In line with Beck and Rygl (2015), search terms such as 'retail', 'logistics', 'logistics aspects', 'warehouse operations' and 'geographical expansion', were combined into search strings to collect literature related to a specific paper. Also, synonyms of key words, such as 'supply chain', 'distribution operations', 'foreign expansion', 'internationalisation' and 'retail internationalisation', were used to find relevant literature (Beck and Rygl, 2015). In addition, backward snowball sampling was used to find additional literature relevant to the study (Bryman, 2015).

\section{Collection}

For the literature collection, the databases UniSearch and Google Scholar were used. UniSearch was the primary database as it includes a large range of databases such as Web of Science, Scopus, and Business Source Premier, which cover an extensive amount of literature on strategic management, RBT, logistics and SCM. In addition, Google Scholar was used to find recommended papers as well as to find papers that were not accessible via UniSearch.

\section{Analysis}

Throughout the literature reviews, literature was analysed in three main steps (inspired by Snyder, 2019). Firstly, the titles of the collected literature were scanned, and papers that related to Study 1 were retained for further analysis. As a second step, the abstracts of the remaining papers were carefully read and papers that lacked relevance were removed.

\footnotetext{
${ }^{4}$ Note, the supply-chain capabilities presented in Paper III are entitled logistics capabilities in this dissertation. This is due to the intraorganisational perspective used to study DCs in Study 1. Supply-chain capabilities could easily be mistaken for IDCs, and therefore logistics capabilities is a more suitable term.
} 
Thirdly, the researcher scanned each paper in full and made notes with respect to the specific purpose of the literature review. Notes on the remaining papers were summarised in a separate document to save the results of the literature review in one place, which reduced the risk of losing relevant literature throughout the study.

\section{Case studies}

Study 1 encompassed three multiple case studies involving three large-sized, Swedish retail companies. The purpose of these case studies was to improve the understanding of how retailers manage their expansion into foreign sales markets. The case studies provide an indepth understanding of how retailers adapt their logistics function to upcoming foreign establishments and changing market conditions. It should be noted that Study 1 first applied an RBT lens (e.g. Paper III) but, in order to further understand how retailers manage logistics challenges over time, a DC lens was found more suitable to capture the dynamics of this challenge. Multiple case studies were chosen, since this method typically yields more robust and generalisable findings (Eisenhardt and Graebner, 2007) and provides a strong base for theory building (Yin, 1994), which was the focus of Study 1. Studying multiple cases enables comparisons between cases, which clarifies whether an emergent finding is unique to a single case or consistently replicated across several cases (Eisenhardt and Graebner, 2007). This was especially helpful in distinguishing DCs from ad hoc problem-solving (Sune and Gibb, 2015).

\section{Case selection}

The case selection of Study 1 was made using a set of selection criteria that included several key characteristics. A major selection criterion was retail chains with relatively recent experience of geographical expansion, in which top management teams were willing to share knowledge and data about their on-going geographical expansion. The case companies were chosen using theoretical sampling (Eisenhardt and Graebner, 2007), in which cases are selected because they are particularly suitable for illuminating the studied phenomenon. For this study, information-rich case companies were chosen because they provided an in-depth understanding of the DCs supporting the geographical expansion of retailers. According to Flyvbjerg (2006), information-rich cases should be selected because they often represent some kind of extreme, which are often preferable to facilitate a deeper understanding of the causes behind a specific problem. The case companies in Study 1 can be seen as extremes in the sense of their specific situations. They provided rich, up-to-date information regarding their ongoing foreign sales establishments, including the dynamic capabilities involved, which was key for this study. In addition, dynamic capabilities by their nature are not easily identified (Sune and Gibb, 2015). Thus, a few content-rich cases were preferable for Study 1 in order to study the capabilities of each case in detail, rather than scratching the surface of the capabilities of a larger number of cases.

A further criterion was that the chosen retail chains needed to have been present in at least one of their new foreign sales markets for a minimum of three years to have passed the initial phase in a new foreign sales market. Also, retailers that established themselves with physical stores was selected for this study because this is the most common expansion strategy among large retail chains (Elsner, 2012; Picot-Coupey et al., 2014). This was relevant for the generalisability of Study 1's findings. In addition, expansion using online 
stores has also been covered to some extent due to the importance of having an online presence in foreign sales markets (Picot-Coupey et al., 2014). Another important selection criterion was to select retail companies that ensured relevance to the overall retail sector, which was also important for the generalisability. Study 1 focused on retail sectors that offer affordable everyday customer products (e.g. home and leisure products and clothes). Furthermore, large retail chains (see the definition at the European Commission, 2009) were desired because they were likely to be more involved in designing their own logistics and using DCs to manage logistics issues during their expansion. This case selection resulted in the selection of three retail companies, which are presented Table 3. A further presentation of the case companies is found in the appended papers.

Table 3. Overall information about the case companies in Study 1.

\begin{tabular}{|c|c|c|c|c|}
\hline Company & Retail sector & Sales channels & $\begin{array}{l}\text { Sales markets via } \\
\text { physical stores }\end{array}$ & $\begin{array}{l}\text { Sales markets via } \\
\text { online store }\end{array}$ \\
\hline$A$ & $\begin{array}{l}\text { Home and } \\
\text { leisure }\end{array}$ & Physical stores & $\begin{array}{l}\text { Sweden, Norway } \\
\text { and Germany }\end{array}$ & No online stores \\
\hline$B$ & $\begin{array}{l}\text { Clothing and } \\
\text { fashion }\end{array}$ & $\begin{array}{l}\text { Physical stores and } \\
\text { online stores }\end{array}$ & $\begin{array}{l}\text { Sweden, Norway, } \\
\text { Finland, Denmark and } \\
\text { Germany }\end{array}$ & $\begin{array}{l}\text { European Union } \\
\text { countries and } \\
\text { Norway }\end{array}$ \\
\hline$C$ & $\begin{array}{l}\text { Hobby } \\
\text { materials }\end{array}$ & $\begin{array}{l}\text { Physical stores and } \\
\text { online stores }\end{array}$ & $\begin{array}{l}\text { Sweden, Norway, } \\
\text { Finland, the } \\
\text { Netherlands, and } \\
\text { Belgium }\end{array}$ & $\begin{array}{l}\text { European Union } \\
\text { countries and } \\
\text { Norway }\end{array}$ \\
\hline
\end{tabular}

\section{Data collection}

In Study 1, the data collections included semi-structured interviews, company visits and secondary data material, such as annual reports, company websites and newspapers. Interviews were the primary source of knowledge and provided in-depth insights into the case companies' resources, capabilities, DCs and their antecedents, while company visits and secondary data provided basic information about the companies, including their vision, strategy and overall company operations. All empirical data was gathered during the time period autumn 2016 to spring 2018, with the exception of a small complementary data collection conducted during autumn 2018.

First, semi-structured interviews were conducted, inspired by guidelines presented by Kallio et al. (2016). All the interviews were conducted using a standardised interview guide, including open-ended questions (see Appendix 2). The questions were based on the literature on geographical expansion, including marketing-oriented and logistics-oriented aspects, as well as RBT, including the theory of DCs. The identification of key respondents followed a top-down approach, starting with strategic company staff such as top executives or logistics manager. The respondents ranged from key strategic staff, such as company managers and project managers closely involved in the geographical expansion, to logistics managers who were centrally responsible for the logistics functions and operations involved in the foreign sales establishments. In addition, two respondents from two export promotion organisations (EPOs) were interviewed to gain a basic understanding of how retailers enter new foreign sales markets. These interviews were conducted to better understand the context of geographical expansion. The interviews continued until a 
saturation of new data was reached (Eisenhardt, 1989). For instance, when similar answers were repeated by several respondents, the marginal benefit of additional interviews became very small. This saturation typically occurred after a couple of interviews with different company respondents. In Table 4, the respondents in Study 1 are presented. The interview guide was sent to the respondents a few days in advance to give the respondents an overview of questions of interest for the study. Most interviews were conducted face-toface, took place on the premises of each retailer and typically lasted 50-120 minutes. Additional interview questions were answered by phone and/or email. In total, 21 interviews were conducted in Study 1, and all were recorded and transcribed.

Table 4. The respondents in Study 1.

\begin{tabular}{ll}
\hline Company/organisation & Title(s) of respondent(s) \\
\hline $\boldsymbol{A}$ & $\begin{array}{l}\text { Company founder, Project manager of the foreign establishments, Logistics } \\
\text { manager, Logistics developer, Supply-chain excellence manager, Warehouse } \\
\text { manager }\end{array}$ \\
\hline B & $\begin{array}{l}\text { Head of expansion, Brand director, Logistics manager, Transport and } \\
\text { customs manager }\end{array}$ \\
\hline C & Establishment manager, Supply-chain director \\
\hline EPO1 & Senior project manager \\
\hline Not: & Business area manager
\end{tabular}

Note: A number of informants were interviewed more than once.

\section{Analysis}

In Study 1, the analysis of the collected data was conducted in a stepwise manner, starting with coding of the empirical data, followed by within-case analyses and a cross-case analysis. First, a coding scheme was created based on the literature related to geographical expansion. The literature resulted in several codes, which were useful for coding and creating basic propositions based on the coded data. The same coding logic was used for all three papers in Study 1. For Paper I, the coding scheme was based on the literature on store establishments and aspects of geographical expansion (including foreign market selection, entry modes and retail format transfer). The coding scheme of Paper II was based on the literature on logistics in geographical expansion and the theory of embeddedness. The coding scheme of Paper III was based on the literature on logistics in geographical expansion and RBT.

In terms of analysis, the codified data from each respondent at an individual company were compared in several within-case analyses to find similarities and differences related to the specific aim. These findings were carefully documented for each paper. Thereafter, a crosscase analysis was performed using a pattern-matching technique (Yin, 2003) in order to compare the findings between the case companies. Paper I resulted in a map of the establishment process of retailers into foreign sales markets. Paper II resulted in the identification of four logistics characteristics and how they can support the embeddedness of retailers in foreign sales markets. Paper III resulted in three categories of logistics capabilities that facilitate geographical expansion. 


\subsubsection{Research design of Study 2}

Study 2 is based on an explanative approach. IDCs and the antecedents of IDCs have been studied in previous logistics and SCM literature (e.g. Defee and Fugate, 2010) and in general business management literature. There exist several descriptions and categorisations of IDCs; however, they are still highly conceptual and there is a lack of empirical understanding of how such capabilities support collaboration between supply-chain members, such as retailers and LSPs (Defee and Fugate, 2010). Therefore, an explanative approach was appropriate to further build on the existing knowledge about IDCs. Based on this approach, case studies were chosen as a suitable research method for Study 2 (Ellram, 1996). In contrast to Study 1, the case studies chosen for Study 2 were appropriate for both theory testing and theory elaboration (Gammelgaard, 2017), as there already exist theories and models related to IDCs from previous research that need to be further developed. In addition to case studies, literature reviews were also conducted to create a theoretical foundation for how IDCs are related to the OC transition.

Study 2 includes the findings of three papers (Paper IV, Paper V and Paper VI), which contributed to the understanding of IDCs and their antecedents that support collaboration between retailers and LSPs in the OC transition. The research designs of the papers are summarised in Table 5. The next sections present the literature reviews and case studies in Study 2.

Table 5. Summary of the research design used in the appended papers in Study 2.

\begin{tabular}{|c|c|c|c|}
\hline & Paper IV & Paper V & Paper VI \\
\hline Purpose & $\begin{array}{l}\text { Develops a } \\
\text { conceptualisation of } \\
\text { interorganisational } \\
\text { dynamic capabilities. }\end{array}$ & $\begin{array}{l}\text { Examines how learning } \\
\text { occurs in retailer-LSP } \\
\text { collaborations }\end{array}$ & $\begin{array}{l}\text { Explores how dynamic } \\
\text { supply chain capabilities } \\
\text { (DSCCs) support retailer- } \\
\text { LSP collaborations that } \\
\text { aimed to improve the } \\
\text { logistics system }\end{array}$ \\
\hline Research approach & Explanative & Explorative & Explorative \\
\hline Unit of analysis & IDCs & Retailer-LSP dyad & Retailer-LSP dyad \\
\hline Perspective & IDCs in networks & A dyadic perspective & $\begin{array}{l}\text { IDCs that support retailer- } \\
\text { LSP collaboration }\end{array}$ \\
\hline Theory & The theory of DCs & $\begin{array}{l}\text { The theory of DCs } \\
\text { (with a focus on } \\
\text { absorptive and } \\
\text { desorptive capacities) }\end{array}$ & $\begin{array}{l}\text { The theory of DCs (with a } \\
\text { focus on DSCCs) }\end{array}$ \\
\hline Method & $\begin{array}{l}\text { Systematic literature } \\
\text { review }\end{array}$ & $\begin{array}{l}\text { Deductive, single case- } \\
\text { study approach }\end{array}$ & $\begin{array}{l}\text { Deductive, multiple case- } \\
\text { study approach }\end{array}$ \\
\hline Key findings & $\begin{array}{l}\text { A conceptual framework } \\
\text { of IDCs that are } \\
\text { categorised by } \\
\text { governance and } \\
\text { beneficiary }\end{array}$ & $\begin{array}{l}\text { A description of } \\
\text { absorptive and } \\
\text { desorptive capacity } \\
\text { elements in retailer- } \\
\text { LSP collaborations. } \\
\text { The interplay between } \\
\text { these elements is found } \\
\text { to rely on two types: } \\
\text { one-directional support } \\
\text { and bi-directional } \\
\text { support }\end{array}$ & $\begin{array}{l}\text { A refinement of DSCCs }{ }^{5} \\
\text { and their antecedents in } \\
\text { retailer-LSP collaborations }\end{array}$ \\
\hline
\end{tabular}

\footnotetext{
${ }^{5}$ Note, the DSCCs studied in Paper VI are entitled IDCs in this dissertation.
} 


\section{Literature reviews}

In Study 2, several literature reviews were conducted, including a systematic literature review, narrative literature studies and reviews using a forward and backward snowball approach. The main objective of the literature reviews was to provide an in-depth understanding of retailer-LSP collaborations related to the OC transition, as well as IDCs supporting the transition to OC retailing.

\section{Systematic literature revien}

As an initial step, a systematic literature review (SLR) was performed to provide an overview of IDCs. An SLR approach was used to synthesise existing research in a systematic, transparent and reproducible manner (Snyder, 2019). For Study 2, the purpose of the SLR was to identify, categorise and describe research regarding IDCs. This provided a comprehensive overview of existing research on IDCs. The overview is presented in Paper IV and provides a theoretical foundation for IDCs that is used in the other appended papers of Study 2.

The conducted SLR can be described as "domain-based" (Palmatier et al., 2018) and was defined by the overarching concept of IDCs, which has its theoretical starting point in DCs (e.g. Helfat et al., 2007). As seen from the SLR, IDCs encompass other commonly used terms, such as capabilities relating to "strategic nets" (Schepis et al., 2018), "ecosystem capabilities" (Kay et al., 2018), and “dynamic supply chain capabilities” (Defee and Fugate, 2010).

The SLR was conducted based on stepwise instructions inspired by Palmatier et al. (2018) and Snyder (2019). In particular, the SLR included three main steps: (1) objective and search string formulation, (2) location and selection of articles and (3) paper analysis. An in-depth description of the SLR is found in Paper IV.

\section{Narrative literature reviews}

In addition to the SLR, several narrative literature reviews were conducted. The aim of the literature reviews depended on the specific purpose of Study 2. In addition, the different IDC frameworks and perspectives used in the appended papers determined the focus of each narrative literature review. For instance, Paper VI used a conceptual framework developed by Defee and Fugate (2010), including two IDCs called dynamic supply chain capabilities (i.e. knowledge accessing and co-evolving), and their antecedents (i.e. supply chain orientation and learning orientation), and here individual literature reviews were conducted to provide additional knowledge about these four elements. In a similar vein, individual literature reviews were conducted for each component of the theoretical framework of absorptive and desorptive capacities used in Paper V.

\section{Forward and backward snowball approach}

A forward and backward snowball approach was also used (Hinde and Spackman, 2015). For instance, a forward snowball approach was used in Paper VI to explore literature that had referenced the conceptual framework developed by Defee and Fugate (2010). In addition, a backward snowball approach was used multiple times throughout the research process to find relevant literature (Bryman, 2015). 


\section{Cases studies}

Study 2 encompasses two case studies, a multiple-case study and a single-case study. The purpose of the case studies was to explain how IDCs support retailers in their transition to OC retailing, with a focus on retailer-LSP collaboration. The case studies provided an indepth understanding of how IDCs can facilitate knowledge exchange between retailers and their LSPs, which support the transition to OC retailing.

A multiple case study was conducted, which studied learning in four retailer-LSP collaborations. A multiple case study is useful because it typically yields more robust and generalisable findings (Eisenhardt and Graebner, 2007). The multiple case study in Study 2 enabled comparisons between different retailer-LSP dyads, which clarified whether emergent findings in terms of IDCs and their antecedents were unique to a single case or consistently replicated across several cases (Eisenhardt and Graebner, 2007). The main aim of the multiple case study was to apply empirical data from the dyads to test and refine existing, conceptual frameworks on IDCs. In addition, a single case study was conducted to further understand learning in retailer-LSP collaboration. In particular, a single case enabled in-depth contextual insights into the studied dyad (Dubois and Gadde, 2014), which was appropriate for understanding the IDCs at play in a retailer-LSP dyad during the OC transition. Generalisability was not the goal of this study; instead, deepened contextual insight and further understanding of the complexity of collaboration between retailers and LSPs was the main goal. In the next three sections, case selections, data collections and analyses of the case studies in Study 2 are presented.

\section{Case selection}

The case companies in Study 2 were chosen using theoretical sampling (Eisenhardt and Graebner, 2007), in which cases were selected because they were likely to offer theoretical insights into IDCs. Similarly to Study 1, information-rich cases were desired in Study 2 in order to gain an in-depth understanding of the IDCs at work in retailer-LSP collaborations when transitioning to OC retailing. The cases in Study 2 can be viewed as extremes (Flyvbjerg, 2006) in the sense that their specific collaboration and situation is unique, and the development of logistics is an individual journey for that specific retailer-LSP dyad. Extreme cases are typically preferable to facilitate a deeper understanding of the causes behind a specific problem (Flyvbjerg, 2006). In this study, the cases provided rich, up-todate information regarding the firms' collaborative efforts related to OC retailing, including the involved IDCs and their antecedents. Similarly to Study 1, a few cases were chosen in Study 2 in order to study IDCs in detail. A few cases were preferable because DCs are not easily identified and can require a lot of empirical data (Sune and Gibb, 2015). The case selection for Study 2 resulted in the selection of four retailer-LSP dyads, which are presented in Table 6. All four case companies were used in the multiple-case study in Paper VI, and Dyad A was used for the single-case study in Paper V, due to the large amount of empirical data from that specific dyad. A presentation of the case companies is found in Papers V and VI. 
Table 6. Overall information about the dyads in Study 2.

\begin{tabular}{|c|c|c|c|c|}
\hline & Dyad A & Dyad B & Dyad C & Dyad D \\
\hline Companies & $\begin{array}{l}\text { Retailer A and } \\
\text { Major LSP }\end{array}$ & $\begin{array}{l}\text { Retailer B and } \\
\text { Major LSP }\end{array}$ & $\begin{array}{l}\text { Retailer A and } \\
\text { Specialised LSP } \\
\text { A }\end{array}$ & $\begin{array}{l}\text { Retailer B and } \\
\text { Specialised LSP } \\
\text { B }\end{array}$ \\
\hline $\begin{array}{l}\text { Scope of } \\
\text { collaboration }\end{array}$ & $\begin{array}{l}\text { Most of the } \\
\text { distribution and } \\
\text { most of the } \\
\text { warehouse } \\
\text { operations }\end{array}$ & $\begin{array}{l}\text { Most of the } \\
\text { distribution and a } \\
\text { few of the } \\
\text { warehouse } \\
\text { operations }\end{array}$ & $\begin{array}{l}\text { Additional } \\
\text { distribution } \\
\text { (such as same- } \\
\text { day delivery) }\end{array}$ & $\begin{array}{l}\text { Additional } \\
\text { distribution } \\
\text { (such as same- } \\
\text { day delivery) }\end{array}$ \\
\hline $\begin{array}{l}\text { Years of } \\
\text { collaboration }\end{array}$ & 10 & 10 & $2-3$ & 2 \\
\hline
\end{tabular}

\section{Data collection}

In Study 2, the data collection included semi-structured interviews, observations, company visits and secondary data material, such as annual reports, company websites and newspapers. Similarly to Study 1, interviews were the primary source of knowledge in Study 2 and were used to gain in-depth insights into IDCs and their antecedents. In addition to the interviews, observations of joint meetings and workshops were undertaken in order to further understand IDCs. Company visits and secondary data provided basic information about the case companies, including their vision, strategy and overall company operations. All empirical data was gathered during the time period autumn 2019 to spring 2020.

All the interviews were conducted using a standardised interview guide, including openended questions (see Appendix 3). The questions were based on the literature about shipper-provider relationships and IDCs. The identification of key respondents followed a "snowball approach" in which the company contacts (such as the logistics manager), together with the researcher, identified suitable respondents based on the purpose of Study 2. The respondents included strategic, tactical and operational staff who were closely involved in the transition to $\mathrm{OC}$ retailing. At the retailers, the respondents ranged from logistics managers to operational staff in the logistics function, but also staff operating in other parts of the retailer, such as corporate management, marketing and sales managers, as well as IT developers. At the LSPs, the corresponding party (such as the Key Account Manager) and other relevant staff involved in operational transport planning and joint logistics projects were interviewed. For the single-case study (involving Retailer A and the Major LSP), a larger number of respondents were interviewed in order to further understand the IDCs involved. The interviews continued until a theoretical saturation of data was achieved, that is, until the marginal benefit of interviewing additional people became very small (Eisenhardt, 1989). For instance, when similar answers about collaborative efforts were repeated by several respondents, the marginal benefit of additional interviews was small. In Table 7, the respondents in Study 2 are presented. 
Table 7. The respondents in Study 2.

\begin{tabular}{ll} 
Company & Title(s) of respondent(s) \\
\hline Retailer $A$ & Logistics manager, Quality manager of logistics, Supply chain specialist, \\
& Operational logistics manager, Manager of logistics operations \\
Retailer B & Logistics manager \\
Major SSP & Business development director, Senior project manager, Key account \\
& manager, Production manager, Technical specialist \\
Specialised LSP $A$ & Cofounder/CEO \\
Specialised LSP B & Business developer \\
\hline
\end{tabular}

In addition to interviews, observations of joint meetings and workshops were undertaken in order to study the retailer-LSP dyad and their interorganisational knowledge transfer "in action". More specifically, three separate observations were undertaken, lasting between four and six hours each. The observations took place onsite at both case companies and included tactical and operational joint meetings. The observations were particularly important for the single-case study, which studied more firm-specific IDCs and provided an additional element for the IDCs within the dyad that can otherwise be hard to capture. As "actions speak louder than words", these observations were conducted in order to further improve understanding of the IDCs at play within retailer-LSP dyads. Notes were taken during the observations to enable the data material to be included in the analysis phase.

Field visits and secondary data were useful additions to the primary data and provided basic information about the case companies, including their vision, strategy and overall company operations and joint logistics operations.

\section{Analysis}

In Study 2, the general analysis of the collected data was conducted in a stepwise manner, starting with coding, followed by within-case analyses and cross-case analysis. A coding scheme was established that included codes based on the relevant literature, including literature about IDCs, shipper-provider relationships, and OC retailing. For instance, the coding scheme for Paper $\mathrm{V}$ was based on the literature on absorptive and desorptive capacities. The coding scheme created a basis for the analysis within a retailer-LSP dyad as well as between dyads.

The data analysis was divided into two sequential steps, starting with a within-case analysis. Firstly, within-case analyses were performed to study IDCs and their antecedents for each retailer-LSP dyad, before comparing them with the other dyads in a cross-case analysis. In particular, a pattern-matching technique was used (Yin, 2003) in order to find similarities between the studied dyads.

\subsection{Answering the research questions}

The purpose of this dissertation is addressed through two research questions, RQ1 and RQ2. Table 8 presents the link between the research questions and the studies, including the appended papers, of this dissertation. The answering of the research questions is described in the upcoming sections, starting with RQ1. 
Table 8. Linking the research questions to the studies and appended papers

\begin{tabular}{ccccccc}
\hline & Study 1 & \multicolumn{5}{c}{ Study 2 } \\
\hline & Paper I & Paper II & Paper III & Paper IV & Paper V & Paper VI \\
\hline RQ1 & X & & X & X & X & X \\
\hline$R Q 2$ & X & X & X & & X & X \\
\hline
\end{tabular}

\subsubsection{Dynamic capabilities for managing logistics challenges of retailers}

The first research question, RQ1, asks: How do DCs enable retailers to manage logistics challenges? To answer this question, DCs were studied using a theoretical lens of DC. This theoretical lens of DC worked as a basis of identifying, describing and explaining DCs, and was based on the Theoretical frame of reference given in Chapter 3. In particular, this lens includes the definition of DCs as well as the key characteristics (or criteria) of DC used to study DCs from both an intra- and inter-organisational perspective. In this dissertation, the definition of DCs given by Helfat et al. (2007, p. 4) has been used, which defines DCs as "the capacity of an organisation to purposefully create, extend, or modify its resource base". Although this definition is often associated with the second view of being managerial and strategic processes and routines, the definition given by Helfat et al. (2007) does not necessarily exclude DCs from being portrayed as learning abilities as well. This was important so as not to restrict this research and to be mindful that DCs can be viewed as both learning abilities and processes. In addition, Sune and Gibb (2015) presented three characteristics: (1) a patterned element, (2) degree of intent and (3) a change of resources, which were useful to identify, describe and explain DCs. In addition, the theoretical lens for studying IDCs also includes the conceptual framework presented in Paper IV, which was useful to further describe and explain IDCs. An overview of how the first question was answered is presented in Figure 5. The analyses of intraorganisational and interorganisational DCs are presented in the following section.

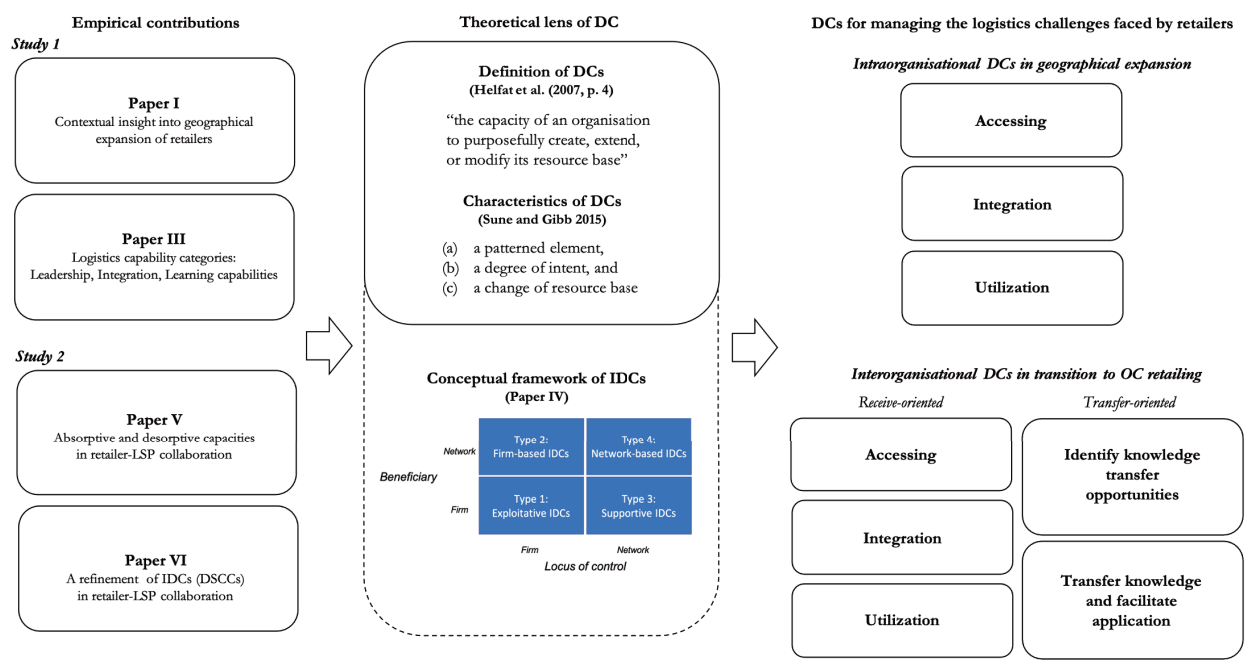

Figure 5. Answering the first research question, RQ1. 
In terms of intraorganisational DCs, the answer of RQ1 is based on an analysis of the findings presented in Paper I and Paper III. Firstly, Paper I provides an in-depth contextual insight into the geographical expansion of retailers, including the resources and capabilities involved in the foreign establishment of retailers. In addition, Paper III identifies three logistics capability categories: leadership, integration and learning, which include seven logistics capabilities (i.e. top management support, company founder involvement, organisational integration, functional integration, external integration, organisational learning and experiential learning). Based on the contextual insight and logistics capabilities, the theoretical DC lens was applied in order to identify, describe and explain how DCs enable retailers to manage geographical expansion. In particular, the characteristics identified by Sune and Gibb (2015) were applied to the logistics capabilities in order to find new DCs. For instance, accessing is a combination of all capability categories, whereas integration is based on the integration capabilities described in Paper III, but also to some extent on leadership and learning capabilities as they also support integration. Based on this analysis, three DCs were found: accessing, integration and utilisation.

In terms of IDCs, the answer is based on the analyses of different IDCs presented in Papers $\mathrm{V}$ and VI. Both papers present IDCs that support the OC transition. Together, the two papers cover two perspectives on DCs, with Paper V studying the learning abilities of absorptive and desorptive capacities, whereas Paper VI studies IDCs as strategic processes and routines. The subprocesses (or elements) of absorptive capacity (acquisition, assimilation, transformation and exploitation) and desorptive capacity (identifying knowledge-transfer opportunities, and transferring knowledge and facilitating application) described in Paper V, were combined with the two IDCs (knowledge accessing and coevolving) from Paper VI, to identify new IDCs. In particular, the similarities and differences between the IDCs in the two papers were analysed based on the theoretical lens of DC. For instance, accessing is a combination of acquisition of the absorptive capacity from Paper $\mathrm{V}$ and knowledge accessing from Paper VI, while integration is a combination of assimilation from Paper V and knowledge accessing and co-evolving from Paper VI. Due to the dyadic perspective when studying absorptive and desorptive capacities in Paper V, it was found that there are two types of IDCs, receive-oriented and transfer-oriented IDCs. Receive-oriented IDCs involve the accessing, integration and utilisation of external knowledge, whereas transfer-oriented IDCs involve the identification and transfer of internal knowledge. This distinction was also useful for the interorganisational perspective, as it covered the capacities of retailers both to receive external knowledge and to transfer internal knowledge. Based on this analysis, five IDCs was found, three receive-oriented: accessing, integration and utilisation, and two transfer-oriented: identifying knowledge-transfer opportunities and transferring knowledge and facilitating application.

As a final step in answering RQ1, the intra- and inter-organisational DCs were compared. The contextual aspects of the challenges and the characteristics of the DCs were discussed in order to find and explain similarities and differences between the DCs. For instance, both studies illustrated the importance of accessing, integrating and utilising different resources in the studied challenges. The analysis revealed a difference between what and how resources were accessed among the studied challenges and that accessed, integrated and utilised resources were challenge specific. In addition, the DCs of identifying knowledge-transfer opportunities and transferring knowledge and facilitating application were only identified from the 
interorganisational perspective for the challenge of OC transition. However, these DCs are believed to be important for all challenges in order to access both internal and external resources.

\subsubsection{Antecedents of dynamic capabilities for managing logistics challenges of retailers}

The second research question, RQ2, asks: How do antecedents support DCs that enable retailers to manage logistics challenges? To answer this question, antecedents were studied using a theoretical lens of the antecedents of DCs. This theoretical lens worked as a basis for identifying, describing and explaining the antecedents of DCs, and was based on the Theoretical frame of reference given in Chapter 3. This lens includes a definition of antecedents as well as the characteristics of antecedents found in previous DC literature. In this dissertation, antecedents are defined as factors or conditions that influence the development and use of DCs (Ambrosini and Bowman, 2009; Teece, 2007) and can be seen as inputs to DCs (Eriksson, 2014; Zahra et al., 2006). In addition, previous DC literature has made a distinction between different internal (e.g. structural, social) and external (e.g. environmental, network) antecedents, which was useful for identifying, describing and explaining antecedents. An overview of how RQ2 was answered is presented in Figure 6. The analyses of the antecedents of intra- and inter-organisational DCs are presented in following section.

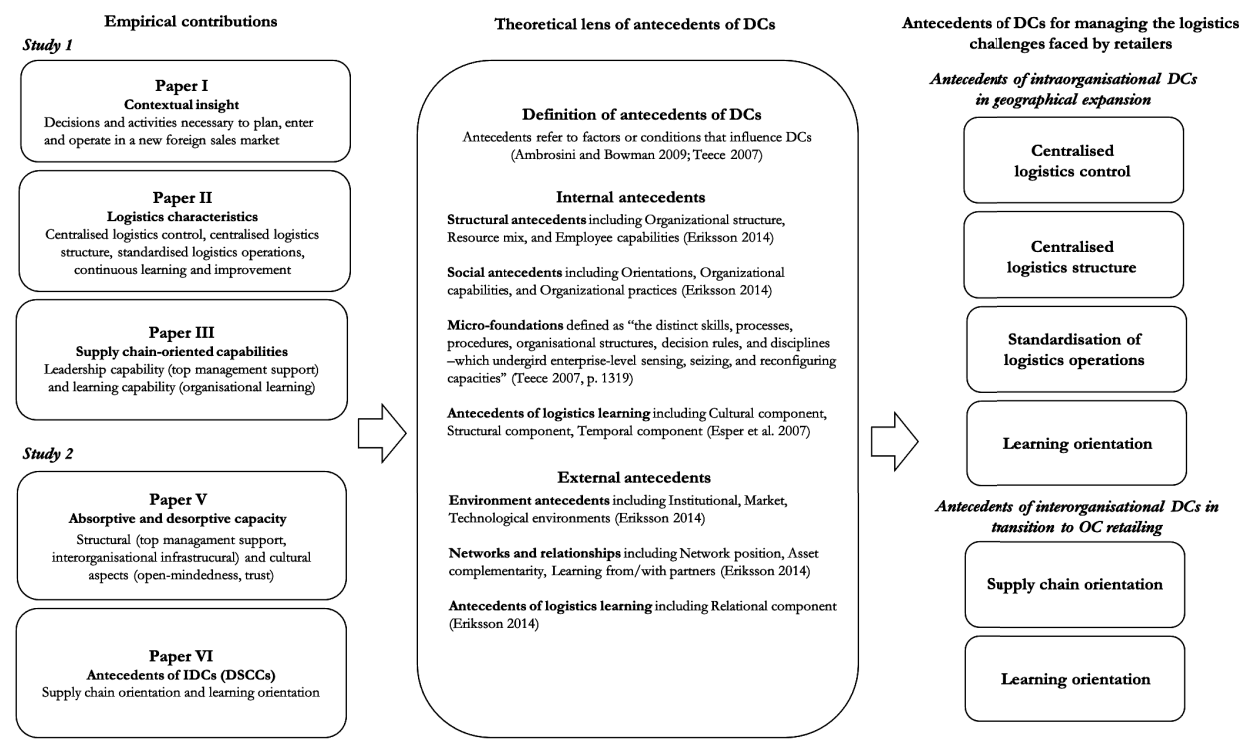

Figure 6. Answering the second research question, RQ2.

In terms of the antecedents of intraorganisational DCs, the answer is based on a combination of the antecedents presented in Papers I, II and III. Firstly, Paper I provides an in-depth contextual insight into the geographical expansion of retailers, including the resources and capabilities involved, which was useful to identify, describe and explain the different antecedents of the DCs found when answering the first research question. In 
particular, the four logistics characteristics (centralised logistics control, centralised logistics structure, standardised logistics operations and continuous learning and improvement) described in Paper II were combined with the logistics capabilities (top management support, company founder involvement, organisational learning, and experiential learning) from Paper III. Based on the theoretical lens, the characteristics in Paper II and Paper III were restructured into four antecedents of DCs: centralised logistics control, centralised logistics structure, standardised logistics operations and learning orientation.

In terms of the antecedents of IDCs, the answer is based on a combination of antecedents presented in Papers V and VI. Firstly, Paper V discusses the importance of cultural (openmindedness, shared logistics vision, learning commitment) and structural (top management support, interorganisational infrastructure) aspects for developing absorptive and desorptive capacities, whereas Paper VI presents two antecedents (supply chain orientation and learning orientation) of IDCs. Based on the theoretical lens, the antecedents of Papers $\mathrm{V}$ and VI were combined and restructured into two antecedents of IDCs: learning orientation and supply chain orientation.

As a final step in answering RQ2, the antecedents of DCs and IDCs were compared. The contextual aspects of the challenges, as well as the characteristics of the antecedents of DCs, were discussed to explain similarities and differences between the antecedents. For instance, both studies showed the importance of a learning orientation to support DCs.

\subsection{Research quality}

As with any research, it is crucial to produce valid and reliable findings (Eisenhardt, 1989; Yin, 2014). To evaluate the findings of this dissertation, the researcher needs to be transparent regarding how the research was conducted and how issues of trustworthiness were addressed (Yin, 2014). The following sections discuss how research quality has been ensured for the chosen research methods in the studies that make up this dissertation.

\subsubsection{Literature reviews}

This dissertation includes several literature reviews, which need to be properly conducted in order to ensure high research quality. Seuring and Gold (2012) highlighted the importance of transparency when conducting literature reviews and how this can enhance the research quality. Based on Mayring (2008), Seuring and Gold (2012) proposed four content analysis milestones: material collection, descriptive analysis, pattern of analytical categories and material evaluation, which were useful when conducting the literature reviews for this dissertation. Based on these milestones, Table 9 shows how research quality has been ensured for the literature reviews. 
Table 9. Content analysis milestones used in the dissertation (based on Seuring and Gold, 2012)

\begin{tabular}{ll}
\hline Milestones of literature reviews & Key considerations \\
\hline Material collection & Find suitable keywords for database search \\
& Awareness of different terminology in different research \\
disciplines & Only English-speaking, peer-reviewed journal articles \\
& Searches and articles were recorded in an Excel spreadsheet \\
& Consistent review process throughout the material collection \\
\hline Descriptive analysis & Distribution of articles over time \\
& Distribution of articles across different journals \\
\hline Pattern of analytical categories & Deductive versus inductive category building \\
& Discussion between authors \\
\hline Material evaluation & Clear coding rules (e.g. an explicit coding schema) \\
& Iterative coding cycles \\
& Discursive alignment of interpretation \\
& Transparency and objectivity \\
\hline
\end{tabular}

In terms of material collection, the following aspects were considered in order to provide rigour in the literature reviews:

- Based on the specific goal of the literature review, suitable keywords were identified. Potential keywords were tested by initially scanning a handful of articles at the beginning of the collection to be able to adjust to more suitable keywords as necessary.

- Awareness of the different terminologies used in different research disciplines was ensured by discussions with other researchers to reduce the risk of missing relevant keywords. Especially in Paper IV, IDCs in different research disciplines were studied that used different terminology for IDCs.

- Delimitations were set to include only English-speaking, peer-reviewed journal articles from selected databases: Unisearch, Scopus and Web of Science.

- All searches and articles in the structured literature reviews were recorded in an Excel spreadsheet, which included basic publication information (e.g. title, year of publication and journal name) and information of interest for that specific review

- The process of reviewing the material followed a consistent pattern. Firstly, the title and abstract of the article were read from a content point of view to find suitable articles for the specific review and for further analysis. The articles that contained potentially relevant content were then read in further detail, including the findings and conclusions.

A descriptive analysis was performed for the structured literature review in Paper IV. For this descriptive analysis, the distribution of articles over time and across different journals was considered in order to map the research on IDCs. A detailed account of the descriptive analysis is presented in Paper IV.

In terms of patterns of analytical categories, several measures were applied to ensure rigour in the literature reviews:

- The initial classification was either empirically based or theory based depending on the research approach of the specific paper. Based on basic journal articles about DCs, potential codes and categories were developed to interpret and code the collected journal articles. For instance, the literature on interorganisational DCs in Paper IV were used to code and categorise different types of IDCs. 
- The analytical categories in the literature reviews were also discussed between the co-authors in order to reduce interpretation bias (e.g. Paper IV).

- In addition, the initial theoretical classification of the literature reviews was typically used as a complement to inductive category building (e.g. Paper I).

In terms of material evaluation, the following measures were taken:

- An iterative process was used to revise the categories in Paper IV and Paper VI. According to Seuring and Gold (2012), an iterative process enhances a study's validity because the analysis is based on existing theory as well as new insight.

- The coding and evaluation were discussed with supervisors and co-authors to reduce interpretation bias. In addition, several of the papers (e.g. Papers I, III, VI) were presented at conferences and later revised based on comments from conference participants. This enabled the interpretations to be discussed and aligned with more senior researchers, which Seuring and Gold (2012) described as the "discursive alignment of interpretation".

- The literature reviews typically involved several researchers (e.g. in Papers II, III, IV and V) to further enhance the literature sampling and data analysis (Duriau et al., 2007; Seuring and Gold, 2012). This allowed valuable input throughout the literature reviews.

- Coding rules were set for each specific literature review, which helped to improve the objectivity and transparency of the literature reviews (Gaur and Kumar, 2018; Seuring and Gold, 2012). For instance, explicit coding schemas were used in Paper V and Paper VI.

- The transparency and replicability of the research design were further ensured by careful documentation of the entire research process. For instance, searches and Excel sheets were created throughout the literature reviews.

Finally, to reduce any question marks regarding the research quality of the appended papers, the methodology section for each paper describes in further detail how the literature reviews were performed, which also helps to ensure transparency.

\subsubsection{Case studies}

For the case studies in this dissertation, the criterion of trustworthiness has been used to ensure high research quality. Trustworthiness refers to "how good" a qualitative study is and is based on four research criteria: credibility, transferability, dependability and confirmability (Bryman and Bell, 2011; Halldórsson and Aastrup, 2003). According to Halldórsson and Aastrup (2003), these four criteria are suitable for "soft" logistics research in the sense that it often includes a lot of qualitative data that needs to be carefully interpreted. The means to ensure trustworthiness in this dissertation are summarised in Table 10 and further presented in the next section. 
Table 10. Means to ensure research quality in case studies

\begin{tabular}{lll}
\hline Quality criteria & Case study tactic & $\begin{array}{l}\text { Research phase where the tactic was } \\
\text { applied }\end{array}$ \\
\hline Credibility & $\begin{array}{l}\text { Use of multiple sources of evidence } \\
\text { Have respondents review drafts of case } \\
\text { descriptions and empirical data }\end{array}$ & $\begin{array}{l}\text { Data collection } \\
\text { Composition }\end{array}$ \\
\hline Transferability & $\begin{array}{l}\text { In-detail descriptions of the studied } \\
\text { cases (e.g. studied case companies and } \\
\text { logistics challenges) }\end{array}$ & Research design \\
& $\begin{array}{l}\text { In-detail descriptions of the research } \\
\text { methods applied }\end{array}$ & Composition \\
\hline Dependability & $\begin{array}{l}\text { A replication logic related to the case } \\
\text { studies }\end{array}$ & Research design \\
& $\begin{array}{l}\text { Input on the replication of case studies } \\
\text { was received from supervisors, } \\
\text { colleagues and opponents }\end{array}$ & Composition \\
& $\begin{array}{l}\text { Input on methodology descriptions in } \\
\text { journal and conference papers was } \\
\text { received from journal and conference } \\
\text { reviewers }\end{array}$ & Composition \\
\hline Conformability & $\begin{array}{l}\text { Establish a chain of evidence } \\
\text { Have other researchers review drafts }\end{array}$ & $\begin{array}{l}\text { Data collection } \\
\text { Composition }\end{array}$ \\
& $\begin{array}{l}\text { Use of multiple sources of evidence } \\
\text { Data collection }\end{array}$ \\
\hline
\end{tabular}

A problematic characteristic of qualitative research is the difficulty of creating an accurate representation of the reality that is being studied. Credibility refers to "how believable findings are" and how well the reality of the respondents is represented (Halldórsson and Aastrup, 2003; Merriam and Tisdale, 2016). For this dissertation, credibility has been ensured by several measures.

- For all studies, credibility has been ensured by using multiple methods for data collection, including interviews, observations, company reports, company websites and presentation slides, which ensured method triangulation (Barratt et al., 2011).

- In addition, credibility has also been ensured by source triangulation as multiple respondents helped to better capture the reality of the respondents included in the studies (Barratt et al., 2011).

- In addition, most interviews were recorded, transcribed and summarised into different types of written material, including case descriptions and other empirical data in the papers (e.g. tables), which were later sent to the respondents for feedback to ensure that the collected data was valid (Halldórsson and Aastrup, 2003; Merriam and Tisdale, 2016).

Transferability refers to generalisability and whether the findings can be applied to other contexts (Bryman and Bell, 2011). Although transferability has not been a clear aim of this specific research, it has been ensured by a couple of measures.

- Transferability has been ensured by providing detailed descriptions of the studied context (Bailey, 2007), including characteristics of the studied case companies (i.e. retail sectors, retail offer, company size, organisation including the logistics function), and characteristics of the studied logistics challenges. These detailed descriptions in the dissertation and the appended papers enable the reader to evaluate the transferability of the research findings. 
- Transferability criteria have also been met in terms of the generalisability of research methods. The multiple case-study approach applied in this research has been described in detail, including the data collection and data analysis. This enables the reader to evaluate the chosen methodology of this specific research and the generalisability of the findings.

Dependability refers to the extent to which a study can be replicated with the same or similar results (Bryman and Bell, 2011). Dependability has been ensured by several measures.

- A replication logic was used for the case studies, which supported the replication of the research. Each step of the case studies has been carefully described and performed in a standardised, logical manner. For instance, the data collection used standardised interview guides (see Appendix 2 and 3), and the analysis step included coding, and within-case and cross-case analyses, all of which were based on contextspecific literature related to the specific study.

- Throughout the research process, the research in this dissertation (including the licentiate thesis, and appended papers) has received valuable input from supervisors, colleagues and opponents. These inputs concerned the replication of case studies and helped to strengthen the methodology description of the research.

- In addition, journal papers and conference papers have been reviewed by journal and conference reviewers, which has also helped to improve the methodology description and in turn strengthen the replication of findings in the papers.

The fourth and last criterion, conformability, refers to how the researcher has allowed her values to intrude on the quality of the findings (Bryman and Bell, 2011). Although it is almost impossible for a researcher to completely avoid transferring some of their own values onto their research, conformability has been ensured by several measures.

- A strong chain of evidence between transcripts, case descriptions and empirical data in the analysis has been critical to ensure conformability. This chain involves verification between the different steps of the case studies to ensure that the findings are based on the collected data material.

- In addition, other researchers reviewed the papers and highlighted unclear aspects of the data collection, collected data, literature and findings, which helped to strengthen the logical chain of evidence.

- Furthermore, multiple respondents and data methods have been used, which enabled both source and method triangulation (Barratt et al., 2011), and reduced the risk of interpretation bias (Halldórsson and Aastrup, 2003).

\subsection{Research ethics}

In addition to research quality, research ethics is an important aspect to discuss because the research in this dissertation is empirical. In particular, research ethics related to confidentiality, informed consent and deception are three important ethical aspects for this research to address (Vetenskapsrådet, 2017). Firstly, confidentiality refers to an "obligation not to communicate information given in confidence and entails protection against unauthorized persons partaking of the information" (Vetenskapsrådet, 2017, p. 40). It is a researcher's duty to ensure the confidentiality of respondents' records. Throughout the data collection, the researcher communicated the planned process for handling the collected information and asked the 
respondents if they had any specific requests for how their information should be handled. As some companies and respondents wished to be anonymous, it was decided to anonymise all the companies and respondents involved in the research. In agreement with the case companies, the firms were presented at a general level, including only the retail sector and some overall characteristics of the companies, and the respondents were presented based on their functional responsibility, including their working title and overall responsibility.

Informed consent refers to the opportunity of informants to make an informed judgement about their involvement and whether they will allow interviews to be recorded or not (Vetenskapsrådet, 2017). In this research, the researcher informed respondents both orally and in writing about the research aim, and asked permission to participate in interviews and meetings, as well as asking permission to record them. In addition, the researcher sent the data material to the respondents (e.g. case descriptions and paper drafts) to enable them to read the collected data material and provide feedback. This reduced the risk of misunderstandings between the researcher and respondents, as well as reducing the risk of sharing companies' sensitive information.

Another important ethical aspect in this research is deception. This aspect refers to "giv [ing] misleading information about someone's contribution to the research" (Vetenskapsrådet, 2017, p. 64). In this research, deception has been avoided by informing all respondents about the nature of the research, including the overall research aim. However, deception is quite a problematic concept in research because investigations can take unexpected turns and new features may be added during the process, which makes it nearly impossible to avoid deception completely. With this in mind, the researcher has tried to explain the motives for each interview and meeting, as well as clarifying the research aim by allowing the respondents to read the data material (e.g. case descriptions and paper drafts) throughout the research process. 




\section{Overview of appended papers}

This chapter presents the six appended papers of this dissertation. In each case, a summary and the paper's contributions to the dissertation are presented. The papers are also found in Appendix 1.

\subsection{Paper I}

The identification of phases of the retail establishment into foreign markets - a multiple case study of two Swedish retailers

Haag, L. (2018), "The identification of phases of the retail establishment into foreign markets - a multiple case study of two Swedish retailers". Books of proceedings presented at the Recent Advances in Retail and Consumer Service Conference 17-18 July 2018, Portugal.

\section{Summary}

Paper I describes the process of retail establishment into new foreign sales markets, including the internal and external individuals/functions involved. Previous research has focused on specific aspects of this geographical expansion, such as motives for foreign establishments and market entry strategies, but has neglected the actual establishment process of retailers into new markets, including the activities and staff involved. Based on a multiple-case study of two large-sized Swedish retail companies and two export promotion organisations, the establishment process of both physical stores and ecommerce into foreign markets was explored. The findings identified an establishment process that includes three sequential phases: a market-analysis phase, an implementation phase and a follow-up phase (see Figure 5).

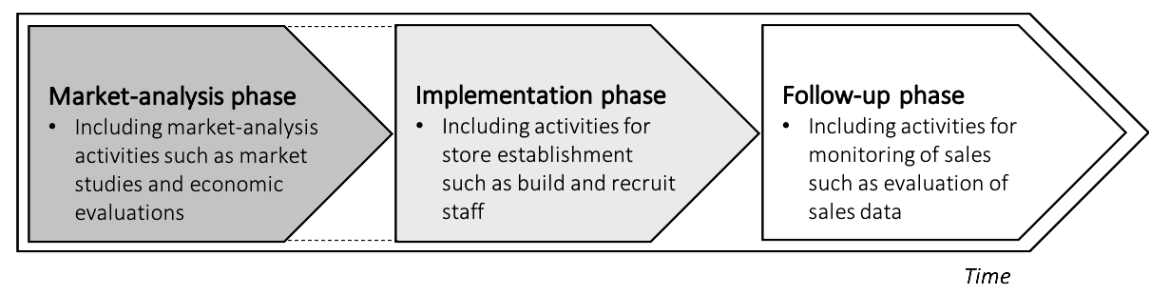

Figure 7. The phases in the establishment process of retailers into foreign sales markets (from Haag, 2019).

\section{Contribution to the dissertation}

Paper I contributes to an improved understanding of the process of retail establishment into foreign sales markets, by providing a basic understanding of the different issues related to the challenge of geographical expansion for retailers. In particular, the establishment phases, including key activities and key staff, have provided valuable insights into different issues throughout the establishment process. By viewing the establishment process from a logistics perspective in this paper, the logistics aspects of foreign establishment are visualised. This in turn provides an improved understanding of logistics aspects related to expansion, which was useful when studying the key logistics characteristics (in Paper II) and logistics capabilities (Paper III) that support the expansion of retailers. 


\subsection{Paper II}

\section{Exploring key logistics characteristics supporting embeddedness in retailers' geographical expansion}

Haag, L. and Sandberg, E. (2020), "Exploring key logistics characteristics supporting embeddedness in retailers' geographical expansion”. The International Review of Retail, Distribution and Consumer Research, Vol. 30 No. 1, pp. 1-26.

\section{Summary}

Paper II explores how the logistics function of retailers supports embeddedness in the geographical expansion of retailers. Although previous research has identified logistics as a key aspect of expansion, logistics in conjunction with the expansion of retailers has seldom been studied. This paper is empirically grounded in an explorative multiple-case study involving three large-sized Swedish retailers that have expanded their retail businesses abroad. As a theoretical lens, the theory of embeddedness, including societal, network and territorial embeddedness, was used to analyse how logistics characteristics have supported the expansion. The findings of this paper identify four key logistics characteristics: Centralised logistics control, Centralised logistics structure, Standardised logistics operations and Continuous learning and improvement, which support retailers' embeddedness in foreign sales markets (see Figure 8).
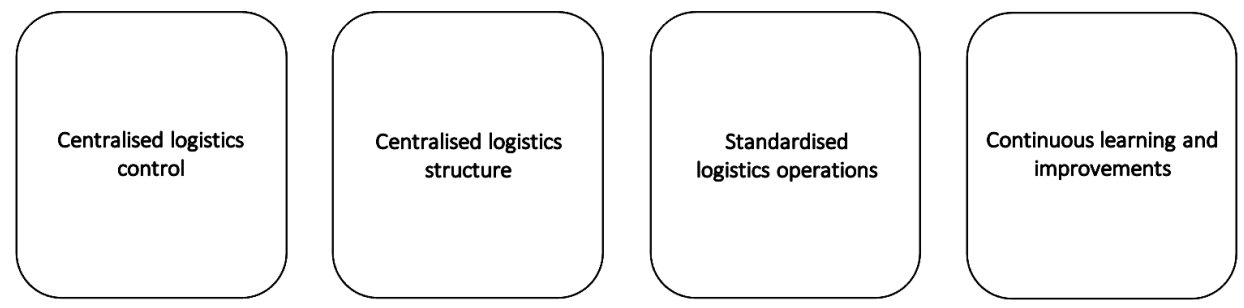

Figure 8. Logistics characteristics supporting the geographical expansion of retailers (inspired by Paper II).

\section{Contribution to the dissertation}

Paper II contributes by identifying four logistics characteristics (Centralised logistics control, Centralised logistics structure, Standardised logistics operations and Continuous learning and improvement) that support the geographical expansion of retailers. For the dissertation, these characteristics were studied from a DC perspective in order to understand how they can support the development of DCs. This was useful when studying the antecedents of DCs for the expansion. In addition, the empirical data on logistics aspects has provided additional contextual insights into different logistics issues in the expansion. 


\subsection{Paper III}

\section{Supply chain capabilities for facilitating the internationalisation of retailers - a multiple case study of three Swedish retail companies}

Haag, L., Sallnäs, U. and Sandberg, E. (2019), "Supply chain capabilities for facilitating the internationalisation of retailers - a multiple case study of three Swedish retail companies". The International Review of Retail, Distribution and Consumer Research, Vol. 29 No. 3, pp. 321-339.

\section{Summary}

Paper III explores supply chain capabilities that facilitate the internationalisation, or geographical expansion, of retailers. In addition to previous market-oriented research, this paper focuses on the logistics aspects, including logistics resources and capabilities, of geographical expansion. Through the lens of RBTs, a multiple-case-study approach was used to explore the supply-chain-oriented capabilities supporting retailers' expansion. In particular, three large-sized Swedish retailers were studied, which were in the early phases of their expansion. Paper III identifies three supply-chain-oriented capability categories: a Leadership capability, an Integration capability and a Learning capability, which facilitate the expansion. These categories each include several capabilities (see Figure 9). Firstly, the leadership-capability category includes Top management support and Company founder involvement. Secondly, the integration-capability category includes Organisational integration, Functional integration and External integration. Thirdly, the Learning-capability category includes Organisational learning and Experiential learning.

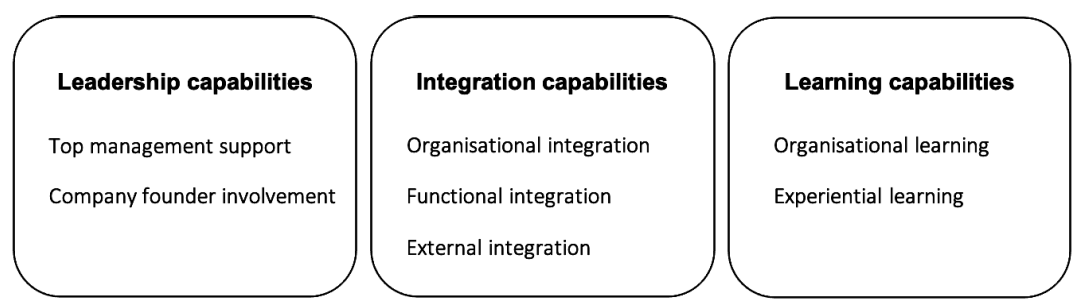

Figure 9. Supply-chain capability categories supporting the geographical expansion of retailers (inspired by Paper III).

\section{Contribution to the dissertation}

The key contribution of Paper III to this dissertation is the supply-chain capability categories. These capabilities provide a foundation for identifying, describing and explaining DCs that support retailers to manage their geographical expansion. Note, the capabilities presented in Paper III are entitled logistics capabilities in this dissertation. This is due to the intraorganisational perspective used to study DCs that enable retailers to manage geographical expansion. A supply-chain capability could easily be mistaken for an IDC, and therefore logistics capabilities is a more suitable term. 


\subsection{Paper IV}

\section{Delineating interorganizational dynamic capabilities: A literature review and a conceptual framework}

Sandberg, E., Kindström, D. and Haag, L. (2021), "Delineating interorganizational dynamic capabilities: A literature review and a conceptual framework". The Journal of Inter-Organizational Relationships, pp. 1-16.

\section{Summary}

Paper IV develops a conceptualisation of interorganisational dynamic capabilities (IDCs). Previous literature on dynamic capabilities has hinted at the possibility of a wider scope than merely the individual firm, and thus the existence of IDCs. The paper takes its stance in previous IDC literature, for which a systematic literature review of 75 papers was conducted. This review provided a comprehensive overview of IDCs from different research disciplines (e.g. marketing, innovation, and supply chain management). Based on this, a conceptual framework was established, which enabled the categorisation of different IDCs.

\section{Contribution to the dissertation}

The systematic literature review in Paper IV contributes to a comprehensive overview of IDCs from different research disciplines and contributes to an improved understanding of different IDCs. Furthermore, the paper contributes with a conceptual framework (see Figure 10) that categorises different IDCs based on the two dimensions of who controls a specific IDC (i.e. the locus of control), and who takes advantage of a specific IDC (i.e. who is the beneficiary). This framework offers a more precise classification of IDCs and simplifies the distinction between different IDCs, which was useful when studying IDCs in this dissertation.

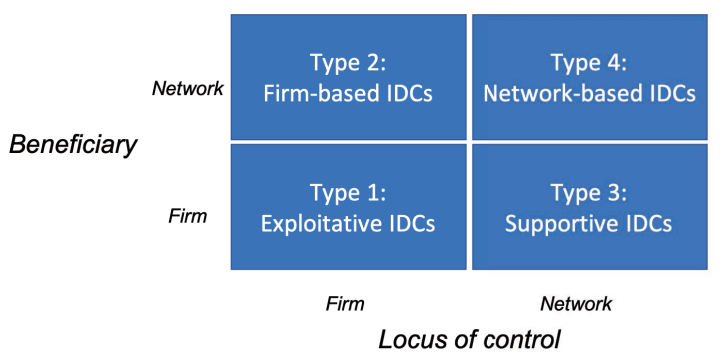

Figure 10. The conceptual framework of IDCs (from Paper IV). 


\subsection{Paper V}

Towards an increased understanding of learning: A case study of a collaborative dyad between a retailer and a logistics service provider

\section{Haag, L., Sandberg, E. and Sallnäs, U. (202X), "Towards an increased understanding of learning: A case study of a collaborative dyad between a retailer and a logistics service provider". The paper has been submitted and is under review at a journal.}

\section{Summary}

Paper V explores how learning occurs in retailer-LSP collaborations. Based on a theoretical lens of absorptive and desorptive capacities, this paper studies learning between retailers and LSPs based on a single case study of a Swedish retailer-LSP dyad. Furthermore, a dyadic perspective has been used to describe and study the interplay between the learning elements of absorptive and desorptive capacities. To study absorptive and desorptive capacities, five specific learning situations were used, which each include four absorptive elements at the receiving company and two desorptive elements at the submitting company.

\section{Contribution to the dissertation}

Paper V provides valuable insights into learning in retailer-LSP collaborations. This paper provides a description of the learning elements of absorptive and desorptive capacities and presents an improved understanding of the interplay between these elements in a retailerLSP collaboration. In particular, two interplay types are presented: one-directional support and bi-directional support. These types are illustrated in Figure 11. For this dissertation, the interplay between the two DCs of absorptive and desorptive capacities was important to further understand learning for both retailers and LSPs.

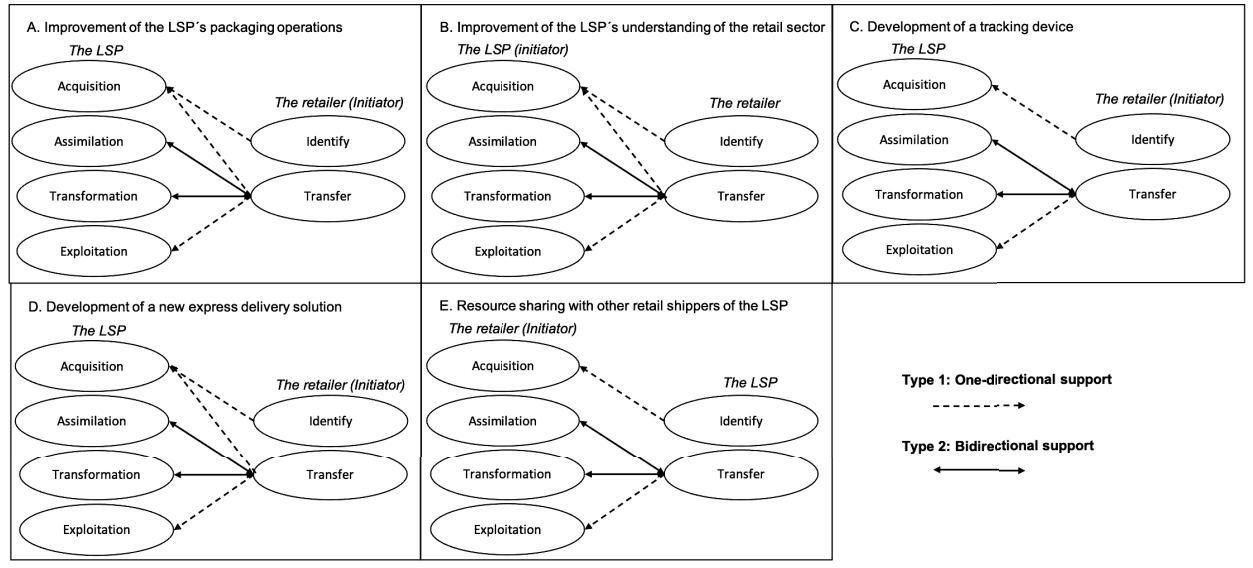

Figure 11. The interplay of the absorptive and desorptive capacities in the five learning situations in a retailer-LSP collaboration (from Paper V). 


\subsection{Paper VI}

\section{Dynamic supply chain capabilities supporting collaboration between retailers and logistics service providers}

Haag, L. (202X), "Dynamic supply chain capabilities supporting collaboration between retailers and logistics service providers". Books of proceedings presented at the NOFOMA digital conference 17-18 September 2020. Awarded with the Best Doctoral Student Paper at the Nordic Logistics Conference NOFOMA 2020. A new version of the paper is in progress.

\section{Summary}

Paper VI explores how dynamic supply chain capabilities (DSCCs) support retailer-logistics service provider (LSP) collaborations, with the aim of improving the logistics system. The study takes its stance in a conceptual framework developed by Defee and Fugate (2010), including DSCCs (knowledge accessing and co-evolving) and their antecedents (learning orientation and supply chain orientation), which can improve supply chain performance. Previous research on DSCCs has been conceptual and has lacked empirical research (Chen et al., 2019). Therefore, empirical data from four retailer-LSP dyads was added to further refine this framework, and resulted in a refinement of DSCCs and their antecedents.

\section{Contribution to the dissertation}

The main contribution of Paper VI to the dissertation is the refinement of DSCCs, by which means the key characteristics of these DCs and their antecedents were explored (see Figure 12). The empirical data improved the understanding of DSCCs in the setting of retailer-LSP collaboration, which was important to further understand the IDCs supporting retailer-LPS collaboration. In particular, these characteristics are useful for understanding the antecedents of IDCs. Note, the DSCCs studied in Paper VI are entitled IDCs in this dissertation.

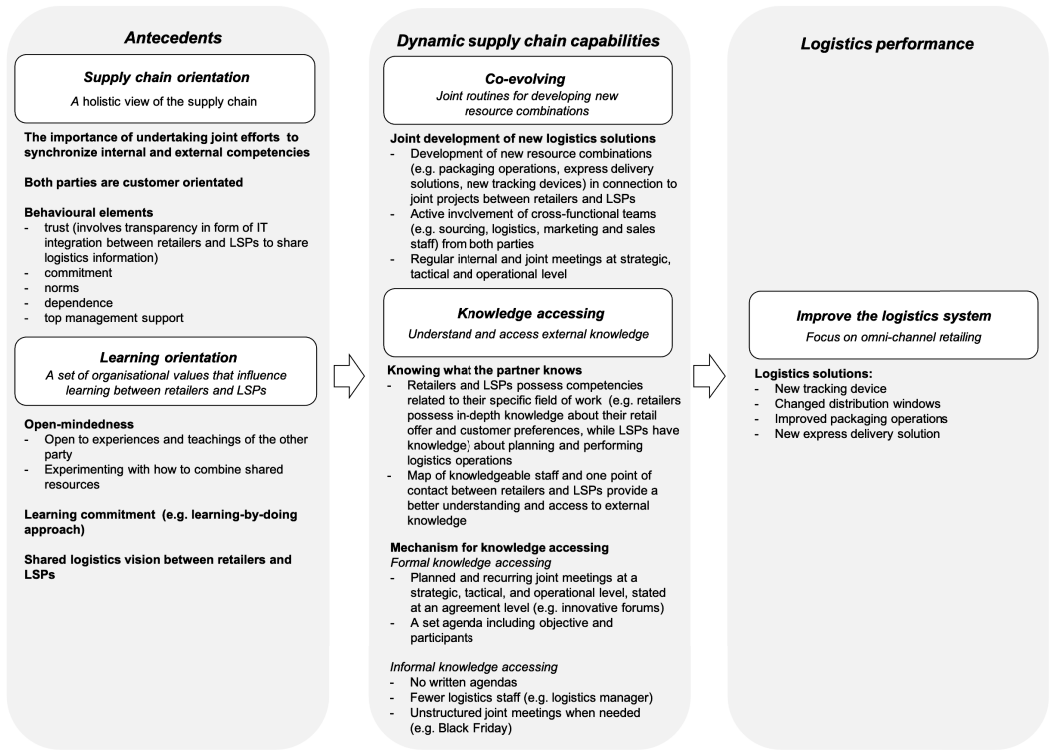

Figure 12. The findings of Paper VI (from Paper VI). 




\section{Dynamic capabilities for managing logistics challenges of retailers}

This chapter presents the answer to the first research question, RQ1: How do DCs enable retailers to manage logistics challenges? DCs refer to "the capacity of an organisation to purposefully create, extend, or modify its resource base" (Helfat et al., 2007, p. 4). In this dissertation, DCs are studied from both an intraorganisational perspective based on the logistics challenge of the geographical expansion of retailers, and an interorganisational perspective based on the logistics challenge of the transition to $\mathrm{OC}$ retailing. The answer is presented in the following sections, starting with the intraorganisational DCs required for managing the geographical expansion of retailers.

\subsection{Intraorganisational dynamic capabilities for managing the geographical expansion of retailers}

To understand how intraorganisational DCs enable retailers to manage geographical expansion, the contextual insight from Paper I and the logistics capabilities from Paper III, as well as the theoretical lens of DCs, were used. This resulted in three intraorganisational DCs: accessing, integration and utilisation. The structures used to identify, describe and explain these DCs are presented in Figure 13. A detailed description of how these IDCs were identified is found in the Methodology chapter. The three intraorganisational DCs are presented in the upcoming sections, starting with accessing.

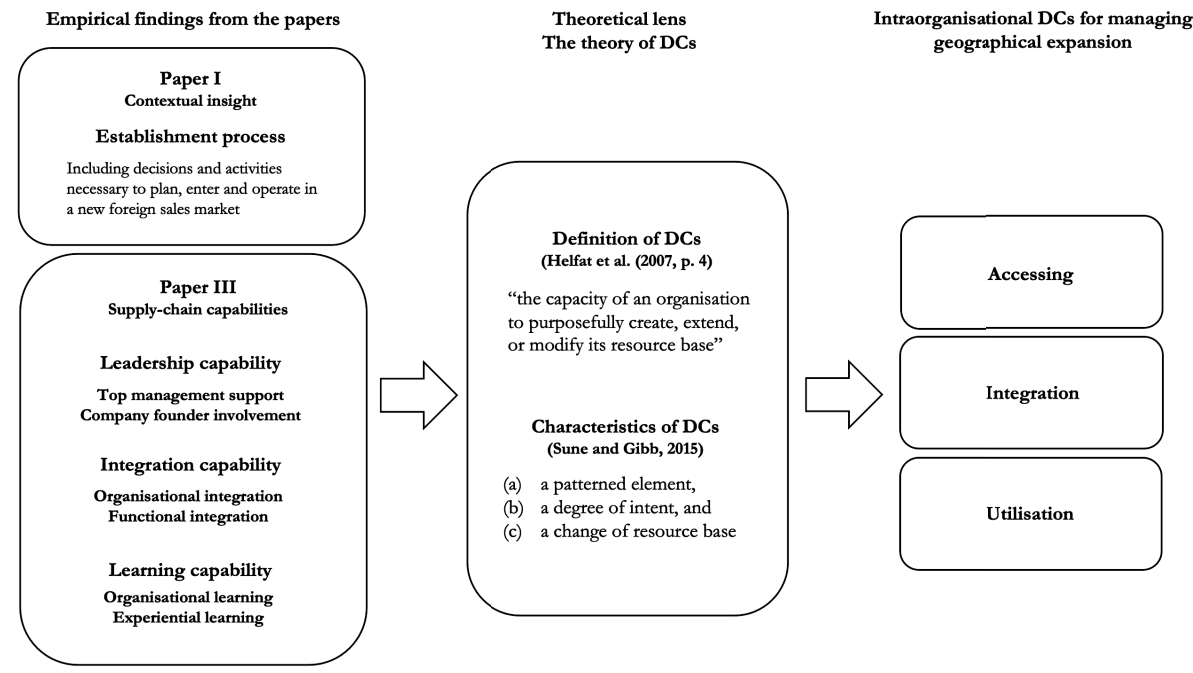

Figure 13. The structure to identify, describe and explain intraorganisational DCs for retailers to manage geographical expansion of retailers.

\subsubsection{Accessing}

The findings show that retailers need to frequently identify and access new logistics resources in order to manage their geographical expansion. Therefore, an accessing capacity 
is needed, which refers to the capacity of retailers to identify and access the resources necessary for expanding into foreign sales markets.

According to several scholars (e.g. Burt et al., 2016; Douglas and Craig, 2011), retailers typically lack the resources needed for expansion, such as foreign market experience, business networks and foreign market knowledge. This is especially true at the beginning of the expansion, as retailers tend to lack a lot of the necessary resources (including logistics resources) to operate in foreign countries (Dimitrova et al., 2018). Therefore, they need to frequently find and access new or enhanced resources in order to successfully expand their sales operations into foreign sales markets (Burt et al., 2016; Dimitrova et al., 2018; Douglas and Craig, 2011). Based on Paper III, the findings indicate that retailers access valuable experience and learning related to logistics from different company functions (e.g. the logistics function, marketing function and sales function), which are used to modify the logistics throughout the expansion. For instance, the logistics function of Company A accessed knowledge about foreign markets (e.g. foreign retail offers) from the marketing function (Paper III). Based on Paper I, the findings also show that the top management team and company functions have established organisational activities (e.g. regular meetings and cross-functional projects) that aim to identify and access different internal resources throughout the expansion. For instance, the logistics function of Company B frequently collected feedback from store staff regarding the performance of foreign deliveries (e.g. delivery accuracy and lead times), in order to later fine-tune the logistics operations for the foreign sales markets (Paper III). In addition, the logistics function of Company $\mathrm{C}$ engaged in activities for collecting logistics statistics for the different channel flows (physical stores and online store) involved in the expansion, which enabled them to identify and access logistics data in the expansion. In particular, the Logistics manager of Company $\mathrm{C}$ said:

For instance, output per hour, how many order do you get through at a packing station on e-commerce, how many do you get through the packing for the store. We are aware of these [statistics], so we can follow them per flow [in the expansion]. (Logistics manager, Company C)

\subsubsection{Integration}

The findings show that the accessed logistics resources become valuable through integration with the retailers' existing resource base. In particular, logistics resources need to be properly understood within the retail organisation as a whole in order to manage the expansion. Therefore, an integration capacity is needed. This refers to the capacity of retailers to interpret and understand the accessed resources necessary for expanding into foreign sales markets.

The findings indicate that integration is an important DC, because it enables retailers to interpret and understand the newly accessed logistics resources that are needed in the expansion. This DC is also mentioned by Eriksson (2014), who highlighted the need to properly integrate new and enhanced resources within the existing resource base. Due to their lack of experience of operating in foreign sales markets (Burt et al., 2016; Douglas and Craig, 2011), retailers need to actively integrate newly accessed resources so they can interpret and understand new expertise and learning related to the expansion. The findings 
imply that integration can result in new resource combinations in the form of new logistics solutions (such as new logistics operations), which can enable retailers to manage different logistics issues (e.g. a shortage of storage space, the increased complexity of retail flows) that arise during the expansion. For instance, the logistics function of Company $B$ combined marketing and logistics resources in order to better understand how to supply different foreign sales markets based on local marketing knowledge (Paper III). In particular, the logistics function of Company B used information from the marketing function to adjust and diversify the distribution schedule of different clothing collections in order to better serve the local demand.

According to Eriksson (2014), integration is highly complex and rests on systematically pulling together resources to combine new resources with the existing resource base. Based on the integration capabilities described in Paper III, the findings indicate that there are two different integration strategies for retailers in relation to resources. These strategies involve collaborative activities (e.g. meetings and projects) between the logistics function and the top management team (Organisational integration), and other company functions (Functional integration), such as the marketing function. This is in line with Macpherson et al. (2004), who stated that there are various integration strategies that rely on different organisational interactions and collaborative activities. Traditionally, company functions are seen as silos that work in isolation, which can increase the risk of suboptimal solutions and poor performance related to expansion. Based on the findings of this study, crossfunctional activities within retail organisations are crucial for combining the internal resources necessary for the expansion. In contrast to joint activities in accessing, integration involves joint activities (e.g. meetings and projects) that focus on understanding the accessed resources and combining them into new logistics solutions. This typically requires the organisation to frequently discuss logistics issues and how they can jointly combine their specific expertise. Similarly to this, Chen et al. (2009) stressed the importance of an "effective relationship" between the logistics function and the marketing function of retailers in order to create value for end customers. In addition, Swoboda and Anderer (2008) stated that resources from the logistics function and the marketing function of retailers need to be understood if they are to be combined into well-functioning, international logistics activities. This was also seen in the findings, in which the logistics function and the marketing function discussed a number of logistics issues (e.g. delivery preferences, delivery sizes) in the expansion.

\subsubsection{Utilisation}

The findings also show that accessed and integrated logistics resources need to be properly utilised by retailers in order to fully manage their geographical expansion. In particular, the establishment into new foreign sales markets requires retailers to adapt their logistics based on previously accessed and integrated resources. Thus, a utilisation capacity is needed, which refers to the capacity of retailers to implement and utilise the new logistics solutions required for expanding into foreign sales markets.

The findings show that utilisation is an important DC because it enables retailers to implement and fully utilise the new logistics solutions that are necessary for managing the expansion. Marchet et al. (2016) emphasised the match between logistics and the chosen 
expansion strategy (e.g. retail format, entry mode and market selection) for a successful expansion. In line with this, the findings show that retailers use integrated resources to improve their logistics performance in foreign sales markets, as well as adjusting the logistics to better meet local customer demands (e.g. logistics customer preferences). For instance, Company B used feedback from foreign store staff to alter its foreign distribution in the Norwegian market to better serve the local customer demand. In addition, Company A altered its customs procedures for the Norwegian market by preparing customs documents in-house, which shortened the processing time at the Norwegian border and reduced delays in its foreign distribution. In line with this, both Marchet et al. (2016) and Swoboda et al. (2008) stated that retailers need to adjust their logistics operations throughout the expansion, which seems to be the case for studied cases as well.

Based on Paper III, the findings imply that collaborative activities (e.g. cross-functional projects) within a retail organisation enable retailers to implement and use new logistics solutions throughout their expansion. For instance, Company $\mathrm{C}$ runs several logistics projects to alter its foreign logistics. These projects include changes in warehouse processes for different sales channels, as well as the implementation of new IT tools (e.g. voicepicking) at the central warehouse, in order to more cost-effectively supply multiple sales markets. In particular, the Logistics manager at Company $\mathrm{C}$ stated:

[We have] run many projects in recent years, including process changes, implementation of new IT tools and other new stuff and so on. (Supply chain manager, Company C)

A close interaction between the top management team and company functions (including the logistics function and the marketing function) are crucial for implementing and utilising new logistics solutions during the expansion. This has also been discussed by previous scholars. For instance, Schramm-Klein and Morschett (2006) argued that the establishment of an "effective coordination" between the logistics function and marketing function is crucial for retailers' overall performance. In addition, Swoboda et al. (2008) claimed that supply-chain processes (e.g. logistics operations and order management) and marketingoriented processes (e.g. sales promotion and customer relationships) are reciprocal and need to be carefully combined in order to achieve both internal efficiencies (typically ensured by well-functioning logistics operations) and external effectiveness (represented by a marketing-oriented logic). The collaborative activities (e.g. projects) in utilisation focus on the implementation of new logistics solutions, before implementing them at full scale.

\subsubsection{Summary of the intraorganisational dynamic capabilities}

To manage the challenge of geographical expansion of retailers, three intraorganisational DCs were found: accessing, integration and utilisation. Firstly, accessing refers to the capacity of retailers to identify and access the resources necessary for expanding into foreign sales markets. Retailers typically lack knowledge and experience of foreign cultures, regulations and consumer behaviour (Burt et al., 2016; Douglas and Craig, 2011) and therefore seek to access new resources throughout their expansion. Secondly, integration refers to the capacity of retailers to interpret and understand the newly accessed resources that are required for expanding into foreign sales markets. Based on these accessed resources, retailers interpret new resources using two different integration strategies (organisational integration and 
functional integration), which involve different activities (such as internal discussions and meetings) to interpret and combine resources. Thirdly, utilisation is needed, which refers to the capacity of retailers to implement and utilise the new logistics solutions that are necessary for expanding into foreign sales markets. Implementation of new logistics solutions is carried out in joint projects initiated and supervised by the retailers' top management teams.

These intraorganisational DCs are interdependent and are constantly reiterated throughout the geographical expansion. In particular, they are sequential because the integration capacity depends on accessed resources (i.e. accessing). In addition, utilisation depends on previously accessed (i.e. accessing) and integrated resources (i.e. integration). During the expansion, retailers are facing several issues simultaneously, which require these DCs to be active in parallel in order to manage the various ongoing logistics issues and realise different objectives throughout the expansion. Figure 14 summarises the intraorganisational DCs.

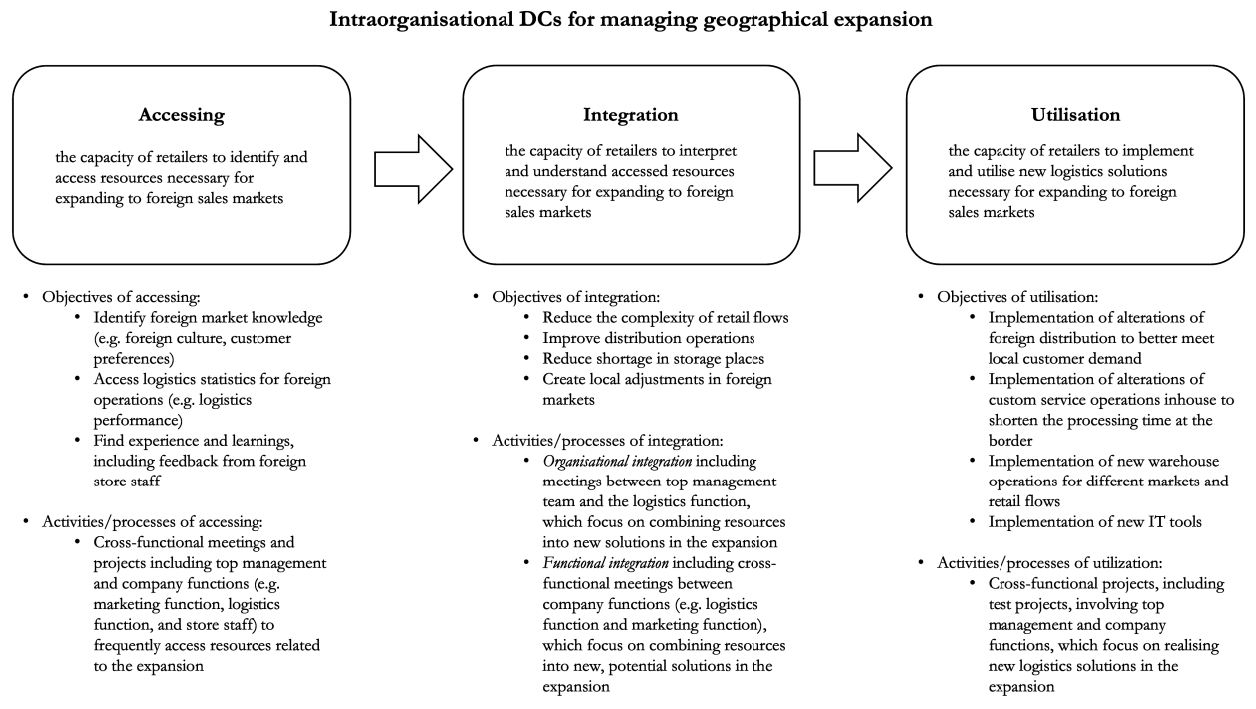

Figure 14. A summary of the intraorganisational DCs that support the geographical expansion of retailers.

\subsection{Interorganisational dynamic capabilities for managing the transition to omni-channel retailing}

This section presents the IDCs that enable retailers to manage the transition to OC retailing. To understand how such IDCs enable retailers to manage this transition, the empirical contributions from Paper V and Paper VI, as well as the theoretical lens of DCs, including the IDC framework in Paper IV, were used. This resulted in three receive-oriented IDCs: accessing, integration and utilisation, which were similar to intraorganisational DCs found in the geographical expansion case, as well as two transfer-oriented IDCs: identify knowledge-transfer opportunities and transfer knowledge and facilitate application. The structure used to identify, describe and explain these IDCs is presented in Figure 15. A detailed description of how 
these IDCs were identified is found in the Methodology chapter. The five IDCs are presented in the upcoming sections, starting with accessing.

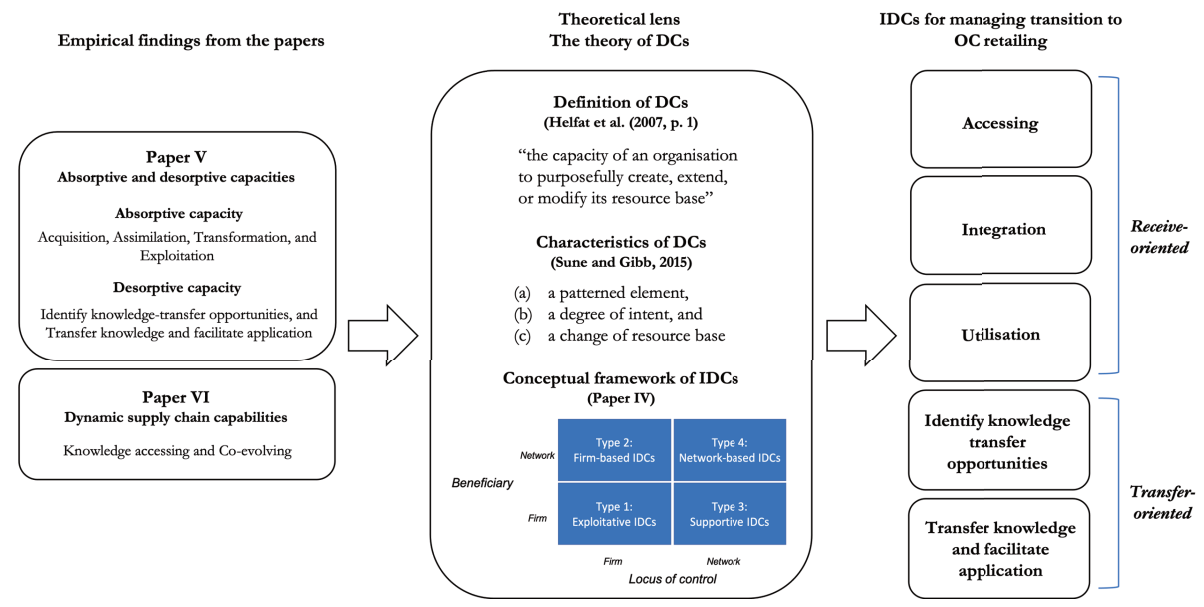

Figure 15. The structure used to identify, describe and explain the IDCs used by retailers to manage the transition to $\mathrm{OC}$ retailing.

\subsubsection{Accessing}

The findings imply that knowledge exchange between retailers and LSPs is a crucial element of managing the transition to $\mathrm{OC}$ retailing. The findings show that retailers need to frequently identify and access knowledge from LSPs in order to realise an OC strategy, and vice versa. Thus, an accessing capacity is needed, which refers to the capacity of retailers to identify and access the knowledge held by LSPs that is necessary for transitioning to OC retailing, and vice versa.

The findings suggest that accessing is an important IDC because it enables retailers to identify and access the knowledge necessary to manage the transition to $\mathrm{OC}$ retailing. The OC transition involves several unexpected logistics issues and changing logistics requirements (Skipper and Hanna, 2009), including channel integration, channel management and checkout solutions (Simone and Sabbadin, 2018), which require retailers and LSPs to frequently exchange different OC knowledge related to logistics, IT, marketing and sales. Based on the IDC framework developed in Paper IV, this IDC is firm-based because it is controlled by the retailer and can benefit the retailer as well as its LSPs. Based on Papers V and VI, the findings show that accessing involves collaborative activities, such as joint meetings, workshops and joint projects, during which knowledge related to OC retailing is shared. For instance, the Logistics manager of Retailer A established a series of joint meetings with its LSP partner to access OC knowledge, including expertise about instore integration, express deliveries and tracking devices. Such activities have also been highlighted by several scholars (e.g. Aharonovitz et al., 2018; Viera et al., 2009), who all emphasised the importance of frequent joint meetings to align objectives, share information and jointly solve logistics issues. Joint activities for sharing knowledge between retailers and LSPs is also highlighted by the Logistics manager of Retailer B, who stated: 
The need for both parties to make an effort and share information and talk together is extremely important. (Logistics manager, Retailer B)

Joint activities in accessing focus on identifying and accessing new OC knowledge. The findings show that such activities typically involve different retail areas, including marketing, sales, IT and logistics, which all share different knowledge related to the transition to $\mathrm{OC}$ retailing. For instance, Retailer A had involved several retail areas, including marketing, IT, logistics and store staff, in its OC transition. In a similar way, Galipoglu et al. (2018) stated that an OC strategy involves different areas of retail (e.g. marketing, IT and logistics) that need to actively share knowledge in order to manage different issues, such as channel integration (Simone and Sabbadin, 2018), and the management of reverse logistics (Galipoglu et al., 2018).

Furthermore, the findings show that accessing can be made in a formal and/or informal manner. Firstly, formal accessing is a planned and structured routine for accessing external knowledge, which typically has a set agenda, including specific objectives and participants (Paper VI). For instance, Dyad A holds a series of joint meetings at a strategic, tactical and/or operational level, which is a formal channel that provides dedicated time to frequently identify and access knowledge (e.g. logistics expertise, logistics data) throughout the OC transition (Paper VI). In contrast to formal accessing, informal accessing is a less structured way of accessing external knowledge, which involves fewer logistics staff and no written agendas, and new knowledge is accessed when needed. Informal accessing typically occurs in relation to specific events, tests or issues related to OC retailing, which require retailers and LSPs to exchange knowledge. For instance, the implementation of using physical stores as fulfilment centres required a high degree of knowledge exchange (e.g. follow-up of logistics operations) between Retailer B and its LSPs, to ensure sufficient logistics performance in relation to end customers. In line with this, store integration is an important $\mathrm{OC}$ issue that enables retailers to capture the demands of all sales channels by means of in-store fulfilment (Hübner et al., 2016).

In addition, the findings show that retailers and LSPs typically share logistics data through the use of joint information systems (e.g. warehouse management systems and transport administration systems) to efficiently plan and control different flows and activities linked to OC. Such IT systems are important tools for accessing logistics knowledge throughout the OC transition. This was also mentioned by Kembro and Norrman (2019b), who highlighted the need for shared IT systems and for continuously updating such systems in OC retailing.

\subsubsection{Integration}

In addition to accessing, the findings also show that accessed knowledge needs to be integrated and combined into new logistics solutions to support the OC transition. Thus, an integration capacity is needed, which refers to the capacity of retailers to interpret and combine the knowledge from LSPs that they need for transitioning to OC retailing, and vice versa. 
Based on Papers IV, V and VI, the findings show that integration is an important firmbased IDC in the OC transition, because it enables retailers and LSPs to interpret and combine newly accessed knowledge into new logistics solutions. The OC transition involves developing new solutions for managing different OC issues, including channel integration (such as in-store integration) and changes in channel management (Simone and Sabbadin, 2018). According to Eriksson (2014), integration typically rests on activities for systematically pulling together new and existing knowledge. In a similar vein, the findings show that integration rests on recurring activities, including discussions, interviews and workshops, that allow retailers and LSPs to interpret and combine the accessed knowledge throughout the OC transition. In particular, the findings show that retailers and LSPs frequently discuss and ask questions in order to better understand their joint knowledge base in greater depth (e.g. logistics operations, performance, limitations and expertise). For instance, the logistics function of Retailer A interprets logistics statistics from the LSP's logistics operations in order to analyse the logistics performance and identify suggestions for improvement. Furthermore, the findings show that retailers can invite LSPs to joint workshops in order to combine their different knowledge bases to solve specific OC issues (e.g. in-store integration, checkout solutions and new delivery alternatives). For instance, the retailer in Paper V invited the LSP to take part in field visits to its retail stores for the LSP to observe and discuss the retail operations, which was useful for interpreting and combining their expertise to jointly develop a new OC solution. The importance of understanding each other is also highlighted by the Logistics manager of Retailer B, who stated:

Both shippers and providers must understand each other early and continuously to have a chance to succeed together. To not only focus on transportation costs but rather what is provided to our consumers... Focus on suitable logistics solutions and how to document and build them together. (Logistics manager, Retailer B)

\subsubsection{Utilisation}

The findings show that the accessed and integrated knowledge needs to be utilised in the form of new logistics solutions that enable retailers to manage different issues related to the OC transition. Therefore, a utilisation capacity is needed, which refers to the capacity of retailers to test, refine and implement new solutions, based on the necessary external knowledge gained from LSPs for transitioning to OC retailing, and vice versa.

The findings show that utilisation is an important IDC in the transition to OC retailing, because it enables retailers to test, refine and implement knowledge in form of new logistics solutions (e.g. new logistics operations, updated IT systems). Based on Paper IV, this IDC is firm-based because it is controlled by the retailer, but it can benefit both the retailer and the LSP. OC retailing involves several logistics modifications, which require retailers and LSPs to jointly develop and implement new logistics solutions. This also seen among other scholars (e.g. Galipoglu et al., 2018; Mishra et al. 2021). In addition, the importance of utilisation is also highlighted by Eriksson (2014), who argued that new knowledge can only be leveraged when external knowledge has been properly accessed and integrated within a company's existing resource base. The findings of Papers V and VI imply that utilisation involves collaborative activities, including joint projects, which enable retailers and LSPs to 
test, refine and implement new solutions. For instance, in Paper V, the logistics functions of the retailer and the LSP communicated intensively though a series of joint meetings and engaged in several joint projects to test, refine and implement new logistics solutions (e.g. in-store fulfilment) related to OC retailing. In particular, the Logistics manager of Retailer A stated:

We have been operating and developing [logistics solutions] together with our logistics partner... We have several joint forums, in which I present what we are aiming for, what trends we see and that we want to invest in... In addition, we have continuous dialogue... (Logistics manager, Retailer A)

In particular, Paper $\mathrm{V}$ found that small-scale test projects are performed before implementing a new logistics solution (e.g. in-store fulfilment, tracking devices or express delivery) at full scale. For instance, in Paper V, the retailer and the LSP jointly developed a new express delivery alternative that used physical stores as distribution centres, which included several joint test projects. Such test projects can be seen as important learning opportunities, with experiences from these projects providing valuable insight into what works and what does not. Based on these insights, a new logistics solution can be refined and later implemented at full scale. For instance, in Paper V, the LSP tested potential packaging operations based on suggestions from the retailer, which were later evaluated and refined before being implemented at full scale.

\subsubsection{Identifying knowledge-transfer opportunities}

In addition to the receive-oriented IDCs, the findings also indicate that retailers need transfer-oriented IDCs to be able to identify and transfer internal knowledge that can be useful for LSPs to jointly manage different OC issues. To do so, the capacity to identify knowledge-transfer opportunities is needed. This refers to the capacity of retailers to identify opportunities to transfer the necessary knowledge to their LSPs for transitioning to OC retailing, and vice versa.

The findings show that identifying knowledge-transfer opportunities is an important firmbased IDC during the OC transition, because it enables retailers to identify potential knowledge-transfer opportunities that can be relevant to solving different $\mathrm{OC}$ issues. In a similar vein, Ayuso et al. (2006) argued that partners can help each other to identify opportunities to fulfil unmet needs. To manage the OC transition, retailers and LSPs need to be aware of each other's expertise and limitations in order to identify knowledge-transfer opportunities that can help both parties to solve OC issues. For instance, the logistics function of the retailer in Paper $\mathrm{V}$ realised that its expertise in telecoms was a useful thing to transfer to the LSP so as to jointly develop a new tracking device. Based on Papers $\mathrm{V}$ and VI, the findings suggest that knowledge-transfer opportunities are identified by collaborative activities, such as joint strategic, tactical and operational meetings and projects, in which logistics staff communicate their logistics needs, limitations and expertise related to OC retailing. In a similar vein, Kembro and Norrman (2019b) stated that retailers and LSPs need to actively collaborate to improve their OC performance. As seen in Paper $\mathrm{V}$, this IDC is also based on observations and interviews, which can support the identification of knowledge-transfer opportunities between retailers and LSPs. For instance, in Paper V, by observing and interviewing the operational logistics staff of the 
LSP, the operative logistics manager of the retailer recognised internal logistics expertise that could be transferred to the LSP to improve the LSP's packaging process. The same goes for LSPs, which also identified internal knowledge that could be useful for retailers in the OC transition. This is also highlighted by the Business developer at LSP B, who stated:

We need to identify what we can do to make Retailer B and their customers happier. (Business developer, LSP B)

\subsubsection{Transferring knowledge and facilitating application}

In addition to identifying knowledge-transfer opportunities, the findings also show that retailers need to be able to transfer internal knowledge to LSPs in order to facilitate the application of new logistics solutions to manage the OC transition. Therefore, a capacity to transfer knowledge and facilitate application is needed. This is the capacity of retailers to transfer and facilitate the application of internal knowledge at their LSPs that is necessary for transitioning to $\mathrm{OC}$ retailing, and vice versa.

Based on Papers IV, V and VI, the findings suggest that this firm-based IDC is facilitated by joint activities (e.g. joint meetings and joint projects), which aim to share and discuss knowledge (e.g. logistics expertise and learning between retailers and LSPs). Such activities enable retailers and LSPs to "mix and match" their expertise and apply knowledge in new and interesting ways to create new logistics solutions related to OC retailing (e.g. in-store integration, packaging operations, checkout solutions). In particular, the findings show that cross-functional teams facilitate the cross-fertilisation of knowledge, which can reinforce or complement the existing knowledge base necessary for the transition to OC retailing. For instance, when the retailer and LSP jointly developed a tracking device, the retailer shared company-specific knowledge about tracking devices, which enabled the LSP to test and implement a new tracking device in its own distribution operations. In addition, the Quality manager of Retailer A highlighted how LSP A had transferred logistics knowledge and facilitated its application based on the specific needs of the retailer. In particular, they stated:

I am fully convinced that the fact that we expressed a desire to develop our service was a key factor, in which they [the LSP] said "this is interesting". Thereafter, they came to us with suggestions on investments to delay our cut-off times in order to achieve more efficient deliveries. There was a package that they came to us with where they said: "You have this vision; we could do this for you". (Quality manager, Retailer A)

\subsubsection{Summary of interorganisational dynamic capabilities}

To manage the logistics challenges of the transition to OC retailing, the findings show that retailers need five IDCs, three receive-oriented IDCs: accessing, integration and utilisation, and two transfer-oriented IDCs: identifying knowledge-transfer opportunities and transferring knowledge and facilitating application. Firstly, accessing refers to the capacity of retailers to identify and access the knowledge held by LSPs that is necessary for transitioning to OC retailing, and vice versa. Secondly, integration refers to the capacity of retailers to interpret and combine this knowledge, and vice versa. Thirdly, utilisation refers to the capacity of retailers to test, refine and implement new solutions, based on the external 
knowledge held by LSPs that is necessary for transitioning to OC retailing, and vice versa. Fourthly, identifying knowledge-transfer opportunities is the capacity of retailers to identify knowledge-transfer opportunities to their LSPs that are necessary for transitioning to OC retailing, and vice versa. Fifthly, transferring knowledge and facilitating application is the capacity of retailers to transfer and facilitate the application of the internal knowledge of their LSPs that is necessary for transitioning to OC retailing, and vice versa. Based on the IDC framework presented in Paper IV, the identified IDCs can all be categorised as firm-based IDCs, because they are controlled by the individual firm (e.g. a retailer) and can benefit that firm, as well as other firms (e.g. LSPs).

Similarly to the intraorganisational DCs in the geographical expansion, the IDCs in the OC transition are also interdependent and are constantly reiterated throughout the transition to OC retailing. The receive-oriented IDCs (accessing, integration and utilisation) are sequential and enable the retailer to make use of external knowledge gained from the LSP, and vice versa. In addition, the transfer-oriented IDCs (identifying knowledge-transfer opportunities, and transferring knowledge and facilitating application) are sequential and enable the retailer to identify and transfer internal knowledge to the LSP, and vice versa. Based on Paper V, the receive-oriented and transfer-oriented IDCs support each other and can result in improved learning between retailers and LSPs. For instance, the IDC of identifying internal knowledge supports the IDCs of accessing and integration, as it can result in a higher level of knowledge exchange between retailers and LSPs. In the same way, the transferring of internal knowledge can support integration and utilisation. In line with the DCs in geographical expansion, the transition to OC retailing includes several different OC issues and objectives (in-store integration, track and trace, last-mile deliveries) that need to be managed simultaneously by retailers and LSPs. This requires the IDCs to be active in parallel in order to manage these ongoing logistics issues throughout the transition. Figure 16 summarises the IDCs necessary to manage the transition to OC retailing. 
6 Dynamic capabilities for managing logistics challenges of retailers

IDCs for managing transition to $\mathrm{OC}$ retailing

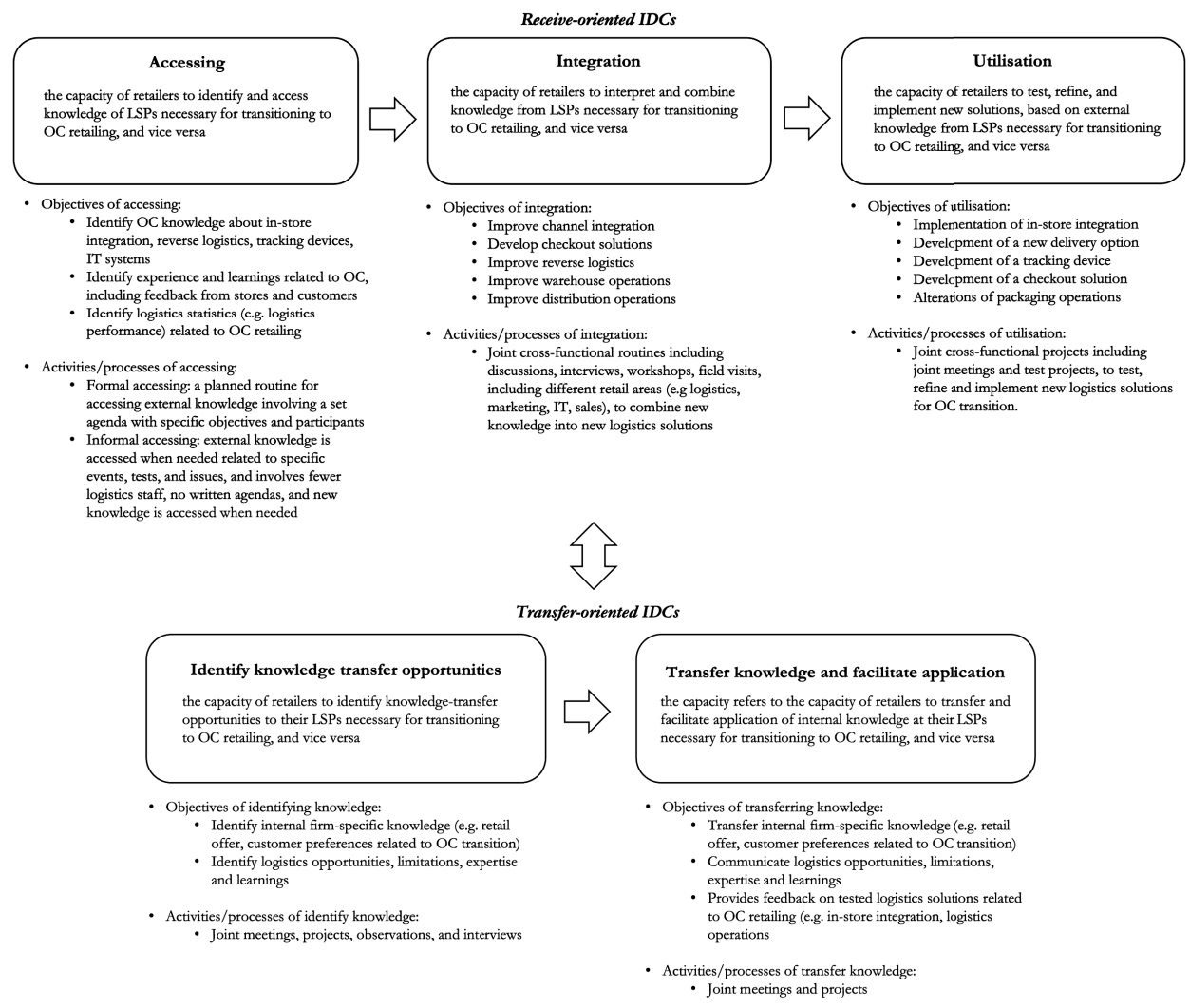

Figure 16. A summary of the IDCs that support the transition to OC retailing. 




\section{Antecedents of dynamic capabilities for managing logistics challenges of retailers}

This chapter presents the answers to the second research question, RQ2: How do antecedents support the DCs that enable retailers to manage logistics challenges? The antecedents of DCs refer to factors or conditions that support the development and use of DCs (Ambrosini and Bowman, 2009; Teece, 2007). In this dissertation, antecedents are studied from both an intraorganisational perspective, based on the logistics challenge of geographical expansion by retailers, and from an interorganisational perspective, based on the logistics challenge of the transition to OC retailing. The answer is presented in the following sections, starting with the antecedents of intraorganisational DCs for managing the geographical expansion.

\subsection{Antecedents of intraorganisational dynamic capabilities for managing geographical expansion by retailers}

To understand how the antecedents of intraorganisational DCs enable retailers to manage geographical expansion, the contextual insight from Paper I, the logistics characteristics from Paper II and the logistics capabilities from Paper III, as well as the theoretical lens of the antecedents of DCs, were used. These resulted in the identification of four antecedents of intraorganisational DCs: centralised logistics control, centralised logistics structure, standardised logistics operations and learning orientation. The structure used to identify, describe and explain these antecedents is presented in Figure 17. A description of how these antecedents were identified is found in the Methodology chapter. The four antecedents are presented in the upcoming sections, starting with centralised logistics control.

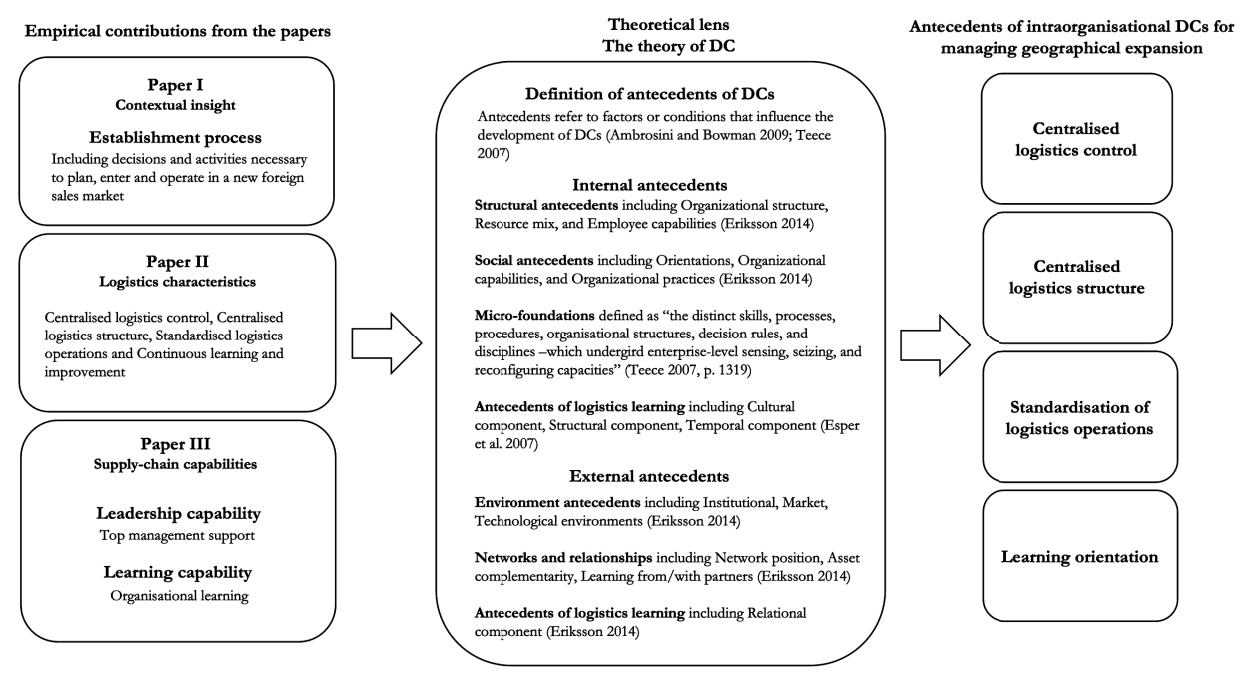

Figure 17. The structure used to identify, describe and explain the antecedents of intraorganisational DCs needed for retailers to manage their geographical expansion. 


\subsubsection{Centralised logistics control}

The findings show that a centralised logistics control supports the intraorganisational DCs of accessing, integration and utilisation of resources during the expansion. This antecedent refers to centralised control of the planning and execution of logistics throughout the expansion. Based on Paper II, the findings indicate that centralised logistics control can simplify resource sharing between the logistics function and top management team, as well as other internal functions and external actors (accessing). In a similar vein, Ambrosini and Bowerman (2009) stated the importance of management in the accumulation of knowledge, as the top management team's beliefs about how the company should evolve can play an important role in the development of DCs. In addition, the findings indicate that centralised logistics control can actively encourage integration activities (e.g. cross-functional meetings and projects) between the logistics function, other company functions and external actors, in order to share and learn about competencies outside the logistics function (integration). This was also stressed by the Project manager of the establishment process of Company A, who encourages frequent resource sharing among company functions, including the logistics function and the marketing function involved in the expansion. In addition, the findings also imply that centralised control of the logistics function can allow strategic logistics staff to prioritise, initiate and perform logistics projects relevant to the expansion (utilisation). In a similar vein, Eriksson (2014) argued that DCs are likely to have positive organisational outcomes only when they are part of top management's agenda, which in turn supports the accessing and integration of knowledge, as well as the utilisation of new logistics solutions.

The findings of Paper III illustrate the importance of the top management support team, which is closely involved in different aspects of the expansion, including the logistics aspects. For instance, the Project manager responsible for the geographical expansion of Company A plays a key role in accessing different resources during the expansion, including logistics expertise (Paper I). In particular, the project manager had regular meetings with the top management team and company functions (including the logistics function), to discuss logistics issues (Paper III). In line with this, Dimitrova et al. (2018) highlighted the importance of a strong commitment by top management, because a lack of management is a common impediment in geographical expansion. Also, Marchet et al. (2016) emphasised that logistics managers need to support the overall expansion strategy, including foreign market selection, entry mode and retail format. In addition, Eriksson (2014) argued that top management support is an internal structural antecedent that can influence the outcomes of DCs. In a similar vein, other scholars (e.g. Bruni and Verona, 2009; Eriksson, 2014) have cited top management support as a key antecedent of DCs.

Based on the findings of Paper II, centralised logistics control is characterised by strategic logistics managers, such as a supply chain manager and a logistics manager, physically situated at the headquarters in close proximity to other top executives involved in the expansion. The findings suggest that this proximity to the top management team can enable shorter communication lines between the logistics function and top management, other company functions and external actors, which in turn can simplify the communication of logistics issues, as well as allowing such issues to be prioritised at a strategic level. Similar to this, the empirical findings suggest that representation of strategic logistics staff in the 
top management team is important in the expansion. Based on learning from the expansion, the Logistics manager at Retailer B stated:

For the next establishment, the logistics function will be involved and make a logistics assessment. I will receive the assignment by the CEO to investigate how the logistics should be done in the best way. (Logistics manager, Retailer B)

\subsubsection{Centralised logistics structure}

In addition to centralised logistics control, the findings suggest that a centralised logistics structure within retailers can serve as an important antecedent of DCs. This antecedent of retailers refers to the centralisation of logistics facilities (e.g. a central warehouse and hubs) in the expansion. Based on Papers II and III, the findings show that a centralised organisational structure enables shorter communication lines and resource sharing as staff are located in just one or a few physical locations, which supports the identification and accessing of internal resources (accessing). In addition, a centralised allocation of logistics resources simplifies the interpretation and combination of resources and capabilities into new logistics solutions (integration). A centralised organisational structure also simplifies the implementation and utilisation of new logistics solutions by retailers (utilisation), because changes need to be made in fewer locations, such as a central warehouse.

The findings of Paper II show that a central warehouse is essential to ensure smooth supply to multiple sales markets in a time- and cost-efficient manner. Before the expansion started, the top management of Company A decided to centralise its warehouse facilities into one central warehouse to simplify the management of the logistics function, as well as reducing the cost of operating abroad. According to the Logistics manager at Company A, this consolidation into one central warehouse simplified the logistics operations for the foreign operations. In addition, the Logistics manager argued that the centralisation was essential for cost-efficient expansion:

It is possible to operate a (logistics) organisation from many warehouses, but it becomes very costly. If we had not carried out the centralisation, we would not have had as much capital to invest in other things. For example, in the expansion. (Logistics manager, Company A)

In a similar vein, the logistics function of Company B experienced a dramatic increase in logistics costs at the beginning of the expansion and thus centralised its logistics facilitates in order to reduce the logistics costs and gain better control of warehouse operations. In the words of the Logistics manager of Company B:

As sales increased, logistics costs increased and then it was thought that logistics was such an important aspect for us, so we had to have it in-house. (Logistics manager, Company B)

These examples are also in line with the findings of previous scholars. For instance, previous scholars (Abrahamsson et al., 2003; Pedersen et al. 2012) argued that a centralised, physical logistics structure (i.e. a central warehouse) improves control and overview of the logistics function, including the physical flows within the supply chain. In addition, this antecedent enables retailers to be more flexible and respond better to unforeseen events 
during the expansion, as well as enabling a greater extent of resource pooling within the logistics function of retailers (Paper II). One clear example of the latter is found in the central warehouse at Company $\mathrm{B}$, in which the physical centralisation allowed the logistics manager to more freely allocate logistics staff between different product flows, depending on the demand for the flows by a specific market (Paper II). In a similar vein, Eriksson (2014) argued that organisational structure is an important internal, structural antecedent of DCs that supports the coordination of resources within an organisation. In relation to a centralised structure, Karim (2009) stated that larger firms typically need a more structured organisation in order to better coordinate their resource base. This seems to also apply to the physical organisation of the logistics function of the studied large-sized retailers, as the centralised logistics structure simplified their resource coordination throughout the expansion.

\subsubsection{Standardised logistics operations}

The findings show that Standardised logistics operations are a key antecedent of DCs. This refers to standardised logistics operations used by retailers throughout their geographical expansion. The findings of Paper II emphasise the need for robust and well-functioning standardised logistics activities (e.g. warehouse activities) in order to perform daily logistics operations and quickly respond to new conditions related to the expansion. In a similar vein, Eriksson (2014) argued that organisational structure, such as the structure of the logistics function, including logistics operations and processes, is an important internal, structural antecedent of DCs, which provides additional structure for retailers during the expansion. The findings show that standardised logistics operations support the studied intraorganisational DCs in numerous ways. Firstly, standardised logistics operations enable retailers to measure costs and time, as a mean of analysing their logistics performance and in turn identifying potential areas for improvement. For instance, standardised measurements, such as cost per store order and cost per online order, are used by the supply chain manager at Company $\mathrm{C}$ to identify time and cost savings in the different product flows related to the expansion (Paper II). This antecedent enables retailers to analyse their logistics and find potential improvements in the expansion (integration). In addition, the findings show that the standardisation of logistics planning and operations enables retailers to be more flexible and make local logistics adjustments (utilisation). For example, the logistics function of Company B adjusted the transport planning to better meet local demand. The findings also show that standardised logistics operations simplify the upscaling of logistics operations, which enables retailers to quickly expand into new foreign sales markets.

Based on the findings of Paper II, retailers strive to expand using a standardised retail format, including standardised logistics operations, which reduces the logistics costs as well as the complexity of the logistics system. For instance, the logistics function of Company $\mathrm{C}$ had established standardised logistics operations for all markets and all sales channels (Paper II). In addition, the Logistics manager of Company A argued that standardisation was essential in the expansion. In particular, they said: 
For us, it does not matter if the store is located in Germany or in Sweden... You do exactly the same thing, the pickers do not care if they pick for a Swedish or a Norwegian store. (Logistics manager, Company A)

The findings of Paper II show that most logistics operations were already standardised before the expansion started. However, it becomes especially crucial to standardise the handling of market-specific products, including receiving, storing and customs management, because they can become more complex with additional sales markets. In a similar vein, Abrahamsson et al. (2003) pointed out that standardised warehouse operations are not only important in the expansion context but also for domestic operations and for other actors (e.g. producers), because they provide increased economies of scale and scope (Abrahamsson and Rehme, 2010; Wood and Reynolds, 2014). As expansion typically means a dramatic increase in logistics costs, cost-efficient logistics operations are key in any expansion.

In addition, the findings of Paper II reveal an interesting interplay between standardisation and flexibility, in which a high degree of standardised logistics operations paradoxically simplifies the adjustment to foreign sales markets. Geographical expansion requires retailers to be flexible, which enables them to adapt more quickly to changing conditions. Furthermore, Paper II shows that standardised operations enable retailers to make marketspecific adjustments to their logistics operations in order to better meet local regulations and customer demand. For instance, the logistics function of Company $\mathrm{C}$ distributed a small part of its product flow via local suppliers instead of the central warehouse (like the rest of the product flow), in order to offer some market-specific products. This adaptation would not have been possible without a high level of standardised logistics operations. Without a majority of standardised logistics operations, local adjustments would become too difficult to manage because geographical expansion typically increases the complexity of the logistics system. This is also in line with previous scholars (e.g. Abrahamsson and Rehme, 2010; Swoboda and Anderer, 2008), who argued that the standardisation of logistics operations enables local adjustments to different markets.

\subsubsection{Learning orientation}

The findings show that a learning orientation is another essential antecedent for intraorganisational DCs. This antecedent refers to a strong learning culture that enable retailers to continuously learn throughout their expansion. Based on the empirical findings, retailers need to rapidly learn from previous foreign establishments in order to improve their logistics operations. Retailers typically lack knowledge and experience of foreign cultures, regulations, competitive structures and consumer behaviour (Burt et al., 2016; Douglas and Craig, 2011). It is therefore important for retailers to identify and access new and/or enhanced resources (accessing) within the company (e.g. top management, marketing function, logistics function, store staff). For instance, the logistics function of Company B had activities for collecting feedback from staff in its foreign stores, which was used to improve the foreign logistics operations (Paper III). In particular, the Logistics manager of Company B said: 
We always ask and get a lot of feedback. from our stores if something is not working. (Logistics manager, Company B)

In a similar vein, Eriksson (2014) argued that different organisational orientations, such as learning orientation, can work as internal, social antecedents of DCs. In addition, Zollo and Winter (2002) identified organisational learning as a vital antecedent of DCs. The findings show that a learning orientation enables retailers to integrate accessed resources (integration). For instance, throughout the expansion there is continuous communication between the logistics function and other company functions, such as marketing and sales, which enables resources to be properly interpreted and later combined into new solutions. For instance, marketing knowledge (e.g. customer preferences, retail offers) from the marketing function of Company A was discussed between the logistics function and the marketing function in order to better understand the demands of local markets and create new solutions that better served the foreign sales markets. Furthermore, the learning orientation enables retailers to test, implement and fully utilise new resource combinations (utilisation). For instance, new logistics planning was created by the logistics function of Company B based on accumulated and integrated marketing knowledge from the marketing function.

The findings of Papers II and III show that a learning orientation of retailers is characterised by a strong commitment and curiosity to learn from past experiences and lessons from the expansion. For instance, the Project manager of Company A emphasised the importance of seeing each foreign establishment as a learning opportunity in order to gradually improve the company's foreign logistics operations. Developing a cost-optimised logistics solution was not the focus when establishing into a new foreign sales market, instead it was more important to get started and gain experience, and then to gradually improve the logistics using a learning-by-doing approach (Paper II). A clear statement of this comes from the Project manager of Company A, who said:

When you are up and running, like in Sweden, then it becomes relevant to chase costs and become more effective. But priority one when we look at Norway and now Germany is: "Will we sell?" (Project manager responsible for the establishment into foreign sales markets, Company A)

\subsubsection{Summary of the antecedents of intraorganisational dynamic capabilities}

To manage the logistics challenge of geographical expansion by retailers, four antecedents of intraorganisational DCs were identified: centralised logistics control, centralised logistics structure, standardised logistics operations and learning orientation. Firstly, centralised logistics control refers to centralised control of the planning and execution of logistics throughout the expansion. This characteristic creates a base for the accessing, integration and utilisation of resources, because centralised planning and execution enable logistics issues to be prioritised during the expansion. Secondly, a centralised logistics structure refers to the centralisation of logistics facilities (e.g. a central warehouse and hubs) during the expansion. This antecedent is essential for retailers to smoothly access, integrate and utilise new resources and in turn supply multiple sales markets in a time- and cost-efficient manner. Thirdly, standardised logistics operations refer to standardised logistics operations being used by retailers throughout the expansion. Robust and well-functioning operational logistics activities (e.g. warehouse activities) are key in order to perform daily logistics operations 
and quickly upscale operations, as well as responding to new conditions related to the expansion. Fourthly, a learning orientation refers to a strong learning culture that enable retailers to continuously learn throughout the expansion. A learning orientation is the basis of all DCs that facilitate learning within retailers and is characterised by a strong commitment to learning and open-mindedness towards new experiences and learning.

Figure 18 summarises the antecedents of intraorganisational DCs. Based on Eriksson (2014), these internal antecedents are either structural (centralised logistics support, centralised logistics structure. standardised logistics operations) or social (learning orientation) in their nature, and together form a solid foundation that influences the intraorganisational DCs for managing geographical expansion by retailers.

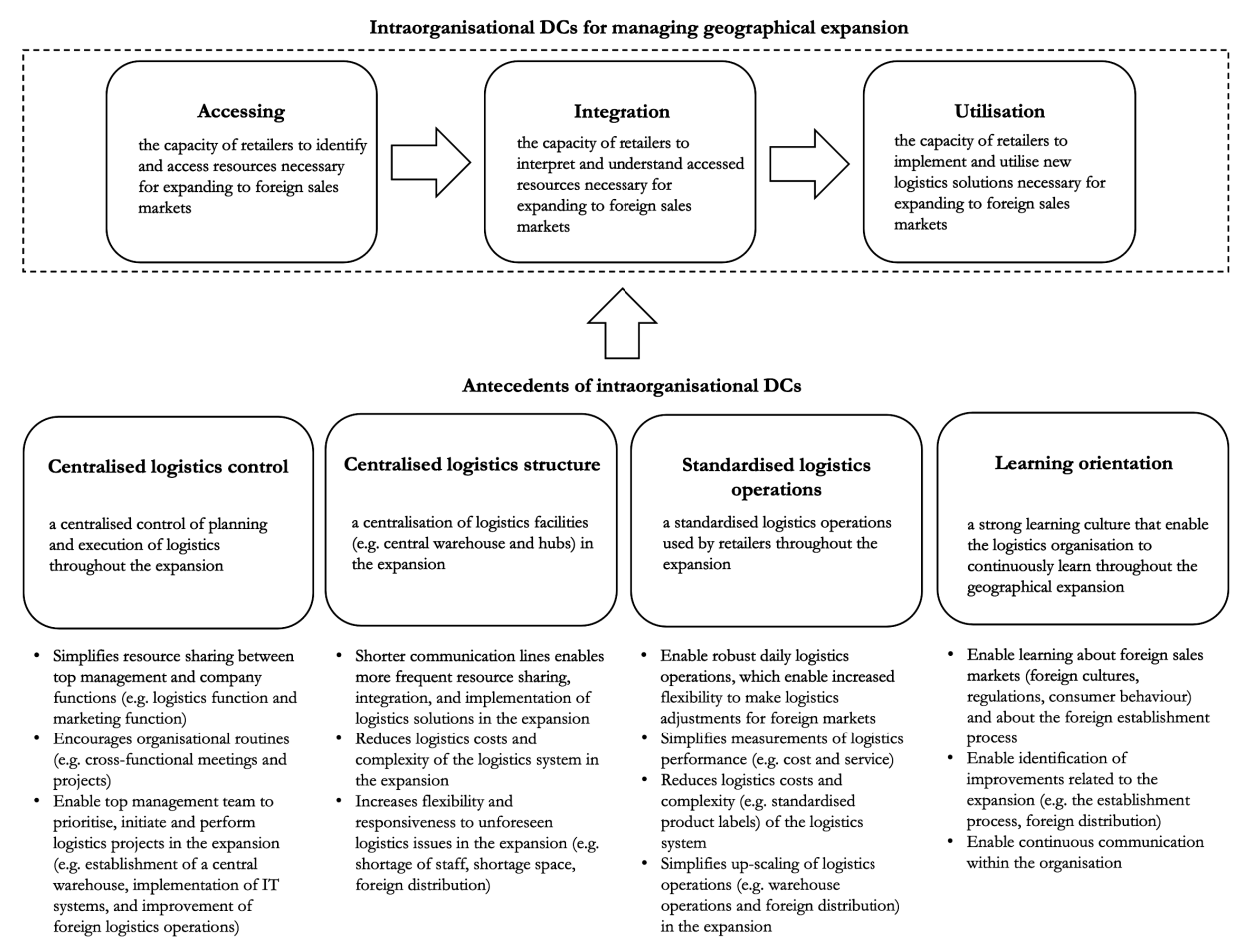

Figure 18. The antecedents of intraorganisational DCs for managing geographical expansion.

\subsection{Antecedents of interorganisational dynamic capabilities for managing the transition to omni-channel retailing}

To understand how the antecedents of interorganisational IDCs enable retailers to manage the transition to OC retailing, the antecedents from Papers V and VI and the theoretical lens of the antecedents of IDCs, including the IDC framework presented in Paper IV, were used. This resulted in the two antecedents of IDCs: supply chain orientation and learning orientation. The structure used to identify, describe and explain these antecedents is presented in Figure 19. A description of how these antecedents were identified is found in 
the Methodology chapter. The two antecedents are presented in the upcoming sections, starting with supply chain orientation.

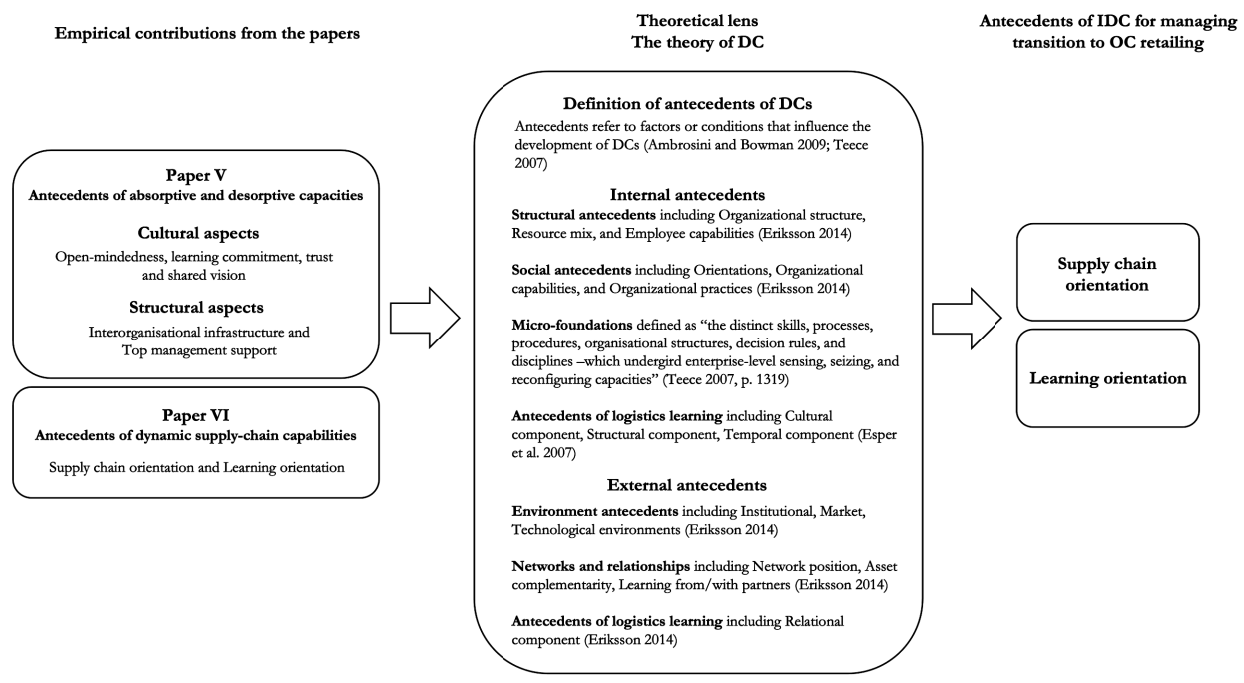

Figure 19. The structure used to identify, describe and explain the antecedents of IDCs for managing the transition to OC retailing.

\subsubsection{Supply chain orientation}

The findings show that a supply chain orientation is a key antecedent of IDCs for retailers to manage the transition to OC retailing. A supply-chain orientation refers to as a firm's view of the supply chain as an integrated entity. This antecedent has also been highlighted by previous scholars (e.g. Defee and Fugate, 2010; Eriksson, 2014). In line with Defee and Fugate (2010), the findings reveal the importance of all parties (including retailers and LSPs) having a supply chain orientation in order to be able to jointly improve the logistics performance. In addition, Eriksson (2014) argued that such an orientation can be categorised as an internal, social antecedent of DCs. Based on Paper VI, a supply chain orientation is characterised by a holistic view of the supply chain, a strong customer orientation, active involvement in collaborative efforts and behavioural elements (including trust, commitment, norms and dependence) as well as top management support. In the OC transition, these characteristics enable both retailers and LSPs to identify (accessing) and share knowledge (identify and transfer knowledge), as well as engaging in joint activities (e.g. projects) (utilisation). Based on Paper VI, all cases have emphasised the importance of a sufficient amount of trust between retailers and LSPs throughout the OC transition. In particular, the findings suggest that transparency between retailers and LSPs is an important element of trust; this is characterised by openly share logistics data, and sharing integrated IT systems (including WMS), which are essential in OC retailing (Kembro and Norrman, 2019b). In particular, the Logistics manager at Retailer B stated: 
We are only human, and this is not something you do in a day. [A good relationship] requires continuity and that you build trust, that you can rely on each other. Honesty - that you deliver what you have promised. (Logistics manager, Retailer B)

In addition, the findings highlight the importance of long-term relationships and the creation of win-win situations between retailers and LSPs when managing the transition to OC retailing. Based on a dyadic perspective, the findings imply that OC transition is best made by retailers and LSPs that have a long history of working together. The findings of Papers V and VI also highlight the importance of commitment from both retailers and LSPs to engage in joint OC efforts, because commitment enables the establishment of joint activities and mutual gains to a greater extent. This has also been emphasised in previous literature (e.g. Aharonovitz et al., 2018; Nyaga et al., 2010). In particular, the Logistics manager at Retailer B stated:

There must be two parties who want [to collaborate]. After all, the personal relationship between those who own the deal is extremely important. If this relationship works, you have created a good foundation for both organisations to work together... It will be difficult to find mutual gains if you don't want to listen or commit. Then it will be a shipper-provider relationship that only focuses on cost. (Logistics manager, Retailer B)

In a similar vein, the Business developer at LSP B stated:

I think it varies a lot... Some [shippers] are very committed and it is much more fun to work with those who are involved. But at the same time, you must try to process the other [shippers] and make them understand that we must work together. We must give each other good conditions to be able to succeed together. (Business developer, LSP B)

In addition, the findings imply that the creation of common norms and a friendly culture between retailers and LSPs is key to creating a unified entity that works together to manage the transition to $\mathrm{OC}$ retailing (integration). For instance, the Logistics manager at Retailer A emphasised the importance of creating a "us" feeling, where the parties treat each other in a respectful manner, to successfully manage logistics issues during the transition. The findings also show that top management support is a key element for initiating and performing joint projects between retailers and LSPs (utilisation). Both the studied retailers and LSPs argued for the importance of strategic logistics staff at a top management level empowered to make strategic logistics decisions (such as logistics investments) related to the joint efforts related to OC retailing. In the same way, the lack of decision-making power among strategic logistics staff (e.g. the Logistics manager at Retailer A) is a hindrance to joint efforts. In particular, the Business developer at LSP B stated:

[A major success factor is] that you have a "real' logistics manager where the logistics manager's role is not only to cut costs for logistics but also to develop the logistics into something good for the consumer. (Business developer, LSP B) 


\subsubsection{Learning orientation}

The findings show that a learning orientation is an essential antecedent for IDCs to manage the transition to OC retailing. This antecedent refers to a strong learning culture that enables retailers to frequently learn from their LSPs, and vice versa. Based on the empirical findings and previous scholars (e.g. Galipoglu et al. 2018; Simone and Sabbadin, 2018), the OC retailing encompasses a number of logistics issues (e.g. channel integration, reverse logistics, checkout solutions), which retailers and LSPs need to learn from in order to modify their joint resource base. A learning orientation has also been highlighted by previous scholars (e.g. Defee and Fugate, 2010; Eriksson, 2014; Sinkula et al., 1997). For instance, Eriksson (2014) argued that such an orientation can be categorised as an internal, social antecedent of DCs. In addition, Sinkula et al. (1997) refer to a learning orientation as a set of organisational values, including open-mindedness, learning commitment and shared logistics vision. This is also in line with the empirical findings, which reveal the importance of open-mindedness, learning commitment and a shared logistics vision. In particular, the findings show that open-mindedness can be characterised by a strong curiosity towards external ideas, experiences and lessons, which can support the accessing of new knowledge (accessing), as well as the identification of knowledge-transfer opportunities (identifying knowledge-transfer opportunities). For instance, the Business developer at LSP B stressed the importance of open-mindedness:

\section{Be keen to embrace the experiences of others. Retailer B can tell me that we have tested that [solution] before and it did not work. Then we say OK, we won't do that. (Business developer, LSP B)}

The findings also highlight a shared logistics vision as a key characteristics of learning orientation. The findings of Papers V and VI show that a logistics vision is an extension of the vision of a retailer and works as a guiding star for all logistics decisions. For instance, the strategic logistics staff of Retailer A had explicitly formulated a logistics vision that was frequently discussed between the retailer and its LSPs. The findings suggest that a logistics vision can support all IDCs, because it determines which knowledge should be accessed (accessing), integrated (integration) and later utilised (utilisation). In addition, a shared logistics vision helps retailers and LSPs to take on joint efforts (e.g. projects) to solve OC issues (Paper VI), which is key for all IDCs. For instance, the Logistics manager at LSP A stated the importance of a shared logistics vision:

That is our logistics vision. However, it is not enough that we [the logistics function of Retailer A] have this vision for it to become a reality... Instead, we need something more. The vision is very central for our logistics partner [the LSP] and it has become our shared logistics vision, which is one of our success factors. (Logistics manager, Retailer A)

In a similar vein, the Quality manager at Retailer A, speaking about LSP B, stated:

Our vision and the development of our vision is of value for the LSP in the same way as it is important for us. We outsource a lot to them [to the LSP] and then we expect them to take the initiative to develop their services in order to develop the customer offer. (Quality manager for logistics, Retailer A) 


\subsubsection{Summary of the antecedents of interorganisational dynamic capabilities}

To manage the challenges of the transition to OC retailing, two antecedents of IDCs were identified: supply chain orientation and learning orientation. Firstly, supply chain orientation refers to a firm's view of the supply chain as an integrated entity. This is characterised by a holistic view of the supply chain, a customer orientation, active involvement in collaborative efforts, behavioural elements (including trust, commitment, norms and dependence) and top management support. A holistic view of the supply chain enables retailers to access, integrate and utilise knowledge from LSPs, and vice versa. Secondly, learning orientation refers to a learning culture characterised by open-mindedness, learning commitment and a shared logistics vision, which enable learning between retailers and LSPs.

Figure 20 summarises the antecedents of IDCs. Based on Eriksson (2014), these internal antecedents are internal, social antecedents that together enable the logistics function of retailers to manage the transition to OC retailing.

IDCs for managing transition to $\mathrm{OC}$ retailing

\begin{tabular}{|c|c|c|c|c|}
\hline \multicolumn{3}{|c|}{ receive-oriented } & \multicolumn{2}{|c|}{ transfer-oriented } \\
\hline \begin{tabular}{l}
\multicolumn{1}{c}{ Accessing } \\
the capacity of retailers to \\
identify and access \\
knowledge of LSPs \\
necessary for \\
transitioning to OC \\
retailing, and vice versa
\end{tabular} & \begin{tabular}{l}
\multicolumn{1}{c}{ Integration } \\
the capacity of retailers \\
to interpret and combine \\
knowledge from LSPs \\
necessary for \\
transitioning to OC \\
retailing, and vice versa
\end{tabular} & \begin{tabular}{l}
\multicolumn{1}{c}{ Utilisation } \\
the capacity of retailers to \\
test, refine, and implement \\
new solutions, based on \\
external knowledge from \\
LSPs necessary for \\
transitioning to OC \\
retailing, and vice versa
\end{tabular} & $\begin{array}{l}\text { Identify knowledge } \\
\text { transfer opportunities } \\
\text { the capacity of retailers to } \\
\text { identify knowledge-transfer } \\
\text { opportunities to their LSPs } \\
\text { necessary for transitioning } \\
\text { to OC retailing, and vice } \\
\text { versa }\end{array}$ & $\begin{array}{l}\text { Transfer knowledge and } \\
\text { facilitate application } \\
\text { the capacity of retailers to } \\
\text { transfer and facilitate } \\
\text { application of internal } \\
\text { knowledge at their LSPs } \\
\text { necessary for transitioning } \\
\text { to OC retailing, and vice } \\
\text { versa }\end{array}$ \\
\hline
\end{tabular}

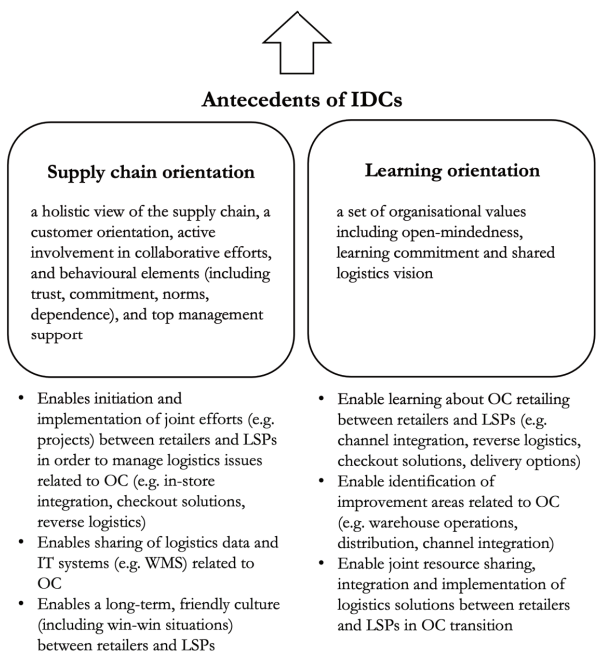

Figure 20. The antecedents of IDCs for managing the transition to OC retailing. 



\section{Conclusions}

In this final chapter, the conclusions of this dissertation are presented. Also, reflective discussion and implications are presented, followed by suggestions for future research.

\subsection{Conclusions}

In an everchanging retail sector, retailers face several logistics challenges that they need to manage in order to create and maintain a competitive advantage. For instance, increased globalisation and digitalisation have vastly changed the retail sector, including retail logistics. To manage these logistics challenges, retailers need specific DCs and antecedents of DCs that enable them to adapt their retail logistics to manage different challenges. Based on this, the research purpose of this dissertation was to:

\section{Using a DC lens, explain how retailers can manage logistics challenges}

To fulfil the research purpose, two research questions were established. The first research question, RQ1, studied DCs for managing logistics challenges and was formulated as: How do DCs enable retailers to manage logistics challenges? The second research question, RQ2, covered the antecedents of these DCs for managing the logistics challenges and was formulated as: How do antecedents support DCs that enable retailers to manage logistics challenges?

The answer to the research purpose was based on two studies that studied DCs and their antecedents from an intraorganisational and an interorganisational perspective, based on two different logistics challenges: the geographical expansion and the transition to OC retailing. Firstly, the findings relating to the first research question presented three intraorganisational DCs: accessing, integration and utilisation, which enable retailers to manage their geographical expansion. In terms of the antecedents of these DCs, the findings revealed four antecedents: centralised logistics control, centralised logistics structure, standardised logistics operations and learning orientation, which are important for managing the geographical expansion of retailers. In addition, the findings presented five interorganisational DC (IDCs), consisting of three receive-oriented IDCs: accessing, integration and utilisation, and two transfer-oriented IDCs: identifying knowledge transfer opportunities and transferring knowledge and facilitating application, which enable retailers to manage their transition to OC retailing. In addition, the findings presented two antecedents of these IDCs: supply chain orientation and learning orientation. Figure 21 summarises the framework for how retailers can manage logistics challenges, which is the answer to the research purpose. 


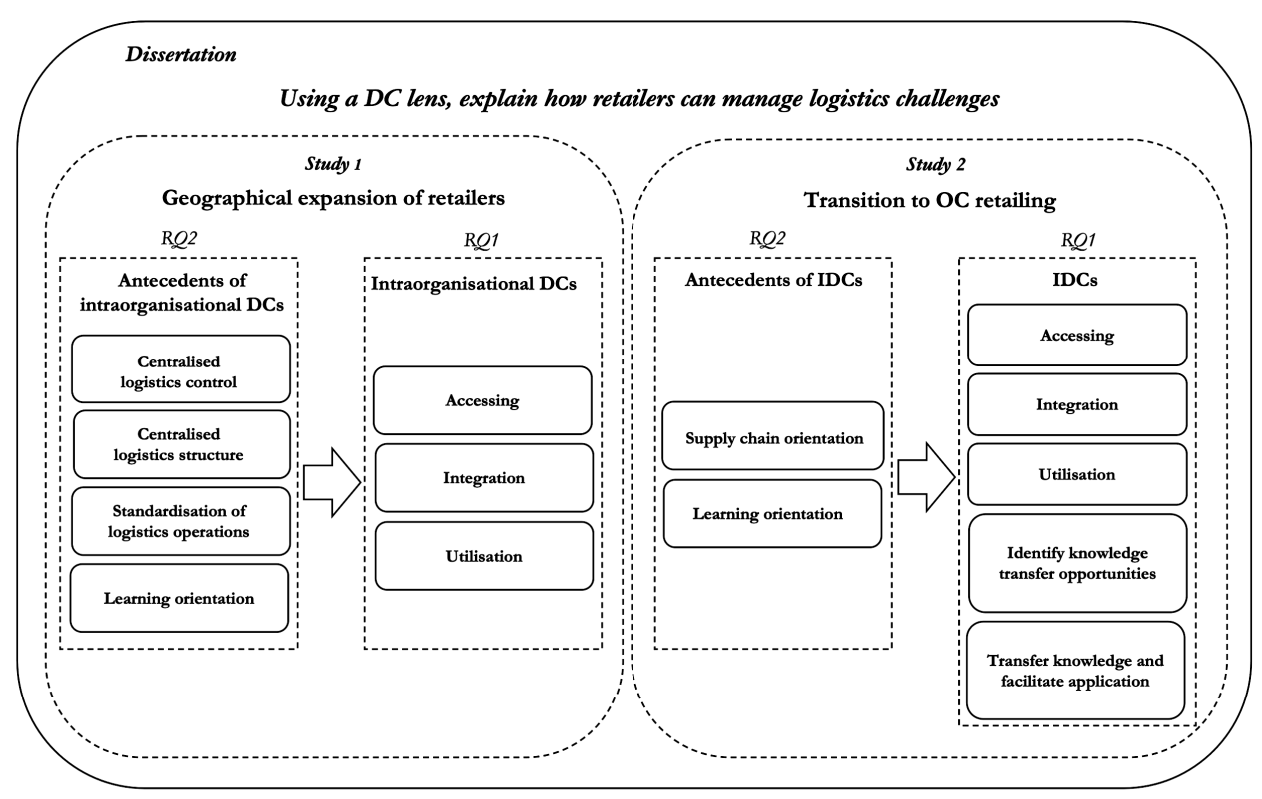

Figure 21. Framework for how retailers can manage logistics challenges using DCs.

\subsection{Discussion - a comparison between the studies}

This section presents a reflective discussion about the findings of the dissertation, starting with the DCs for managing logistics challenges.

\subsubsection{Dynamic capabilities for managing the logistics challenges of retailers}

The findings of this dissertation have presented three intraorganisational DCs: accessing, integration and utilisation, which enable retailers to manage their geographical expansion. In addition, the findings have presented five interorganisational DC (IDCs), consisting of three receive-oriented IDCs: accessing, integration and utilisation, and two transfer-oriented IDCs: identifying knowledge transfer opportunities and transferring knowledge and facilitating application. There are some similarities and differences among these DCs, which are further discussed below.

The findings show that accessing, integration and utilisation are three important DCs for managing both geographical expansion and the transition to OC retailing. However, there is a clear distinction between what retailers access, integrate and utilise in terms of resources and how they do so. Based on the findings, what resources are being accessed differ depending on the specific logistics challenge at hand. In particular, this research clarified the different objectives of DCs, including what resources were being accessed, for managing the studied challenges (see Figures 14 and 16). For instance, retailers focus on accessing resources related to their expansion, including foreign market knowledge (e.g. local customer behaviour and demand), statistics of foreign retail operations (e.g. foreign logistics operations) and experiences and lessons learned from previous foreign establishments. In a similar vein, retailers seek knowledge related to OC transition, including expertise on in-store integration, integrated IT systems, track and trace, and last- 
mile delivery options. The differences in the objective of accessing in turn influence the combination of resources put into potential logistics solutions (integration), and the implementation of refined logistics solutions (utilisation) related to the different challenges. For instance, when it comes to geographical expansion, the focus is on integrating resources in order to improve foreign distribution operations, reduce the complexity of retail flows and create local adjustments to foreign markets. In a similar vein, integration in the OC transition focuses on improving channel integration, improving reverse logistics and developing checkout solutions. In addition, the objectives of integration influence the objectives of utilisation, including the solutions being implemented. For instance, in geographical expansion, the objective of utilisation is to refine and implement new logistics solutions, including implementing alterations in foreign distribution and customs procedures. In a similar vein, the objective of utilisation in the OC transition was typically to implement in-store integration and develop a tracking device and a new checkout solution related to the OC transition.

In terms of how retailers access, integrate and utilise challenge-related resources, all the DCs involved regular joint activities (e.g. joint meetings and projects) involving cross-functional staff (e.g. between different company functions and top management) and/or staff from external actors (e.g. LSPs). These activities focused on solving different challenge-related issues. For instance, one retailer described the establishment into foreign sales markets as a large project, incorporating several smaller projects (e.g. logistics projects), which involved the top management team, company functions and external actors. In addition, the results point to the importance of joint projects between retailers and LSPs to overcome different OC issues (e.g. track and trace, in-store integration). Based on these findings, both retailers and LSPs engage in similar activities for accessing, integrating and utilising external resources. For instance, both employed a structured approach involving internal discussions at joint meetings and projects to identify, integrate and utilise external knowledge. In addition, the results also show that interview studies, field visits and observations are important activities for accessing and integrating resources. For example, field visits and observations of the logistics business resulted in an additional resource exchange between a retailer and an LSP, which had not been possible with only joint meetings. Although the importance of joint meetings is not a new finding in research, the DC lens enables a better understanding of what such activities actually look like in a retail setting, and how DCs enable retailers to manage different challenge-related issues. It is the series of recurring, goal-oriented joint meetings that can result in the accessing, integration and utilization necessary to manage different logistics challenges. Furthermore, the findings show that the activities of DCs differ in terms of scope, whereby the intraorganisational DCs focused on the accessing, integration and utilisation of internal resources involving the own retail organisation (including the top management team and company functions). In contrast, the IDCs focused on exchanging internal and external resources between retailers and LSPs. The difference in scope is based on the two complementary perspectives used in this research, which showed that similar activities for resource exchange were applied by retailers when managing logistics challenges.

In addition to the receive-oriented DCs, the findings in Study 2 also show that identifying knowledge-transfer opportunities and transferring knowledge and facilitating application are two important transfer-oriented IDCs for transferring internal knowledge from retailers to 
LSPs, and vice versa. These IDCs were found due to the interorganisational perspective used for studying OC transition in Study 2. However, these IDCs might also be important for geographical expansion by retailers. Despite the intraorganisational perspective used in Study 1, geographical expansion is an interorganisational challenge that depends heavily on both internal and external resources. In line with previous researchers (e.g. Defee and Fugate, 2010), the findings also highlight the importance of an interorganisational perspective when studying DCs in order to better capture the resource exchange between different supply chain members. At the same time, the intraorganisational perspective used in this research provides an in-depth understanding of DCs within a retail organisation, and how retailers combine their internal resources to manage their expansion. Based on this, the two perspectives used in this research complemented each other very well and resulted in an increased understanding of DCs in a retail setting.

In relation to the different perspectives, this research used the retailer as the unit of analysis to study DCs. In addition, Study 1 also used the retailer as the unit of analysis and focused on resource exchanges within the retail organisation. In contrast, Study 2 used a wider, interorganisational perspective for studying DCs involving both retailers and LSPs, in order to better understand how retailers and LSPs collaborate. For instance, Paper V used a dyadic perspective for studying learning between a retailer and an LSP, including examples of how both actors learned from each other. The wider unit of analysis used in Study 2 resulted in an improved understanding of the different supply-chain members involved when managing different challenges. In particular, it showed that the receive- and transferoriented DCs of retailers and LSPs can enhance resource exchange. A wider unit of analysis can provide us with a better understanding of the world, including the different supply chain members that are interacting. At the same time, a wider unit of analysis can lead to a lack of understanding of individual members, which is also important for understanding DCs. This research has balanced these trade-offs when choosing the unit of analysis for this dissertation.

This research includes the development and use of a conceptual framework for IDCs (see Paper IV), used for categorising IDCs in terms of who benefits and who controls a specific IDC. Based on this framework, the IDCs were categorised as firm-based IDCs because they were controlled by the retailer and benefited both the retailer and LSPs involved. The intraorganisational DCs were studied from a retailer's perspective, and how such DCs impacted upon other supply-chain members in the expansion was not examined. However, inspired by the framework in Paper IV, the intraorganisational DCs of accessing, integration and utilisation seem to be controlled by the retailer and can benefit both the retailer and other supply-chain members (e.g. LSPs).

\subsubsection{Antecedents of dynamic capabilities for managing the logistics challenges of retailers}

The findings of this dissertation have presented four antecedents of intraorganisational DCs: centralised logistics control, centralised logistics structure, standardised logistics operations and learning orientation, for managing the expansion. In addition, the findings have also presented two antecedents of IDCs: supply chain orientation and learning orientation, for managing the transition to OC retailing. There are similarities and differences among some of these antecedents, which are further discussed in the upcoming section. 
Based on the findings, this research has shown that there are differences in terms of both structural and social antecedents. For instance, Study 1 identified structural antecedents (centralised logistics control, centralised logistics structure and standardised logistics operations) and social antecedents (learning orientation), whereas Study 2 identified only social antecedents (supply chain orientation and learning orientation). These antecedents differ in terms of type. Firstly, the intraorganisational perspective of antecedents has captured several structural antecedents of the retail organisation, whereas the interorganisational perspective has placed greater emphasis on social antecedents. In spite of their many differences, some of the antecedents share similar elements. For instance, the antecedents of centralised logistics control and supply chain orientation both show elements of top management support, which is a common antecedent in previous DC research (Eriksson, 2014). Both these antecedents demonstrate the importance of a top management that prioritises, initiates, supervises and performs different logistics issues related to different logistics challenges. In addition, a learning orientation is also found to be an important social antecedent for managing both geographical expansion and the transition to OC retailing. This orientation is characterised by open-mindedness, a commitment to learning and a shared vision, which were characteristics found both within and outside the retail organisation. For instance, the retailers in Study 1 were keen to gather experiences and lessons learned from previous foreign establishments to support their expansion, while the retailers in Study 2 frequently collected feedback from their LSPs in order to jointly support the OC transition. The findings also show that their logistics vision is an important tool that guides retailers in their resource exchange. In particular, an explicit and clearly communicated logistics vision can help retailers to access, integrate and utilise external resources as well as to identify and transfer internal resources. This in turn enable retailers to avoid pitfalls due to misunderstandings, and to more effectively manage the different logistics challenges that arise in retail.

\subsection{Implications}

There are several theoretical and practical implications arising from this research. These implications are further discussed in the upcoming sections.

\subsubsection{Theoretical implications}

This dissertation has several theoretical implications, which are presented below.

\section{A refinement of dynamic capabilities in retail}

This research is positioned at the intersection between retail logistics and DCs, and presents a refinement of the DCs necessary for retailers to manage different logistics challenges. In contrast to previous contributions about DCs in retail (e.g. Esper et al., 2007; Frasquet et al., 2018; Hüseyinoglu et al., 2018; Rajaguru and Matanda, 2019), this research provides more contextual insight into how retailers use DCs in a systematic way to manage two specific logistics challenges: the geographical expansion of retailers and the transition to OC retailing. Furthermore, this research studies the DCs of retailers from both an intraorganisational and an interorganisational perspective, which has increased our understanding of DCs within the retail organisation, as well as between companies. Previous DC research has mostly been conducted from an intraorganisational perspective, while DCs from an interorganisational perspective have been less well understood (Chen 
et al., 2019; Defee and Fugate, 2010). This dissertation demonstrates the importance of also having an interorganisational perspective when studying DCs, as retailers typically rely a lot on resources from external actors to manage different logistics challenges. The interorganisational perspective provides an additional understanding of how retailers need both receive-oriented and transfer-oriented DCs in order to exchange both internal and external resources. The following two sections present the refinement of intra- and interorganisational DCs related to the studied challenges.

Firstly, this dissertation contributes to a refinement of the intraorganisational DCs that enable retailers to systemically manage different logistics issues related to geographical expansion. Previous research has mostly focused on DCs related to marketing issues (e.g. Cao, 2011; Frasquet, 2013; Frasquet et al., 2018; Lowe et al., 2012), while neglecting important DCs for managing supply-chain issues during the expansion. Previous scholars have highlighted the importance of an effective relationship between the marketing and logistics functions within retailers (e.g. Chen et al., 2009; Swoboda and Anderer, 2008), but they have not studied how retailers actually work to establish and maintain such a relationship in order to manage different logistics issues during their expansion. This research provides an in-depth understanding of how DCs enable retailers to systematically access resources within their retail organisation, combine the accessed resources into new logistics solutions and implement them in order to manage logistics issues encountered during the expansion.

Secondly, this dissertation contributes to a refinement of the IDCs that are necessary for both retailers and LSPs to jointly manage the transition to OC retailing. As a complement to previous conceptual contributions on IDCs (e.g. Beske, 2012; Defee and Fugate, 2010), this research provides an empirical understanding of IDCs in a retail setting. The interorganisational perspective used in this research has enabled an explanation of how both receive-oriented IDCs (consisting of accessing, integration and utilisation) and transferoriented IDCs (identifying knowledge opportunities, and transferring knowledge and facilitating application) enable retailers to access, integrate and utilise external resources, as well as to identify and transfer internal knowledge relevant to managing the OC transition. This dissertation also includes the development of a conceptual framework for IDCs (see Paper IV) to categorise them in terms of who benefits and who controls a specific IDC. This framework was useful for categorising the IDCs in this dissertation, and the IDCs found were all categorised as firm-based IDCs, because they are controlled by the individual firm (e.g. a retailer) and can also benefit the external actors (i.e. LSPs) involved. Such a framework can also be useful for further research on the IDCs of retailers, as well as other supply-chain members.

\section{A refinement of the antecedents of dynamic capabilities in retail}

In addition to the refinement of DCs, this dissertation also contributes to a refinement of the antecedents of DCs. Antecedents of DCs are often generally described in the previous literature, and several scholars have recognised universal antecedents of DCs, including microfoundations (Teece, 2007), and internal and external factors (Eriksson, 2014) that influence the development and use of DCs. These antecedents are often only described in general terms and consideration is not given to the specific contexts of firms. As a complement to previous literature, this research provides an in-depth understanding of 
antecedents in a retail setting. In particular, this research provides insights into how antecedents support specific DCs that enable retailers to manage geographical expansion and $\mathrm{OC}$ transition. This research shows that there are differences in antecedents, depending on the specific challenge and perspective at hand.

Antecedents in previous research (e.g. Defee and Fugate, 2010; Eriksson, 2014; Teece, 2007) are often generally described and not linked to a specific DC or setting. Such a context is provided in this research. Firstly, the intraorganisational perspective shows that different logistics conditions can be seen as antecedents of DCs, which enable retailers to expand into new foreign sales markets. In particular, this research presents four antecedents of intraorganisational DCs: centralised logistics control, centralised logistics structure, standardised logistics operations and learning orientation, which are important in the geographical expansion of retailers. In particular, this research has provided insight into how these antecedents support DCs during geographical expansion, including numerous empirical examples from different retailers.

In addition, the interorganisational perspective emphasises antecedents of more crossorganisational character. In particular, this research presents two antecedents of IDCs, supply chain orientation and learning orientation, which are important for the OC transition. In terms of supply chain orientation, this research reveals the importance of a holistic view of the supply chain in order to make the transition to OC retailing. In many ways, this research confirms what previous researchers have said about supply chain orientation, including the importance of aspects such as trust and commitment (e.g. Beske, 2012; Defee and Fugate, 2010), but in the light of OC retailing. For instance, trust with a focus on transparency (in terms of logistics data and IT systems) between retailers and LSPs is an important element of supply chain orientation during the $\mathrm{OC}$ transition. In terms of learning orientation, this research shows that retailers learn within the retail organisation (e.g. logistics function and marketing function) as well as from external actors (e.g. LSPs). In line with previous literature (e.g. Esper et al., 2007; Sinkula et al., 1997), openmindedness, a commitment to learning and a shared vision are found to be key elements of a learning orientation. In particular, this research refines these elements and demonstrates the importance of a shared logistics vision, both within the retail organisation and between retailers and LSPs, in order to manage the different logistics challenges that arise in retail.

\section{An increased understanding of how retailers manage different logistics challenges in retail}

As already mentioned, this dissertation presents a refinement of the DCs necessary for retailers to manage two different logistics challenges: geographical expansion and the transition to OC retailing. These challenges cover multiple common issues, including the need to develop new competencies, coordination and collaboration between crossfunctional teams within the retail organisation, as well as with external actors. Although these challenges are widely recognised, there is a lack of understanding of how retailers manage these challenges logistically (Marchet et al., 2016; Swoboda et al., 2014). This research applies a DC lens to explain how retailers manage these logistics challenges. 
Firstly, this research provides new contextual insights into how retailers manage geographical expansion. These insights are summarised below.

- Firstly, this research provides an improved understanding of the different decisions, resources and functions involved in the expansion of retailers. For instance, this research presents a detailed description of the establishment process of retailers into new foreign markets.

- Secondly, this research uses a DC lens to study how retailers manage geographical expansion. According to Dimitrova et al. (2019), resource-based theories, including the theory of DC, can be a valuable approach to improve our understanding of the resources and capabilities involved in expansion, and how retailers evolve over time to manage ongoing expansion. This research confirms that a DC lens is a valuable addition to better understand this challenge and supports the identification of three DCs (accessing, integration and utilisation). In addition, this research has shown that retailers encounter several logistics issues (e.g. lack of logistics staff, shortage of storage space, long processing times for customs procedures), which need to be carefully solved by retailers if they are to continue their expansion. Such issues require retailers to seek new resources (accessing), interpret and combine these resources into new logistics solutions (integration) and implement and leverage new solutions to solve specific logistics issues (utilisation).

- Thirdly, this research generates in-depth insight into several expansions of retailers, including concrete examples of how DCs enable retailers to adapt their logistics to support their ongoing expansion. In previous research, little attention has been given to how retailers adapt their retail operations (including logistics operations) to manage such a geographical expansion (Dimitrova et al., 2019; Golgeci et al., 2014). Previous scholars have focused on marketing operations (e.g. entry modes).

Secondly, this research contributes to the OC literature and provides insight to how retailers manage the transition to OC retailing. These insights are summarised below.

- Previous research calls for a more robust theoretical foundation when studying OC retailing (Galipoglu et al., 2018), in which this research takes its stance in the theory of DC to study IDCs that enable retailers to manage the transition to OC retailing.

- Previous literature on OC retailing has to some extent covered different logisticsrelated aspects, including warehousing (Kembro et al., 2018), logistics and supply chain management (Galipoglu et al., 2018), information systems (Kembro and Norrman, 2018) and e-fulfilment and distribution (Hübner et al., 2016; Melacini et al., 2018; Taylor et al., 2019). As a complement to previous work, this research provides an improved understanding of how retailers and LSPs collaborate in order to adapt their logistics related to the different aspects of OC retailing.

- In addition, this research shows that the transition to OC retailing is made in several smaller steps, including the development of new IT systems, distribution and warehousing operations to offer end customers a more seamless shopping experience. New logistics solutions are developed in different joint projects, involving several different company functions (e.g. marketing, IT, logistics) and external actors (e.g. LSPs). The transition to OC retailing is a large commitment, which needs to be anchored between retailers and LSPs, and requires them to work closely together to synchronise their operations and expertise (e.g. retail offers, websites, stock levels, distribution options) to create seamless logistics solutions in 
relation to end customers. This research shows that many retailers fail to develop a holistic view of the transition to OC retailing, including the different functions and actors involved.

\subsubsection{Practical implications}

This dissertation offers several practical implications to various practitioners, including top management staff and strategic logistics staff, who are facing different logistics challenges in retail. These implications are presented in the next section.

\section{The importance of retailers systematically managing logistics challenges in retail}

Using a DC lens, this research has demonstrated the importance of retailers working systematically to manage the different logistics challenges in retail. In particular, the findings identified, described and explained several DCs that are needed for retailers to manage the challenges of geographical expansion and the transition to OC retailing in a systematic manner. It is important for retailers to have strategic activities for accessing, integrating and utilising new resources, as well as to identify and transfer internal resources, in order to systematically manage different logistics issues. This involves regular, goal-oriented activities (e.g. joint meetings, projects, observations and interviews) that involve both the retail organisation (e.g. the top management team, marketing function and logistics function) and external actors (e.g. LSPs) in order to sufficiently access and combine resources and implement new logistics solutions. In relation to the DC definition given of Helfat et al. (2007), which emphasises "the capacity of an organization to purposefully create, extend or modify its resource base", the findings reveal the importance of retailers being goal-oriented in order to access, integrate and utilise resources in a sufficient manner.

\section{The importance of a logistics vision to manage logistics challenges in retail}

This research demonstrates the importance of retailers having a logistics vision in order to manage the different logistics challenges in retail. In particular, the antecedent of learning orientation in the findings indicates the importance of a shared logistics vision in order to access, integrate and utilise experiences and expertise. Based on the findings, a logistics vision is an extension of the overall retail strategy, which influences how retailers manage different logistics challenges. Such a vision supports strategic retail decisions (including logistics decisions) and resource sharing, both within the retail organisation and with external actors (e.g. LSPs). The findings show that a shared logistics vision is an important tool that supports collaboration between retailers and external actors, enabling them to work towards the same goals and jointly manage different logistics challenges in retail. For instance, Retailer A and Retailer B in Study 2 had a logistics vision that supported their transition to $\mathrm{OC}$ retailing. In addition, Study 1 also visualised the importance of a shared vision within the retailer to manage its expansion. To successfully manage challenges, this logistics vision needs to be shared and understood within the retail organisation, including the top management team, company functions (e.g. marketing function and logistics function) and external actors (e.g. LSPs). Otherwise, it will not sufficiently support or guide retailers when accessing, integrating and utilising external resources, or when identifying and transferring external resources. 
The proactive role of the logistics function in managing logistics challenges in retail This research has shown that the logistics functions of retailers often play a reactive role, whereby they are involved as a supporting function in different challenges. As this research shows, there are several situations (e.g. increased costs and complexity of logistics) that could have been avoided if the logistics had been involved from the start. In particular, the findings from Study 1 show that an early involvement by the logistics function of retailers can enable retailers to better manage their geographical expansion and avoid logistics pitfalls (e.g. lack of storage space due to market-specific products, customs-procedures issues, delays in foreign distribution). Instead, the findings show that the logistics function of retailers often only becomes involved at a later stage of the expansion and is often treated as a supporting function, and not involved at the strategic level of retail companies. In addition, Study 2 reveals that the early involvement of strategic logistics staff is crucial to successfully manage logistics issues related to OC retailing. This insight into the importance of proactive logistics needs to be realised at the strategical level of retailers, including the top management team. The findings highlight the importance of involving strategic logistics staff (e.g. the logistics manager) early on in strategic retail decisions, where they can share their views and expertise, as well as having more time to adapt the logistics. In terms of DCs, the early involvement of the logistics function can enhance the accessing, integration and utilisation of new resources, as well as the identification and transfer of resources, in order for retailers to better manage logistics challenges.

\section{The importance of collaboration to manage logistics challenges in retail}

This research demonstrates the importance of collaboration within retail organisations, as well as between retailers and LSPs, in order to manage logistics challenges in retail. Based on the intraorganisational perspective in Study 1, the findings also show the importance of moving away from the traditional silo culture to support collaboration in cross-functional teams within retailers in order to manage different challenges. In line with previous research (e.g. Chen et al., 2009; Swoboda and Anderer, 2008; Swoboda and Elsner, 2013), the findings highlight the importance of an efficient integration between logistics and marketing in order to adapt the retail operations, and create and maintain a sustainable competitive advantage. Here, the top management team is believed to play an essential role in creating collaborative activities between company functions (e.g. marketing, logistics, sales and IT functions). For instance, the project manager of the establishment process at one retailer enabled resource exchange (e.g. feedback about foreign operations) between the logistics function, the marketing function and the sales function, which in turn resulted improved logistics in foreign sales markets. Furthermore, Study 2 shows the importance of collaboration between retailers and LSPs when managing the OC transition. Based on the interorganisational perspective in Study 2, the findings show highlight importance of collaboration between retailers and LSPs in order for them to combine their firm-specific competencies and jointly develop new logistics solutions (e.g. in-store integration, packaging operations, new last-mile delivery solutions).

Despite the existence of previous research on different interactions between supply chain members (e.g. Defee and Fugate, 2010; Esper et al., 2007), the findings reveal the complexity of retailer-LSP collaborations. For instance, retailers and LSPs have different goals and perspectives, which need to be understood and combined in order to work together. Collaboration between different members takes time and priority away from other 
tasks, and the performance of a collaboration is not easily measured or documented. In line with the respondents of Study 2, it is important to acknowledge the importance of collaboration and to fine-tune the collaborative efforts (e.g. joint meetings and projects) between both company functions and external actors, in order to establish well-functioning logistics. For instance, Retailer A reflected upon joint meetings and discussed improvements in their joint activities to further improve the collaboration with its logistics partner. Based on this research, key success factors for managing logistics challenges in retail are to prioritise collaboration at a strategic level, to break free from previous functional barriers within companies, to support increased commitment between functions and external actors and to reward good team efforts. This in turn can encourage further collaboration between different functions and actors to manage other challenges in retail.

\section{The importance of top management support to manage logistics challenges in retail}

In relation to collaboration, the findings also highlight the importance of top management support to manage logistics challenges in retail. Based on the findings from both Study 1 and Study 2, a lack of top management support is a major hindrance to establishing and maintaining collaboration between company functions and between retailers and LSPs. For instance, the logistics managers in Study 2 argued that the lack of top management support hinders logistics initiatives to take on different logistics issues. An active top management team can prioritise different logistics issues as well as initiating, performing and supervising logistics projects to manage the different logistics challenges in retail. This research provides guidance for how top management can support the management of logistics challenges. In particular, this research shows multiple examples where top management has either enhanced or hinder initiatives for managing logistics issues. For instance, the active involvement of the $\mathrm{CEO}$ in the establishment process of one retailer enabled the establishment of a central warehouse to simplify the expansion. In addition, the lack of top management involvement in another case resulted in missed collaboration opportunities related to logistics in the OC transition. Based on these examples, it can be seen that managing a logistics challenge is not easily accomplished without the support of top management.

\subsection{Suggestions for further research}

This section discusses suggestions for further research. These suggestions are influenced by the limitations of the dissertation as well as other interesting areas of research, which are relevant for further research.

\section{Identified dynamic capabilities - transferable to other contexts?}

Even though this research focuses on DCs to manage two specific logistics challenges in retail, the findings are likely to be relevant in other contexts as well. For instance, the DCs identified in this dissertation may be found in other research fields. Independent of discipline, DCs are needed to understand how to modify a resource base in order to remain completive within a dynamic environment. A lot of DC research is highly conceptual and presents general DCs (e.g. Defee and Fugate, 2010; Hussain et al., 2020; Teece, 2007) and there is a need to further explore DCs and how they are portrayed in different settings in order to further understand their practical use and how they may differ depending on the setting. Based on this, an interesting research suggestion would be to study the DCs from 
this research in relation to other logistics challenges in retail (e.g. sustainability challenges), as well as other supply chain members as well.

\section{The antecedents of dynamic capabilities - transferable to other contexts?}

In a similar vein, this research brings forward a number of antecedents of DCs that are explained in relation to two specific logistics challenges in retail. This research does not present a complete list of antecedents, but rather the most prominent ones found for the specific setting and perspective. In addition, based on Eriksson (2014), the identified antecedents were categorised into different antecedent categories (consisting of structural and social antecedents), which was necessary for DCs for the specific logistics challenges. However, these antecedents may be specific to the settings studied in this research and not transferable to other settings. For instance, the antecedent of centralised logistics structure in geographical expansion does not necessarily have to be an antecedent for DCs in another setting. Instead, a decentralised logistics structure may be a better option, and is typically important in $\mathrm{OC}$ retailing. Therefore, an interesting suggestion for further research would be to study antecedents for other logistics challenges in retail, as well as for other supply chain members.

\section{Dynamic capabilities of small and medium-sized retailers}

This dissertation only studied large-sized Swedish retailers. However, small or mediumsized retailers are also of interest for future studies. Such retailers have a smaller organisation that may need other DCs. For instance, such retailers tend to have less resources and fewer staff who can dedicate time to logistics. They may not have their own logistics resources or expertise in house and may have to rely on more IDCs to access, integrate and utilise external resources in order to manage logistics challenges. In addition, retailers from other parts of the world would also be of interest for future research. Foreign retailers can differ in terms of organisational approaches, different cultures and varying regulations, which could impact upon how they manage different logistics challenges.

\section{A quantitative approach to studying dynamic capabilities for managing logistics challenges of retailers}

This study is based on qualitative data from a case study approach, which provided in-depth knowledge about DCs for a few specific case companies. Another interesting research suggestion is to use a more quantitative approach to further explore a larger number of retailers and how they manage logistics challenges. The findings from this research could be used to create surveys, which could be sent to different retailers within the same or different retail sectors. This can provide additional insights into different retail sectors and different sizes of retailers, and how their DCs and their antecedents are portrayed when managing logistics challenges.

To conclude this dissertation, there are several interesting challenges to take on, as well as several different approaches to studying these logistics challenges. This dissertation provides additional knowledge to better understand some of these challenges in retail, and I hope that it was an interesting read!

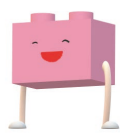






\section{References}

\section{References}

Abrahamsson, M. and Brege, S. (2004). "Dynamic effectiveness-improved industrial distribution from interaction between marketing and logistics strategies". Journal of Marketing Channels, Vol. 12, No. 2, pp. 83-112.

Abrahamsson, M. and Rehme, J. (2010). “The role of logistics in retailers' corporate strategy - A driver for growth and customer value". Supply Chain Forum: An International Journal, Vol. 11, No. 4, pp. 14-23.

Agatz, N. A., Fleischmann, M. and Van Nunen, J. A. (2008). "E-fulfillment and multi-channel distribution-A review". European journal of operational research, Vol. 187, No. 2, pp. 339-356.

Aharonovitz, M. C. S., Vieira, J. G. V. and Suyama, S. S. (2018). "How logistics performance is affected by supply chain relationships". The international journal of logistics management, Vol. 29, No. 1, pp. 284-307.

Akehurst, G. and Alexander, N. (2013). The internationalisation of retailing, London, Routledge.

Alexander, N. (1995). "UK retail expansion in North America and Europe A strategic dilemma". Journal of Retailing and Consumer Services, Vol. 2, No. 2, pp. 75-81.

Alvesson, M. and Sköldberg, K. (1994). Tolkning och reflektion-vetenskapsfilosofi och kvalitativ metod, Lund, Studentlitteratur.

Ambrosini, V. and Bowman, C. (2009). "What are dynamic capabilities and are they a useful construct in strategic management?". International journal of management reviews, Vol. 11, No. 1, pp. 29-49.

Assaf, A. G., Josiassen, A., Ratchford, B. T. and Barros, C. P. (2012). "Internationalization and performance of retail firms: A Bayesian dynamic model". Journal of Retailing, Vol. 88, No. 2, pp. 191-205.

Athreye, S., Kale, D., \& Ramani, S. V. (2009). "Experimentation with strategy and the evolution of dynamic capability in the Indian pharmaceutical sector". Industrial and Corporate Change, Vol. 18, No. 4, pp. 729-759.

Ayuso, S., Rodr'Iguez,M. A. ,\& Ricart,J. E. (2006). “Using stakeholder dialogue as a source for new ideas: A dynamic capability underlying sustainable innovation". Corporate Governance, Vol. 6, No. 4, pp. 475-490.

Bailey, C. A. (2007). A guide to qualitative field research, London, UK, Sage Publication ltd.

Barney, J. and Clark, D. (2007). Resource-based theory: creating and sustaining competitive advantage, Oxford, UK:, Oxford University Press.

Barratt, M., Choi, T. Y. and Li, M. (2011). "Qualitative case studies in operations management: Trends, research outcomes, and future research implications". Journal of operations management, Vol. 29, No. 4, pp. 329-342.

Barreto, I. (2010). "Dynamic capabilities: A review of past research and an agenda for the future". Journal of management, Vol. 36, No. 1, pp. 256-280.

Beck, N. and Rygl, D. (2015). "Categorization of multiple channel retailing in Multi-, Cross-, and Omni-Channel Retailing for retailers and retailing". Journal of retailing and consumer services, Vol. 27, No. 170-178.

Bengtsson, M. (2008). The art of replicating. Linköping University Electronic Press.

Benner, M. J. (2009). "Dynamic or static capabilities? Process management practices and response to technological change". Journal of product innovation management, Vol. 26, No. 5, pp. 473-486.

Beske, P. (2012). "Dynamic capabilities and sustainable supply chain management". International Journal of Physical Distribution \& Logistics Management, Vol. 42, No. 4, pp. 372-387.

Beske, P., Land, A. and Seuring, S. (2014). "Sustainable supply chain management practices and dynamic capabilities in the food industry: A critical analysis of the literature". International Journal of Production Economics, Vol. 152, No. 2014, pp. 131-143.

Bianchi, C. (2011). "The growth and international expansion of an emerging market retailer in Latin America". Journal of Global Marketing, Vol. 24, No. 4, pp. 357-379. 


\section{References}

Blomqvist, K., Hara, V., Koivuniemi, J. and Äijö, T. (2004). “Towards networked R\&D management: the R\&D approach of Sonera Corporation as an example". R\&D Management, Vol. 34, No. 5, pp. 591-603.

Brewer, P. (2009). “Australia's Export Promotion Program: Is It Effective?”. Australian Journal of Management, Vol. 34, No. 1, pp. 125-142.

Brouthers, K., Mukhopadhyay, S., Wilkinson, T. J. and Brouthers, L. (2009). "International market selection and subsidiary performance: a neural network approach". Journal of World Business, Vol. 44, No. 3, pp. 262-273.

Brouthers, K. D., Brouthers, L. E. and Werner, S. (2003). "Transaction cost-enhanced entry mode choices and firm performance". Strategic Management Journal, Vol. 24, No. 12, pp. 1239-1248.

Bryman, A. (2015). Business Research Methods, Oxford, Oxford University Press.

Bryman, A. and Bell, E. (2011). Business Research Methods, Oxford, Oxford University Press.

Brynjolfsson, E., Hu, Y. and Rahman, M. S. (2009). "Battle of the retail channels: How product selection and geography drive cross-channel competition". Management Science, Vol. 55, No. 11, pp. 1755-1765.

Brynjolfsson, E., Hu, Y. J. and Rahman, M. S. 2013. Competing in the age of omnichannel retailing. Cambridge: MIT Cambridge.

Burt, S., Johansson, U. and Dawson, J. (2016). "International retailing as embedded business models". Journal of Economic Geography, Vol. 16, No. 3, pp. 715-747.

Cai, Y. J. and Lo, C. (2020). "Omni-channel management in the new retailing era: A systematic review and future research agenda". International Journal of Production Economics, Vol. 229, No. 107729, pp. 1-16.

Cao, L. (2011). "Dynamic capabilities in a turbulent market environment: empirical evidence from international retailers in China". Journal of Strategic Marketing, Vol. 19, No. 5, pp. 455469.

Cegarra-Navarro, J. G. (2005). "An empirical investigation of organizational learning through strategic alliances between SMEs". Journal of Strategic Marketing, Vol. 13, No. 1, pp. 3-16.

Chen, H., Daugherty, P. and Roath, A. (2009). "Defining and operationalizing supply chain process integration". Journal of Business Logistics, Vol. 30, No. 1, pp. 63-84.

Chen, I. S., Fung, P. K. and Yuen, S. S. (2019). "Dynamic capabilities of logistics service providers: Antecedents and performance implications". Asia Pacific Journal of Marketing and Logistics, Vol. 31, No. 4, pp. 1058-1075.

Christopherson, S. (2007). "Barriers to 'US style'lean retailing: the case of Wal-Mart's failure in Germany". Journal of Economic Geography, Vol. 7, No. 4, pp. 451-469.

Chung, C. C. and Beamish, P. W. (2005). "Investment mode strategy and expatriate strategy during times of economic crisis". Journal of International Management, Vol. 11, No. 3, pp. 331-355.

Clement, J. (2019). E-commerce share of total global retail sales from 2015 to 2023 [Online]. https://www.statista.com/statistics/534123/e-commerce-share-of-retail-salesworldwide/: Statista.com. [Accessed 4 may 2020].

Coe, N. and Hess, M. (2005). "The internationalization of retailing: Implications for supply network restructuring in East Asia and Eastern Europe". Journal of Economic Geography, Vol. 5, No. 4, pp. 449-473.

Cohen, W. M. and Levinthal, D. A. (1990). "Absorptive capacity: A new perspective on learning and innovation”. Administrative Science Quarterly, Vol. 35, No. 1, pp. 128-152.

Corstjens, M. and Lal, R. 2012. Retail Doesn't Cross Borders Here's why and what to do about it. Harvard Business Review. Boston.

Cox, A. (1996). "Relational competence and strategic procurement management: Towards an entrepreneurial and contractual theory of the firm". European Journal of Purchasing \& Supply Management, Vol. 2, No. 1, pp. 57-70. 
Davarzani, H. and Norrman, A. (2015). "Toward a relevant agenda for warehousing research: literature review and practitioners' input”. Logistics Research, Vol. 8, No. 1, pp. 1-18.

Dawson, J. A. (2007). "Scoping and conceptualising retailer internationalisation". Journal of Economic Geography, Vol. 7, No. 4, pp. 373-397.

Defee, C. and Fugate, B. (2010). "Changing perspective of capabilities in the dynamic supply chain era". The International Journal of Logistics Management, Vol. 21, No. 2, pp. 180-206.

Delmas, M. A. (2002). "Innovating against European rigidities: institutional environment and dynamic capabilities". The Journal of High Technology Management Research, Vol. 13, No. 1, pp. $19-43$.

Di Stefano, G., Peteraf, M. and Verona, G. (2010). "Dynamic capabilities deconstructed: a bibliographic investigation into the origins, development, and future directions of the research domain". Industrial and corporate change, Vol. 19, No. 4, pp. 1187-1204.

Dimitrova, B. V., Rosenbloom, B., Larsen Andras, T. and Kim, S. (2018). "Retail internationalization: A review and directions for future research". Journal of Marketing Channels, Vol. 25, No. 1-2, pp. 1-21.

Douglas, S. P. and Craig, C. S. (2011). "The role of context in assessing international marketing opportunities". International Marketing Review, Vol. 28, No. 2, pp. 150-162.

Dubois, A. and Gadde, L.-E. (2014). "Systematic combining-A decade later". Journal of Business Research, Vol. 67, No. 6, pp. 1277-1284.

Duriau, V. J., Reger, R. K. and Pfarrer, M. D. (2007). “A content analysis of the content analysis literature in organization studies: Research themes, data sources, and methodological refinements". Organizational research methods, Vol. 10, No. 1, pp. 5-34.

Dyer, J. H. and Singh, H. (1998). "The relational view: Cooperative strategy and sources of interorganizational competitive advantage". Academy of management review, Vol. 23, No. 4, pp. 660-679.

Døving, E. and Gooderham, P. (2008). "Dynamic capabilities as antecedents of the scope of related diversification: the case of small firm accountancy practices". Strategic management journal, Vol. 29, No. 8, pp. 841-857.

Eisenhardt, K. (1989). "Building theories from case study research". The Academy of Management Review, Vol. 14, No. 4, pp. 532-550.

Eisenhardt, K. M. and Martin, J. A. (2000). "Dynamic capabilities: what are they?". Strategic management journal, Vol. 21, No. 10-11, pp. 1105-1121.

Eisenhardt, M. K. and Graebner, E. M. (2007). "Theory building from cases: Opportunities and challenges". Academy of Management Journal, Vol. 50, No. 50, pp. 25-32.

Elsner, S. (2012). Retail Internationalization Springer Gabler.

Eriksson, T. (2014). "Processes, antecedents and outcomes of dynamic capabilities". Scandinavian journal of management, Vol. 30, No. 1, pp. 65-82.

Esper, T., Fugate, B. and Davis-Sramek, B. (2007). "Logistics learning capability: Sustaining the competetive advantage gained through logistics leverage". Journal of Business Logistics, Vol. 28, No. 2, pp. 57-81.

European_Commission. (2009). What is an SME? [Online]. European Commission - Growth. [Accessed 3 december 2018].

Evans, J., Mavondo, F. T. and Bridson, K. (2008). "Psychic Distance: Antecedents, Retail Strategy Implications, and Performance Outcomes". Journal of International Marketing, Vol. 16, No. 2, pp. 32-63.

Faber, N., De Koster, M. and Smidts, A. (2013). "Organizing warehouse management". International Journal of Operations \& Production Management, Vol. 33, No. 9, pp. 1230-1256.

Fawcett, S. E., Fawcett, A. M., Watson, B. J. and Magnan, G. M. (2012). "Peeking inside the black box: toward an understanding of supply chain collaboration dynamics". Journal of supply chain management, Vol. 48, No. 1, pp. 44-72. 


\section{References}

Flyvbjerg, B. (2006). "Five misunderstandings about case-study research". Qualitative Inquiry, Vol. 12, No. 2, pp. 219-245.

Forkmann, S., Henneberg, S. C. and Mitrega, M. (2018). "Capabilities in business relationships and networks: Research recommendations and directions". Industrial Marketing Management, Vol. 74, No. 4-26.

Foscht, T., Swoboda, B. and Morschett, D. (2006). "Electronic commerce-based internationalisation of small, niche-oriented retailing companies: The case of Blue Tomato and the Snowboard industry". International Journal of Retail \& Distribution Management, Vol. 34, No. 7, pp. 556-572.

Frasquet, M., Dawson, J., Calderón, H. and Fayos, T. (2018). "Integrating embeddedness with dynamic capabilities in the internationalisation of fashion retailers". International Business Review, Vol. 27, No. 4, pp. 904-914.

Frasquet, M., Dawson, J. and Mollá, A. (2013). "Post-entry internationalisation activity of retailers: An assessment of dynamic capabilities". Management Decision, Vol. 51, No. 7, pp. 1510-1527.

Gadde, L. E. and Hulthén, K. (2009). "Improving logistics outsourcing through increasing buyer-provider interaction”. Industrial Marketing Management, Vol. 38, No. 6, pp. 633-640.

Galipoglu, E., Kotzab, H., Teller, C., Hüseyinoglu, I. Ö. Y. and Pöppelbuß, J. (2018). "Omnichannel retailing research-state of the art and intellectual foundation". International Journal of Physical Distribution \& Logistics Management, Vol. 48, No. 4, pp. 365-390.

Gamble, A. (2010). "The political consequences of the crash”. Political Studies Review, Vol. 8, No. 1 , pp. 3-14.

Gammelgaard, B. (2017). "The qualitative case study". The International Journal of Logistics Management, Vol. 28, No. 4, pp. 910-913.

Gaur, A. and Kumar, M. (2018). "A systematic approach to conducting review studies: An assessment of content analysis in 25years of IB research". Journal of World Business, Vol. 53, No. 2, pp. 280-289.

Goldman, A. (2001). "The transfer of retail formats into developing economies: The example of China". Journal of Retailing, Vol. 77, No. 221-242.

Golgeci, I. and Arslan, A. (2014). "Internationalization of emerging economy firms to developed economies: a discussion on institutional pressures and marketing and supply chain capabilities". Journal of Strategic Marketing, Vol. 22, No. 7, pp. 587-602.

Grant, R. (1991). A Resource Based Theory of Competitive Advantage, Berkeley, University of California.

Gu, J., Goetschalckx, M. and Mcginnis, L. F. (2007). "Research on warehouse operation: A comprehensive review”. European journal of operational research, Vol. 177, No. 1, pp. 1-21.

Haag, L. (2019). The Supporting Role of Logistics during the Early Stage of Retail Internationalisation, Linköping University Electronic Press.

Halldórsson, Á. and Aastrup, J. (2003). "Quality Criteria for Qualitative Inquiries in Logistics". European Journal of Operational Research, Vol. 144, No. 2, pp. 321-332.

Halldórsson, A. and Skjøtt-Larsen, T. (2004). "Developing logistics competencies through third party logistics relationships". International Journal of Operations \& Production Management, Vol. 24, No. 2, pp. 192-206.

Hartmann, E. and De Grahl, A. (2011). Logistics outsourcing interfaces: the role of customer partnering behavior. Success Factors in Logistics Outsourcing. Springer.

Helfat, C., Finkelstein, S., Mitchell, W., Peteraf, M., Singh, H., Teece, D. and Winter, S. G. (2007). Dynamic capabilities: Understanding strategic change in organizations, Malden, Blackwell Publishing.

Hotrawaisaya, C., Chandraprakaikul, W. and Suthikarnarunai, N. (2014). "Performance improvement by logistics collaboration management model for orchid flower industry in Thailand”. Engineering Management Research, Vol. 3, No. 2, pp. 52. 


\section{References}

Hwang, W., Jung, H. S. and Salvendy, G. (2006). "Internationalisation of e-commerce: a comparison of online shopping preferences among Korean, Turkish and US populations". Behaviour \& Information Technology, Vol. 25, No. 1, pp. 3-18.

Hübner, A., Wollenburg, J. and Holzapfel, A. (2016). "Retail logistics in the transition from multi-channel to omni-channel”. International Journal of Physical Distribution \& Logistics Management, Vol. 46, No. 6/7, pp. 562-583.

Hüseyinoğlu, I. Ö. Y., Sorkun, M. F. and Börühan, G. (2018). "Revealing the impact of operational logistics service quality on omni-channel capability". Asia Pacific Journal of Marketing and Logistics, Vol. 30, No. 5, pp. 1200-1221.

Ishfaq, R., Defee, C. C., Gibson, B. J. and Raja, U. (2016). "Realignment of the physical distribution process in omni-channel fulfillment". International Journal of Physical Distribution \& Logistics Management, Vol. 46, No. 6/7, pp. 543-561.

Johanson, J. and Wiedersheim-Paul, F. (1975). "The internationalization of the firm: Four Swedish cases". Journal of management studies, Vol. 12, No. 3, pp. 305-322.

Johansson, U. and Thelander, $\AA$. (2009). "A standardised approach to the world? IKEA in China”. International Journal of Quality and Service Sciences, Vol. 1, No. 2, pp. 199-219.

Jonsson, A. and Foss, N. (2011). "International expansion through flexible replication: Learning from the internationalization experience of IKEA". Journal of International Business Studies, Vol. 42, No. 1079-1102.

Kale, P. and Singh, H. (2007). "Building firm capabilities through learning: The role of the alliance learning process in alliance capability and firm-level alliance success". Strategic Management Journal, Vol. 28, No. 10, pp. 981-1000.

Kallio, H., Pietilä, A. M., Johnson, M. and Kangasniemi, M. (2016). "Systematic methodological review: developing a framework for a qualitative semi-structured interview guide". Journal of advanced nursing, Vol. 72, No. 12, pp. 2954-2965.

Karim, S. (2009). "Business unit reorganization and innovation in new product markets". Management Science, Vol. 55, No. 7, pp. 1237-1254.

Kay, N. M., Leih, S. and Teece, D. J. (2018). "The role of emergence in dynamic capabilities: a restatement of the framework and some possibilities for future research". Industrial and Corporate Change, Vol. 27, No. 4, pp. 623-638.

Kembro, J. and Norrman, A. (2019a). "Exploring trends, implications and challenges for logistics information systems in omni-channels". International Journal of Retail \& Distribution Management, Vol. 47, No. 4, pp. 384-411.

Kembro, J. H. and Norrman, A. (2019b). "Warehouse configuration in omni-channel retailing: a multiple case study". International Journal of Physical Distribution \& Logistics Management, Vol. 50 , No. 5, pp. $1-25$.

Kembro, J. H., Norrman, A. and Eriksson, E. (2018). "Adapting warehouse operations and design to omni-channel logistics: A literature review and research agenda". International Journal of Physical Distribution \& Logistics Management, Vol. 48, No. 9, pp. 890-912.

Ketchen, D. J. and Giunipero, L. C. (2004). "The intersection of strategic management and supply chain management". Industrial marketing management, Vol. 33, No. 1, pp. 51-56.

Kihlén, T. (2005). On Logistics in the Strategy of the Firm.

Knoppen, D., Johnston, D. and Sáenz, M. J. (2015). "Supply chain relationships as a context for learning leading to innovation". The International Journal of Logistics Management, Vol. 26, No. 3, pp. 543-567.

Krause, D. R., Handfield, R. B. and Tyler, B. B. (2007). "The relationships between supplier development, commitment, social capital accumulation and performance improvement". Journal of operations management, Vol. 25, No. 2, pp. 528-545.

Larke, R., Kilgour, M. and O'connor, H. (2018). "Build touchpoints and they will come: transitioning to omnichannel retailing". International Journal of Physical Distribution \& Logistics Management, Vol. 48, No. 4, pp. 465-483. 
Lavie, D. (2006). "The Competitive Advantage of Interconnected Firms: An Extension of the Resource-Based View". The Academy of Management Review, Vol. 31, No. 3, pp. 638-658.

Lazaris, C. and Vrechopoulos, A. (Year) Published. From multi-channel to "omnichannel" retailing: review of the literature and calls for research. 2nd International Conference on Contemporary Marketing Issues,(ICCMI), 2014. 1-6.

Liao, H., Proctor, R. W. and Salvendy, G. (2008). "Content preparation for cross-cultural ecommerce: a review and a model”. Behaviour \& Information Technology, Vol. 27, No. 1, pp. 43-61.

Liao, J., Kickul, J. R., \& Ma, H. (2009). “Organizational dynamic capability and innovation: An empirical examination of internet firms". Journal of small business management, Vol. 47, No. 3, pp. 263-286.

Lichtenthaler, U. and Lichtenthaler, E. (2009). "A Capability-Based Framework for Open Innovation: Complementing Absorptive Capacity". Journal of Management Studies, Vol. 46, No. 8, pp. 1315-1338.

Loeb, W. (2020). Looking Ahead To The 2020s: The Challenges For Retail In A New Decade [Online]. https://www.forbes.com/sites/walterloeb/2020/01/02/looking-ahead--the-challengesfor-retail-in-a-new-decade/\#12328ea863a1: Forbes.com. [Accessed 2020-05-04].

Lowe, M., George, G. and Alexy, O. (2012). "Organizational identity and capability development in internationalization: transference, splicing and enhanced imitation in Tesco's US market entry". Journal of Economic Geography, Vol. 12, No. 5, pp. 1021-1054.

Macher, J. T. and Mowery, D. C. (2009). "Measuring dynamic capabilities: practices and performance in semiconductor manufacturing”. British Journal of Management, Vol. 20, No. 5, pp. 41-62.

Macpherson, A., Jones, O. and Zhang, M. (2004). "Evolution or revolution? Dynamic capabilities in a knowledge-dependent firm". R\&d Management, Vol. 34, No. 2, pp. 161-177.

Mahar, S. and Wright, P. D. (2009). "The value of postponing online fulfillment decisions in multi-channel retail/e-tail organizations”. Computers \& operations research, Vol. 36, No. 11, pp. 3061-3072.

Marchet, G., Melacini, M., Perotti, S. and Tappia, E. (2016). "Shaping the international logistics strategy in the internationalisation process". International Journal of Supply Chain and Operations Resilience, Vol. 2, No. 1, pp. 72-93.

Mayring, P. (2008). Qualitative Inhaltanalyse - Grundlagen und Techniken (Qualitative Content Analysis), Weinheim, Beltz Verlag.

Meinlschmidt, J., Foerstl, K. and Kirchoff, J. F. (2016). "The role of absorptive and desorptive capacity (ACDC) in sustainable supply management". International Journal of Physical Distribution \& Logistics Management, Vol. 46, No. 2, pp. 177-211.

Melacini, M., Perotti, S., Rasini, M. and Tappia, E. (2018). "E-fulfilment and distribution in omnichannel retailing: a systematic literature review". International Journal of Physical Distribution \& Logistics Management, Vol. 48, No. 4, pp. 391-414.

Mende, M. and Noble, S. (2019). "Retail apocalypse or golden opportunity for retail frontline management?". Journal of Retailing, Vol. 95, No. 2, pp. 84-89.

Merriam, S. B. and Tisdell, E. J. (2015). Qualitative researcb: A guide to design and implementation, San Francisco, John Wiley \& Sons.

Miles, M., Huberman, M. and Saldana, J. (2014). Qualitative Data Analysis, Thousand Oaks, Sage Publications.

Min, S., Roath, A. S., Daugherty, P. J., Genchev, S. E., Chen, H., Arndt, A. D. and Richey, R. G. (2005). "Supply chain collaboration: what's happening?". The international journal of logistics management, Vol. 16, No. 2, pp. 237-256.

Mishra, R., Singh, R. K. and Koles, B. (2021). "Consumer decision-making in Omnichannel retailing: Literature review and future research agenda". International Journal of Consumer Studies, Vol. 45, No. 2, pp. 147-174. 


\section{References}

Mitrega, M., Henneberg, S. C. and Forkmann, S. (2018). "Capabilities in business relationships and networks: An introduction to the special issue". Industrial Marketing Management, Vol. 74, No. 1, pp. 1-3.

Möller, K. and Svahn, S. (2003). "Managing strategic nets: A capability perspective". Marketing theory, Vol. 3, No. 2, pp. 209-234.

Nyaga, G. N., Whipple, J. M. and Lynch, D. F. (2010). "Examining supply chain relationships: do buyer and supplier perspectives on collaborative relationships differ?". Journal of operations management, Vol. 28, No. 2, pp. 101-114.

Oh, L. B., Teo, H. H. and Sambamurthy, V. (2012). "The effects of retail channel integration through the use of information technologies on firm performance". Journal of operations management, Vol. 30, No. 5, pp. 368-381.

Palmatier, R. W., Houston, M. B. and Hulland, J. (2018). "Review articles: Purpose, process, and structure". Journal of the Academic Marketing Science, Vol. 1, No. 46, pp. 1-5.

Patel, R. and Davidson, B. (2011). Forskningsmetodikens grunder, Lund, Studentlitteratur.

Pavlou, P. A. and El Sawy, O. A. (2011). "Understanding the elusive black box of dynamic capabilities". Decision sciences, Vol. 42, No. 1, pp. 239-273.

Pedersen, S. G., Zachariassen, F. and Arlbjørn, J. S. (2012). "Centralisation vs de-centralisation of warehousing: a small and medium-sized enterprise perspective". Journal of Small Business and Enterprise Development, Vol. 19, No. 2, pp. 352-369.

Penrose, E. (1959). The theory of the growth of the firm, Oxford, Oxford University Press.

Penrose, E. and Penrose, E. T. (2009). The Theory of the Growth of the Firm, Oxford university press.

Perdana, Y. R., Ciptono, W. S. and Setiawan, K. (2019). "Broad span of supply chain integration: Theory development". International Journal of Retail \& Distribution Management, Vol. 47, No. 2, pp. 186-201.

Picot-Coupey, K., Burt, S. L. and Cliquet, G. (2014). "Retailers expansion mode choice in foreign markets: Antecedents for expansion mode choice in the light of internationalization theories". Journal of Retailing and Consumer Services, Vol. 21, No. 6, pp. 976-991.

Porter, M. (1980). "Industry structure and competitive strategy: Keys to profitability". Financial analysts journal, Vol. 36, No. 4, pp. 30-41.

Porter, M. (1985). The Competitive Advantage: Creating and Sustaining Superior Performance, New York, Free Press.

Rajaguru, R. and Matanda, M. J. (2019). "Role of compatibility and supply chain process integration in facilitating supply chain capabilities and organizational performance". Supply Chain Management: An International Journal, Vol. 24, No. 2, pp. 301-316.

Roldán Bravo, M. I., Moreno, A. R. and Llorens-Montes, F. J. (2016). "Supply network-enabled innovations. An analysis based on dependence and complementarity of capabilities". Supply Chain Management: An International Journal, Vol. 21, No. 5, pp. 642-660.

Root, F. R. (1994). Entry strategies for international markets, Lexington, Lexington Books.

Saenz, M. J., Revilla, E. and Knoppen, D. (2014). “Absorptive capacity in buyer-supplier relationships: empirical evidence of its mediating role". Journal of Supply Chain Management, Vol. 50, No. 2, pp. 18-40.

Sakarya, S., Eckman, M. and Hyllegard, K. H. (2007). "Market selection for international expansion: assessing opportunities in emerging markets". International Marketing Review, Vol. 24, No. 2, pp. 208-238.

Sandberg, E. (2014). "Coordination mechanisms in the store opening process". International Journal of Retail and Distribution Management, Vol. 42, No. 6, pp. 482-499.

Saunders, M. N. (2011). Research methods for business students, Pearson Education India.

Schepis, D., Ellis, N. and Purchase, S. (2018). "Exploring strategies and dynamic capabilities for net formation and management". Industrial Marketing Management, Vol. 74, No. 115-125. 


\section{References}

Schramm-Klein, H. and Morschett, D. (2006). "The Relationship between marketing performance, logistics performance and company performance for retail companies". The International Review of Retail, Distribution and Consumer Research, Vol. 16, No. 2, pp. 277-296.

Seuring, S. and Gold, S. (2012). "Conducting content-analysis based literature reviews in supply chain management”. Supply Chain Management: An International Journal, Vol. 17, No. 5, pp. 544-555.

Sievers, M. 2020. Executive Summary - Trends in Retail 2020. Hamburg: KPMG AG \& EHI Retail Institute.

Simone, A. and Sabbadin, E. (2018). "The new paradigm of the omnichannel retailing: key drivers, new challenges and potential outcomes resulting from the adoption of an omnichannel approach". International Journal of Business and Management, Vol. 13, No. 1, pp. 85.

Sinkula, J. M., Baker, W. E. and Noordewier, T. (1997). “A framework for market-based organizational learning: Linking values, knowledge, and behavior". Journal of the Academy of Marketing Science, Vol. 25, No. 4, pp. 305-318.

Snyder, H. (2019). "Literature review as a research methodology: An overview and guidelines". Journal of Business Research, Vol. 104, No. 333-339.

Song, M., Droge, C., Hanvanich, S. and Calantone, R. (2005). "Marketing and technology resource complementarity: An analysis of their interaction effect in two environmental contexts". Strategic management journal, Vol. 26, No. 3, pp. 259-276.

Straube, F., Ma, S. and Bohn, M. (2008). Internationalisation of logistics systems, Springer.

Sune, A. and Gibb, J. (2015). "Dynamic capabilities as patterns of organizational change". Journal of Organizational Change Management, Vol. 28, No. 2, pp. 213-231.

Swoboda, B. and Elsner, S. (2013). "Transferring the Retail Format Successfully into Foreign Countries". Journal of International Marketing, Vol. 21, No. 1, pp. 81-109.

Swoboda, B., Elsner, S. and Morschett, D. (2014). "Preferences and Performance of International Strategies in Retail Sectors: An Empirical Study". Long Range Planning, Vol. 47, No. 6, pp. 319-336.

Swoboda, B., Foscht, T. and Cliquet, G. (2008). "International value chain processes by retailers and wholesalers - A general approach". Journal of Retailing and Consumer Services, Vol. 15, No. 2, pp. 63-77.

Swoboda, B., Foscht, T., Maloles, C. and Schramm-Klein, H. (2009). "Exploring how garment firms choose international sourcing- and sales-country markets". Journal of Fashion Marketing and Management: An International Journal, Vol. 13, No. 3, pp. 406-430.

Teece, D. and Pisano, G. (1994). "The dynamic capabilities of firms: An introduction”. Industrial and Corporate Change, Vol. 3, No. 3, pp. 537-556.

Teece, D. J. (2007). "Explicating dynamic capabilities: the nature and microfoundations of (sustainable) enterprise performance". Strategic management journal, Vol. 28, No. 13, pp. 1319-1350.

Teece, D. J., Pisano, G. and Shuen, A. (1997). "Dynamic capabilities and strategic management". Strategic management journal, Vol. 18, No. 7, pp. 509-533.

Tenorio, M. L. O., Pascucci, S., Verkerk, R., Dekker, M. and Van Boekel, T. A. (2021). "What does it take to go global? The role of quality alignment and complexity in designing international food supply chains”. Supply Chain Management: An International Journal, Vol. 26, No. 4, pp. 467-480.

Verhoef, P. C., Stephen, A. T., Kannan, P., Luo, X., Abhishek, V., Andrews, M., Bart, Y., Datta, H., Fong, N. and Hoffman, D. L. (2017). "Consumer connectivity in a complex, technology-enabled, and mobile-oriented world with smart products". Journal of Interactive Marketing, Vol. 40, No. 1-8.

VetenskapsraDet (2017). Good research practice, Stockholm, Sweden, Swedish research council. 
Vida, I. (2000). “An empirical inquiry into international expansion of US retailers". International Marketing Review, Vol. 17, No. 4/5, pp. 454-475.

Vivek, S. D., Richey Jr, R. G. and Dalela, V. (2009). "A longitudinal examination of partnership governance in offshoring: A moving target”. Journal of World Business, Vol. 44, No. 1, pp. $16-30$.

Wang, C., Wong, C. Y., Johansen, J., Qi, B. and Shen, S. F. (2010). "A Comparison of Supply Chain Decision-Making Factors Between Foreign and Local Retailers in Taiwan". Journal of Business Strategy, Vol. 7, No. 4, pp. 54-71.

Wernerfelt, B. (1984). “A resource-based view of the firm”. Strategic management journal, Vol. 5, No. 2, pp. 171-180.

Wigley, S. and Chiang, R. C. L. (2009). "Retail internationalisation in practice: per una in the UK and Taiwan”. International Journal of Retail \& Distribution Management, Vol. 37, No. 3, pp. 250-270.

Winter, S. G. and Szulanski, G. (2001). "Replication as Strategy". Organization Science, Vol. 12, No. 6, pp. 730-743.

Wollenburg, J., Hübner, A., Kuhn, H. and Trautrims, A. (2018). "From Bricks-and-Mortar to Bricks-and-Clicks-Logistics Networks in Omni-Channel Grocery Retailing”. International Journal of Physical Distribution \& Logistics Management, Vol. 48, No. 4, pp.

Wooten, L. P. and Crane, P. (2004). "Generating dynamic capabilities through a humanistic work ideology: The case of a certified-nurse midwife practice in a professional bureaucracy". American Behavioral Scientist, Vol. 47, No. 6, pp. 848-866.

Yang, C. C. (2016). "Leveraging logistics learning capability to enable logistics service capabilities and performance for international distribution center operators in Taiwan". The International Journal of Logistics Management, Vol. 27, No. 2, pp. 284-308.

Yang, Y., Jia, F. and Xu, Z. (2019). "Towards an integrated conceptual model of supply chain learning: an extended resource-based view". Supply Chain Management: An International Journal, Vol. 24, No. 2, pp. 189-214.

Yin, R. K. (1994). Case Study Research: Design and Methods, Thousand Oaks, Sage Publications.

Yin, R. K. (2003). Case Study Research: Design and Methods, Thousand Oaks, Sage Publications.

Yin, R. K. (2009). Case Study Research: Design and Methods, Thousand Oaks, Sage Publications.

Yin, R. K. (2014). Case Study Research: Design and Methods, Thousand Oaks, Sage Publications.

Yiu, D. W. and Lau, C. M. (2008). "Corporate entrepreneurship as resource capital configuration in emerging market firms". Entrepreneurship Theory and practice, Vol. 32, No. 1, pp. 37-57.

Zaefarian, G., Forkmann, S., Mitręga, M. and Henneberg, S. C. (2017). “A capability perspective on relationship ending and its impact on product innovation success and firm performance". Long Range Planning, Vol. 50, No. 2, pp. 184-199.

Zahra, S. A. and George, G. (2002). "Absorptive Capacity: A Review, Reconceptualization, and Extension". The Academy of Management Review, Vol. 27, No. 2, pp. 185-203.

Zahra, S. A., Sapienza, H. J. and Davidsson, P. (2006). "Entrepreneurship and dynamic capabilities: A review, model and research agenda". Journal of Management studies, Vol. 43, No. 4, pp. 917-955.

Zhang, J., Onal, S., Das, R., Helminsky, A. and Das, S. (2019). "Fulfilment time performance of online retailers-an empirical analysis". International Journal of Retail \& Distribution Management, Vol. 47, No. 5, pp. 493-510.

Zollo, M. and Winter, S. G. (2002). "Deliberate learning and the evolution of dynamic capabilities". Organization Science, Vol. 13, No. 3, pp. 339-351. 



APPENDIX 1

Appended Papers 



\section{Papers}

The papers associated with this thesis have been removed for copyright reasons. For more details about these see:

http://urn.kb.se/resolve?urn=urn:nbn:se:liu:diva-178834 

APPENDIX 2 



\section{Interview guide of Study 1}

In this appendix, the standardised interview guide of Study 1 is presented.

\section{Intervjuguide}

Nedan följer intervjufrågorna för intervjun. På intervjuguidens sista sida återfinns en beskrivning om forskningsprojektet.

\section{Om respondenten}

- Bakgrund.

- Roll och ansvar.

\section{Om internationaliseringen}

1. Vad var startskottet för er internationalisering?

○ Vad är den främsta drivkraften?

○ Vem eller vilka var är drivande av företagets internationalisering?

2. Vilka marknader är ni verksamma i?

○ Vilket år skedde inträdet på dessa marknader?

○ Varför dessa marknader?

3. Har företaget erfarenheter av internationalisering sen tidigare?

○ Vem har den kunskapen inom företaget?

○ Har inspiration tagits från andra företag?

4. Hur ser expansionsplanen ut idag?

\section{Om etableringen till en ny utländsk marknad}

5. Finns det dokumentation kring etableringsprocessen till utländska marknader?

6. Etableras först fysiska affärer eller online-handel?

7. Vilka faser består etableringsprocessen av?

- Namnge dessa?

- Vilka individer ingick inom varje fas? 
○ Under hur lång tid pågick de olika faserna?

○ Finns det faser som överlappar och sker parallellt?

○ Hur länge pågick etableringsprocessen totalt? Går det att uppskatta hur länge de olika faserna på gick?

○ Har etableringsprocessen ändrat sedan den första utländska etableringen?

- Hur skiljer sig etableringen av nya butiker på hemma- och utländska marknaden?

8. Vilka individer/funktioner var involverade i etableringsprocessen?

○ Beskriv deras roll/uppgift.

○ Extern support i form av individer/organisationer/nätverk med erfarenhet av den utländska marknaden?

- Vilka faser hade man externt stöd?

- Vad fick man hjälp med?

9. Vilka är de viktigaste beslutspunkterna i etableringsprocessen?

○ När sker dessa beslutspunkter i etableringsprocessen?

○ Vilka i företaget tar dessa beslut?

- Var i hierarkin fattas dessa beslut?

10. Vad har varit viktiga grundförutsättningar för att möjliggöra etableringsprocessen?

11. Vilka är de viktigaste lärdomarna från tidigare etableringsprocessen?

○ Hur tar man hänsyn till dessa lärdomar i kommande etableringar?

\section{Om logistikverksamheten}

12. Beskriv flödet av färdiga produkter (från centrallager) till den utländska marknaden?

○ Sköter företaget hela sin logistikverksamhet eller sköts delar av extern part?

○ Används ett centralt lager för alla marknader?

- Alla produkter går via centrallagret? 
- Hur sker distributionen av varor till de utländska marknaderna?

- Hur ofta?

13. Hur sker arbetet i logistikverksamheten?

○ Vilka processer/arbetssätt används?

○ Vad använder ni för typ av information- och rapporteringssystem?

14. Hur sker styrningen av logistikverksamheten?

- Finns det en central styrningsenhet som designar logistikverksamhetens struktur och arbetar med logistikkoncept (hur distributionen ska utföras) utifrån ett totallogistikkostnads- och prestationsperspektiv? (Alltså inte utifrån lokala omständigheter eller optimeringar)

○ Finns det en ledare som ansvarar för logistikverksamheten i sin helhet?

- Har ledaren styrande kontroll över logistikverksamheten?

- Finns planeringsverktyg?

○ Finns mätning för logistikprestationer?

\section{Om logistikens roll $\mathrm{i}$ internationaliseringen}

15. Beskriv logistikens roll i internationaliseringsprocessen?

16. Hur stödjer logistiken de strategiska besluten, som en nyetablering och expansion på utländska marknader?

17. Vilka logistikaspekter tas i beaktning vid internationaliseringsbeslut?

- Anses logistik vara en viktig parameter vid val av marknad?

○ Skapas kalkyl på logistikkostnader?

18. Vilken prioritet har logistikaspekter i internationaliseringsprocessen?

○ Har logistikens betydelse förändrats i och med etableringen till flera utländska marknader? 


\section{Bakgrund till forskningsprojektet}

Nedan följer övergripande information om forskningsprojektet 'Logistikens betydelse för detaljhandelns geografiska expansion", samt syffet med intervjuguiden och därefter intervjufragorna.

\section{Om oss}

Erik Sandberg är docent och Biträdande Professor i logistik. Han har de senaste 10 åren forskat om organisations- och strategifrågor som berör logistikens strategiska betydelse $\mathrm{i}$ handels-företag. I detta projekt är han projektledare och huvudhandledare för Linnea.

Linnea Haag är civilingenjör i Energi, Miljö och Management (EMM) från LiTH. Sitt examensarbete genomförde hon inom logistik på SSAB, där hon arbetade fram ledtidsreduceringsförslag för stålföretagets verksamhet i Borlänge. Hösten 2016 började hon som doktorand inom logistik och har därefter påbörjat forskning inom det aktuella projektet.

\section{Om det aktuella forskningsprojektet}

Forskningsprojektet "Geografisk expansion av detaljbandeln" avser att kartlägga och erhålla lärdomar från etableringsprocessen vid geografisk expansion av svensk detaljhandel. Det innefattar processen från det att potentiella marknader utvärderas till att den första butiken är etablerad och i fulldrift, samt den fortsatta etableringen på den nya marknaden. Projektet avser att ge ökad förståelse för logistikens roll i etableringsprocessen och dess betydelse för en lyckosam etablering på sikt. Vidare kommer projektet ge ett teoretiskt och praktiskt bidrag som handlar om hur företags logistikverksamhet bör förberedas och organiseras inför en geografisk expansion. Projektets finansiärer är Hakon Swenson stiftelsen samt Jan Wallander och Tom Hedelius stiftelsen.

\section{Syftet med intervjuguide}

Syftet med kommande intervjuer är att samla in data om företagets expansion till utländska marknader. Den insamlade informationen kommer att användas i två akademiska artiklar och en licentiatavhandling (en avhandling halvväggs till doktor). Den första artikeln beskriver etableringsprocessen till utländska marknader som definieras som processen från första incitamentet från företaget att etablera sig på en ny utländsk marknad, till att etablera fysiska butiker (och online butiker) som varit öppna i minst ett år. Den andra artikeln handlar om hur logistiken möjliggör detaljhandelns expansion till nya utländska marknader. Avhandlingen handlar om att beskriva logistikens roll i den geografiska expansionen av detaljhandelsföretag.

\section{Respondenter}

Tanken är inte att en ensam person som ska besvara alla intervjufrågor, utan frågorna ska delas upp mellan flera respondenter. För att kunna kartlägga etableringsprocessen behöver vi intervjua personal som varit involverad $i$ etableringsprocessen från första initiativet till färdigutvecklade butiker på den utländska marknaden. Vi behöver också intervjua logistiknära personal som exempelvis förtagets logistikchef för att förstå logistikorganisationens uppbyggnad och operationer, samt dess roll under etableringen till utländska marknader. 


APPENDIX 3 



\section{Interview guide of Study 2}

In this appendix, the standardised interview guide of Study 2 is presented.

\section{Intervjuguide}

Denna intervjuguide är uppdelad i två delar; en kortfattad projektbeskrivning och ett frågebatteri.

\section{Kortfattad projektbeskrivning}

I projektet "Utveckling av dynamiska förmågor i detaljhandelns logistiksystem" studeras samverkan mellan handelsföretag och logistikföretag för att få bättre förståelse för hur välfungerande logistik till slutkund skapas. I detta projekt studeras samverkan utifrån så kallade dynamiska förmågor, vilket är strategiska och organisatoriska rutiner hos företag som används för att förnya företags existerande interna och externa resurser, samt statiska förmågor. Dynamiska förmågor krävs för att uppdatera företags resursbas och förmågor så att företag kan tackla förändringar och erhålla långsiktig konkurrenskraft. För en framgångsrik samverkan behöver därmed både handelsföretag och logistikföretag besitta sådana förmågor för att kunna lära och dra nytta av varandras kompetenser och resurser, samt att tillsammans skapa nya förmågor för att bättre möta framtida behov. Att erhålla dynamiska förmågor är dock inte oproblematiskt och alla förmågor som företag besitter behöver inte nödvändigtvis leda till långsiktig konkurrenskraft. Genom att studera samverkan mellan handelsföretag och logistikföretag kan en ökad förståelse för barriärer och förutsättningar för dynamiska förmågor erhållas, vilket i sin tur kan leda till bättre förståelse för hur framgångsrik samverkan skapas.

Detta projekt är finansierat av Hakon Swenson stiftelsen och projektet utförs av Linnea Haag, Erik Sandberg och Uni Sallnäs från Linköpings universitet.

- Linnea Haag är doktorand inom Logistik vid Linköpings universitet. Våren 2016 tog hon sin civilingenjörsexamen med masterprofil inom industriell ekonomi med logistikinriktning vid Linköpings universitet, och har sedan dess arbetat som doktorand. Hennes tidigare forskning har fokuserat på logistiken bakom utlandsetableringar av svenska handelsföretag. I kommande forskningsprojekt kommer fokus vara på samverkan mellan handelsföretag och logistikföretag i skapandet av bättre logistik jämtemot slutkund.

- Erik Sandberg är docent och biträdande professor vid Linköpings universitet. Erik är Linneas handledare och projektansvarig. Hans forskning handlar främst om logistikens strategiska roll i handelsföretag och baserar sig på en blandning av supply chain management och olika organisations-och strategiteorier.

- Uni Sallnäs är lektor i logistik på avdelningen för Logistik- och Kvalitetsutveckling på Linköpings universitet. Hon bedriver forskning inom miljölogistik, med fokus på hur företag och organisationer genom samarbete kan bli bättre på miljösmart logistik. Samarbetet mellan handelsföretag och logistikföretag en viktig grundpelare i Unis forskning. 


\section{Frågebatteri}

Detta frågebatteri innehåller ett antal stödfrågor som är intressanta för studien. Observera, att samtliga frågor inte behöver besvaras av en respondent utan olika respondenter kan besvara olika delar av frågebatteriet.

\section{Respondentens namn: \\ Befattning:}

\section{Beskriv kortfattat verksamheten.}

- Historia och nuläge

- Produkter och tjänster

\section{Samarbete mellan handelsföretag och logistikföretag}

- Vad är motivationen bakom samarbetet mellan handelsföretag och logistikföretag? (t ex fokus på egen verksamhet)

- Hur länge har samarbetet pågått?

- Hur sker samarbetet idag?

- Finns det en uttalad strategi/modell/avtal för samarbetet?

- Hur sker kommunikationen (möten, forum, grupparbeten) mellan parterna?

- Vem är huvudansvarig för kommunikationen mellan parterna?

- Har ni rutiner för att dela information mellan parterna?

\section{Rutiner för samarbetet}

- Hur ofta ses ni för att diskutera logistik?

- Har ni utarbetade rutiner för hur ni tillsammans arbetar med logistik?

- Vem/vilka är drivande i sådana rutiner?

○ Vem/vilka är involverade hos handelsföretaget respektive logistikföretaget?

- Vilken nivå och befattning?

- Hur har tidigare erfarenheter och lärdomar påverkat hur ni samarbetar idag? Ge gärna exempel.

- Att gemensamt skapa nya rutiner brukar kräva att båda parter scannar och undersöker den externa miljön som de arbetar i. Hur skannar ni miljön?

\section{Samarbetsprojekt}

- Har ni projekt tillsammans, t ex för att utveckla nya logistiktjänster?

\section{Vision och samarbetsfaktorer}

- På vilket sätt integreras er vision med er samarbetspartner?

- Hur definieras gemensamma värden och mål för ert samarbete? 
- Vad går bra och mindre bra i samarbetet?

- Vad finns det för utmaningar i samarbetet anser du?

○ Vad finns för förbättringspotential anser du?

- Vad anser du är förutsättningarna till ett framgångsrikt samarbete mellan handelsföretag och logistikföretag? ( $\mathrm{t}$ ex engagemang, tillit, normer, beroendeställning, topledningsstöd)

○ Nämn tre viktiga framgångsfaktorer för ett framgångsrikt samarbete?

- Hur åstadkommer man dessa framgångsfaktorer tror du? T ex:

- Hur skapas en god dialog mellan parterna?

- Hur skapas tillit?

○ Hur skapas bra gränssnitt mellan handelsföretag och logistikföretag? 


\section{FACULTY OF SCIENCE AND ENGINEERING}

Linköping Studies in Science and Technology, Dissertation No. 2158, 2021

Department of Management and Engineering

Linköping University

SE-581 83 Linköping, Sweden

www.liu.se 